\title{
1 Analysing pneumococcal invasiveness using Bayesian models of pathogen
}

progression rates

3

4 Alessandra Løchen ${ }^{1,2}$, James E. Truscottt ${ }^{1}$ and Nicholas J. Croucher ${ }^{1,2, *}$

5

61 Department of Infectious Disease Epidemiology, School of Public Health, Imperial

7 College London, London, W2 1PG, UK

$8 \quad 2$ MRC Centre for Global Infectious Disease Analysis, Department of Infectious

9 Disease Epidemiology, School of Public Health, Imperial College London, London,

10 W2 1PG, UK

11

12 *n.croucher@imperial.ac.uk

13

14 Short title: Bayesian analyses of microbial progression rates 


\section{Abstract}

16 The disease burden attributable to opportunistic pathogens depends on their

17 prevalence in asymptomatic colonisation and the rate at which they progress to cause symptomatic disease. Increases in infections caused by commensals can result from the emergence of "hyperinvasive" strains. Such pathogens can be identified through quantifying progression rates using matched samples of typed microbes from disease cases and healthy carriers. This study describes Bayesian models for analysing such datasets, implemented in an RStan package (https://github.com/nickjcroucher/progressionEstimation). The models converged on stable fits that accurately reproduced observations from meta-analyses of Streptococcus pneumoniae datasets. The estimates of invasiveness, the progression rate from carriage to invasive disease, in cases per carrier per year correlated strongly with the dimensionless values from meta-analysis of odds ratios when sample sizes were large. At smaller sample sizes, the Bayesian models produced more informative estimates. This identified historically rare but high-risk $S$. pneumoniae serotypes that could be problematic following vaccine-associated disruption of the bacterial population. The package allows for hypothesis testing through model comparisons with Bayes factors. Application to datasets in which strain and serotype information were available for $S$. pneumoniae found significant evidence for within-strain and within-serotype variation in invasiveness. The heterogeneous geographical distribution of these genotypes is therefore likely to contribute to differences in the impact of vaccination in between locations. Hence

37 genomic surveillance of opportunistic pathogens is crucial for quantifying the effectiveness of public health interventions, and enabling ongoing meta-analyses that can identify new, highly invasive variants. 


\section{Author summary}

41 Opportunistic pathogens are microbes that are commonly carried by healthy hosts,

42 but can occasionally cause severe disease. The progression rate quantifies the risk

43 of such a pathogen transitioning from a harmless commensal to causing a

44 symptomatic infection. The incidence of infections caused by opportunistic

45 pathogens can rise with the emergence of "hyperinvasive" strains, which have high

46 progression rates. Therefore methods for calculating progression rates of different

47 pathogen strains using surveillance data are crucial for rapidly identifying emerging

48 infectious disease threats. Existing methods typically measure progression rates

49 relative to the overall mix of microbes in the population, but these populations can

50 vary substantially between locations and times, making the outputs challenging to

51 combine across studies. This work presents a new method for estimating

52 progression rates from surveillance data that generates values useful for modelling

53 pathogen populations, even from relatively small sample sizes. 


\section{Introduction}

Opportunistic pathogens are commonly found in the environment, or microbiota of healthy hosts, but have the capacity to cause disease in some host organisms [1].

The frequency with which they transition from asymptomatic colonisation to symptomatic infection can be quantified as a progression rate [2]. Many opportunistic pathogens are diverse, and can be typed by a variety of phenotypic methods [3], or divided into strains using genotyping or whole genome sequencing $[4,5]$. Understanding the variation in progression rates across such species is crucial for understanding changes in the incidence of diseases caused by opportunistic pathogens. Recently, strains with high progression rates, sometimes referred to as "hypervirulent" [6] or "hyperinvasive" [7], have been ascribed as the primary cause of rising case numbers of disease caused by Neisseria meningitidis [8], Streptococcus pyogenes [9] and Klebsiella pneumoniae [10], among others. However, understanding whether such strains drive elevated disease burdens through more rapid transmission, or heightened progression rates, typically requires additional information on the carried population of the opportunistic pathogen.

Progression rates have been extensively studied in the nasopharyngeal commensal and respiratory pathogen Streptococcus pneumoniae (the pneumococcus). Over one hundred serotypes have been identified in this species, each corresponding to a structurally-distinct polysaccharide capsule $[11,12]$. These are clustered into 48 serogroups, based on serological cross-reactivity [13]. This capsule inhibits pneumococci being cleared by the immune system, and is crucial to their ability to cause invasive pneumococcal disease (IPD) [14,15], infections of normally sterile anatomical sites. Hence the rate of progression from carriage to IPD is referred to as 
invasiveness [16]. It has long been assumed the capsule is an important determinant of pneumococcal invasiveness, based on differences in serotypes' ability to cause disease in animal experiments [17]. Epidemiological differences are also apparent in human disease, with paediatric serotypes (including serotypes within serogroups 6, 9, 19, 23, and serotype 14) common in sporadic infant disease, and 'epidemic' serotypes (such as 1, 2, 5 and 12F) capable of causing IPD outbreaks in adults $[18,19]$.

Understanding these differences between serotypes has become crucial for $S$. pneumoniae epidemiology, owing to the introduction of polysaccharide conjugate vaccines (PCVs) [20]. A seven valent PCV (PCV7) was introduced in the USA in 2000, which has been supplanted by ten- and thirteen-valent formulations (PCV10 and PCV13, respectively). These induce immune responses against a specific subset of serotypes, resulting in their elimination from carriage [21]. However, the overall frequency of $S$. pneumoniae colonisation typically remains stable after any PCV's introduction, owing to the replacement of vaccine serotypes by the plethora of non-vaccine serotypes [22,23]. Nevertheless, PCVs have usually proved highly effective at reducing IPD through facilitating the replacement of the pre-PCV carried population with pneumococcal serotypes associated with lower invasiveness [24,25]. Hence optimal PCVs are those which minimise the overall invasiveness of the carried pneumococcal population $[26,27]$. Therefore estimation of invasiveness across vaccine-targeted serotypes, and those which may replace them post-PCV, is vital for reducing the incidence of IPD. Such quantification of invasiveness is typically achieved through paired studies of serotypes' prevalence in geographically and

103 temporally matched surveys of pneumococcal carriage, and surveillance of IPD. 
Multiple methods have been used to estimate invasiveness using such paired case and carrier data. The most common approaches use odds ratios: the ratio of isolates

107 of a given serotype recovered from disease against those recovered from carriage,

108 divided by the same ratio calculated across all other serotypes in the population

$109[28,29]$. However, this statistic is intrinsically imperfect, because even if a serotype

110 causes disease at a consistent rate across populations, the mix of serotypes against

111 which it is compared will differ between locations [30,31]. This geographical

112 heterogeneity has been exacerbated by post-PCV serotype replacement, which has

113 driven increasing divergence between countries' serotype compositions [32]. The

114 interpretability of the odds ratios may be improved by standardising them relative to

115 the geometric mean across all odds ratios [33], but this does not resolve the

116 underlying problem, which likely contributes to the substantial heterogeneity

117 observed for some serotypes when odds ratios are combined in meta-analyses [34].

118 This means carefully-conducted odds ratio analyses can be hampered by having to

119 subsample data, and employ both fixed and random effects analyses, within a single

120 analysis [35]. One solution has been to estimate invasiveness relative to a standard

121 serotype that is common in both carriage and IPD across studied locations [34,36].

122 However, these properties mean such serotypes are likely to be targeted by PCVs.

123 Correspondingly, the original standard, serotype 14 [29], has been eliminated by

124 PCV7 in many settings. Similarly, PCV13 has removed the replacement standard serotype used in post-PCV7 studies, 19A [34].

127 Invasiveness has been more directly characterised as the ratio of disease cases

128 relative to the estimated prevalence in carriage [25]. However, this approach did not 
account for the stochasticity of disease cases being observed, and assumed the uncertainty associated with the estimated case-to-carrier ratio derived only from the

131 colonisation survey data. More comprehensive quantification of the uncertainty in

132 invasiveness can be achieved with Bayesian frameworks, which have been applied

133 to individual pneumococcal populations [2,37]. Invasiveness has been modelled by

134 jointly fitting distributions to carriage and disease data, then using random effects models to estimate invasiveness in different age groups [37]. An alternative approach, using Poisson regression, was used to estimate serotypes' progression

137 rates for causing otitis media [2].

139 In this work, we apply Bayesian modelling to estimate progression rates from meta140 analyses of multiple studies. The ability to synthesise data across populations is 141 important for increasing the sample size of each of the many serotypes observed in 142 species such as S. pneumoniae, particularly as many genotypes that have emerged 143 post-PCV were previously rare, and vary geographically $[32,38]$. The model enables

144 the estimation of progression rates as an opportunistic pathogen's hazard of progressing from carriage to disease in a specified population. Such absolute values avoid a measure that is relative either to the rest of the local pneumococcal

147 population, or to one standard serotype. These properties are crucial for quantifying 148 and modelling changes in disease incidence, such as following vaccine introduction,

149 or the emergence of a hyperinvasive strain. They can be particularly valuable in settings where disease surveillance is not comprehensive, and only carriage data are available $[37,39]$. 
153 Using a Bayesian approach also enables hypothesis testing through statistical

154 comparison of alternative model structures [2,37]. This is crucial for understanding

155 the host and pathogen factors that affect progression rates. For instance, the

156 correlation between pneumococcal serotypes and invasiveness has not been

157 indisputably established as a causal link. In Haemophilus influenzae, changes to an

158 isolate's serotype altered its virulence in an animal model of disease in such a

159 manner that reflected the epidemiology of human disease [40]. While some

160 equivalent experiments in S. pneumoniae have replicated observations from human

161 IPD [41,42], others have found changes in an isolate's serotype did not change its

162 invasiveness in an animal model [43,44], suggesting serotype-independent factors

163 may contribute to this phenotype. Studies of isolates from disease and carriage

164 using comparative genomic hybridisation $[45,46]$ and whole genome sequencing

$165[47,48]$ have both supported links between non-capsular loci and invasiveness. An

166 unambiguous association cannot even be made between the distinctive phenotypes

167 of the epidemic serotypes and their capsules, as these pneumococci tend to have

168 low genetic diversity [35,49], and therefore their capsule polysaccharide synthesis

169 locus is in linkage disequilibrium with many other variable genomic loci [50,51].

171 Epidemiological studies using genotyped and serotyped isolates have also found

172 examples of within-serotype differences in invasiveness [33,52,53], although other

173 studies found evidence of serotype being the primary determinant of invasiveness

174 [29]. Genomic analysis by the Global Pneumococcal Sequencing project also

175 identified differences in the invasiveness of strains of the same serotype [31].

176 However, given the multiple pairwise comparisons conducted in such analyses, it is

177 not clear whether such observations might be expected, even if the capsule is the 
primary determinant of invasiveness. Such questions can be addressed through comparison of different model fits to the data, thereby improving our understanding of the determinants of progression rates. This is essential for deciding on the most

181 effective methods for ongoing pathogen surveillance, and to enable the rapid

182 identification of emerging highly invasive types. Therefore the methods, models and data described in this study are made available as an $\mathrm{R}$ package

(https://github.com/nickjcroucher/progressionEstimation), to enable the ongoing aggregation of case and carrier studies for any opportunistic pathogens,.

\section{Methods}

\section{Model definitions and assumptions}

All models were designed to be applied to a meta-population of a multi-strain

191 opportunistic pathogen. Each population $i$ corresponded to a matched sample of

192 microbes from asymptomatic carriers, or the environment, and a sample from

193 disease. It was assumed all cases of disease emerged independently from the carried or environmental population. Across the meta-population, the microbes were classified according to their serotype $j$, strain $k$, or the combination of both, $j, k$. If $x$ denotes any one of these classifications, then the carriage rate in population $i, \rho_{i, x}$, was estimated based on the total number of samples (including negative results), $\eta_{\text {i, }}$ and the number of samples positive for isolates of type $x, c_{i, x}$ :

$$
c_{i, x} \sim \operatorname{Binom}\left(\rho_{i, x}, \eta_{i}\right)
$$


202 Modelling the number of positive samples using a Binomial distribution follows the precedent of Weinberger et al [37], and assumes all carriage samples are independently drawn from the circulating population.

A set of related statistical models were used to estimate the progression rate [2], v, the hazard of developing a disease given carriage of a microbe per unit time. As $v$ was assumed to be constant for each type $x$ in each study $i$, the number of observed cases of disease caused by $x$ in $i, d_{i, x}$, was modelled as the product of the number of potential hosts in $i, N_{i}$; the proportion carrying $x$ in $i, \rho_{i, x}$; the per unit time probability

211 of $x$ causing disease, $v_{x}$; and the duration of the study, $t_{i .}$. Hence, the expected

212 number of isolates from disease, $\mathbb{E}\left[d_{i, x}\right]$, in all models was proportional to all these quantities:

$$
\mathbb{E}\left[d_{i, x}\right] \propto \rho_{i, x} N_{i} \mathrm{t}_{i} v_{x}
$$

217 Some models also adjusted the expected $d_{i, x}$ between $i$ through a scaling parameter,

$218 \mathrm{Y}_{\mathrm{i}}$, that was relative to a reference population. This corrects for differences between

219 studies both in the actual hazard of developing a disease, due to host population

220 variation, and differences in the comprehensiveness of surveillance across the study

221 populations. Hence, the expected number of isolates from disease, $\mathbb{E}\left[d_{i, x}\right]$, in such models was proportional the quantities:

$$
\mathbb{E}\left[d_{i, x}\right] \propto \rho_{i, x} N_{i} \mathrm{t}_{i} v_{x} \gamma_{i}
$$


226 All these parameters were assumed to be constant within a study over $t_{i}$. All disease

227 cases were assumed to develop independently, and therefore were modelled as a

228 Poisson process. However, relevant unmodelled variation, or oversampling of local

229 transmission chains in either carriage or disease sampling [54], could cause

230 heterogeneity in the observed isolate counts in either component of the paired

231 samples. Hence $d_{i, x}$ was additionally modelled as following a negative binomial

232 distribution, in which overdispersion was quantified by the precision parameter, $\phi$,

233 relative to the mean, $\mu$. Lower $\phi$ values indicate greater overdispersion, as the

234 variance of the distribution was calculated as:

$$
\operatorname{Var}\left[d_{i, x}\right]=\mu+\frac{\mu^{2}}{\phi}
$$

\section{Models of disease prevalence}

239 Four different structures were used to model $\mathbb{E}\left[d_{i, x}\right]$. For each, two different versions

240 were fitted to the data. In the simpler version, the observed disease case counts

241 were assumed to follow a Poisson distribution:

$$
d_{i, x} \sim \operatorname{Poisson}\left(\mathbb{E}\left[d_{i, x}\right]\right)
$$

The more complex version assumed a negative binomial distribution of the observed disease case counts:

$$
d_{i, x} \sim N e g \operatorname{Bin}\left(\mathbb{E}\left[d_{i, x}\right], \phi\right)
$$


250 Null model: In this simplest model, the progression rate was independent of the pathogen's type $\left(v_{x}=v\right.$ for all $\left.x\right)$ and host population $\left(\gamma_{i}=1\right.$ for all $\left.i\right)$. Therefore $d_{i, x}$ is expected to be correlated with $c_{i, x}$ :

$$
\mathbb{E}\left[d_{i, x}\right]=\rho_{i, x} N_{i} \mathrm{t}_{i} v
$$

Type-specific model: This model, similar to that Weinberger et al applied to a single population [37], allowed for variation in progression rate between types, but still assumed host populations to be homogeneous $\left(\gamma_{i}=1\right.$ for all $\left.i\right)$. Therefore $d_{i, x}$ depends on both the carriage prevalence and progression rate of $x$ :

$$
\mathbb{E}\left[d_{i, x}\right]=\rho_{i, x} N_{i} \mathrm{t}_{i} v_{x}
$$

Study-adjusted model: In this model, variation in disease prevalence between studies reflected differences in host population and surveillance, rather than differences between types. Hence the progression rate was independent of the pathogen's type $\left(v_{x}=v\right.$ for all $\left.x\right)$, but varied between $i$ due to $\gamma_{i}$ :

$$
\mathbb{E}\left[d_{i, x}\right]=\rho_{i, x} N_{i} \mathrm{t}_{i} v \gamma_{i}
$$

Study-adjusted type-specific model: This model allowed for both variation in the progression rate between types $x$ and study populations $i$ :

$$
\mathbb{E}\left[d_{i, x}\right]=\rho_{i, x} N_{i} \mathrm{t}_{i} v_{x} \gamma_{i}
$$


Joint modelling of strain and type progression rates

276 For datasets in which information was available on both type (for S. pneumoniae, serotype) $j$ and strain $k, v_{x}$ was modelled in five different ways:

Serotype-determined progression rate: The progression rate was entirely determined by an isolate's type, and independent of its strain background $\left(v_{x}=v_{j}\right)$.

Strain-determined progression rate: The progression rate was entirely determined by the strain to which an isolate belonged, and independent of its type $\left(v_{x}=v_{k}\right)$.

Strain-modified type-determined progression rate: Two approaches were taken to modelling progression rates as being independently affected by type and genetic background. The first modelled the progression rate as being primarily determined by an isolate's serotype, which was modified by its strain background. This was calculated as $v_{x}=v_{j} v_{k}$, where the model priors meant $v_{j}$ was less constrained than $v_{k}$. Hence most variation in $v_{x}$ should be attributed to the type $j$.

Type-modified strain-determined progression rate: The second approach to analysing the independent effects of type and genetic background modelled progression rate as being primarily determined by the strain to which an isolate belonged, which was modified by the serotype it expressed. This was calculated as $v_{x}=v_{j} v_{k}$, where the model priors meant $v_{k}$ was less constrained than $v_{j}$. most variation in $v_{x}$ should therefore be attributed to the strain $k$. 
299 Type and strain-determined progression rate: Each combination of serotype $j$ and

300 strain $k$ was modelled as having a unique progression rate $\left(v_{x}=v_{j, k}\right)$, suggesting non-

301 multiplicative interactions between strain background and type on an isolate's

302 progression rate.

303

Model priors and implementation

305 The characteristics of each study population $\left(\eta_{i}, N_{i}, t_{i}\right)$ and observed counts of type $x$

306 in carriage $\left(c_{i, x}\right)$ and disease $\left(d_{i, x}\right)$ were assumed to be accurate and without error. As

307 each recovery of a type $x$ isolate from carriage contributes to the estimation of $\rho_{i, x}$,

308 even if an individual carries multiple types, the prior distribution was:

$$
\rho_{i, x} \sim \operatorname{Beta}(1,1)
$$

312 This means each type's carriage was independently estimated, and the sum of

313 carriage prevalences $\left(\sum_{x} \rho_{i, x}\right)$ may be greater than one, if there is high level of

314 multiple carriage in a population. The beta distribution was used, as it is the

315 conjugate prior of the binomial distribution, although setting the scale and shape

316 parameters to one make it equivalent to a uniform distribution bounded by zero and

317 one.

319 Invasiveness has been estimated to vary over orders of magnitude in S. pneumoniae

320 [27], and therefore a uniform prior was placed on the logarithm of $v_{x}$ in all models.

321 The lower bound was set at one IPD case per million carriers per year, as the largest

322 studies used surveillance of host populations consisting of tens of millions of

323 individuals (Table S1). The upper bound was ten cases per carrier per year, which 
324 would effectively correspond to an obligate pathogen for a bacterium with the carriage duration of S. pneumoniae [55]:

$$
\log _{10}\left(v_{x}\right) \sim U(-6,1)
$$

329 As the scaling factors were relative measures of disease prevalence between populations, $Y_{i}$ for the population with the largest sample size was fixed at one. The scaling factor for each other population $i$ was allowed to vary higher or lower. The

Cauchy distribution was assumed as the prior for the logarithm of $\mathrm{Y}_{i}$, as this describes the ratio of two normally-distributed random variables. However, the Hamiltonian Monte Carlo algorithm used for model fitting does not efficiently sample heavy-tailed distributions, and therefore the prior was reparameterised to use a random variable $\Gamma_{\mathrm{i}}$ with a unit-sized uniform prior [56]:

$$
\Gamma_{i} \sim U\left(-\frac{\pi}{2}, \frac{\pi}{2}\right)
$$

The $\Gamma_{i}$ values were then transformed to generate $\gamma_{i}$ values with a Cauchy distribution using the location $\left(\mu_{\text {study }}=0\right)$ and scale $\left(\tau_{\text {study }}=2\right)$ parameters:

$$
\left.\log _{10}\left(\gamma_{i}\right)=\mu_{\text {study }}+\tau_{\text {study }} \tan \left(\Gamma_{i}\right)\right)
$$

The $\tau_{\text {study }}$ value allowed for variation in observed incidence over multiple orders of magnitude between datasets, ensuring the model makes allowance for substantial heterogeneity in observed disease incidence [57]. 
349 A similar reparameterization of the Cauchy distribution was used for the models in

350 which type and strain background independently contributed to a genotype's

351 progression rate (the strain-modified type-determined, and type-modified strain-

352 determined progression rate models). The categorisation modelled as determining

353 the progression rate $\left(v_{x}\right)$ had the same prior as when a single factor determined the

354 progression rate. This was multiplied by a second value, $v_{y}$, determined by the classification modifying the progression rate. The prior distribution for the logarithm of this value was a truncated Cauchy, symmetrical around zero. This represented the expectation that the modification of the progression rate would be small (approximately one) in most cases, but may be substantial in rare instances. The truncation was found to be necessary for efficient sampling with the Hamiltonian Monte Carlo algorithm. This was parameterised with a random variable $Y_{y}$, sampled from a uniform distribution with narrower boundaries than those for the analogous $\Gamma_{\mathrm{i}}$ variable:

$$
\Upsilon_{y} \sim U(-1.25,1.25)
$$

366 The $\mathrm{Y}_{\mathrm{y}}$ values were then transformed to generate $v_{y}$ values using the location $\left(\mu_{\text {mod }}\right.$ $367=0)$ and scale $\left(\tau_{\text {mod }}=0.5\right)$ parameters:

$$
\left.\log _{10}\left(v_{y}\right)=\mu_{\text {mod }}+\tau_{m o d} \tan \left(\Upsilon_{y}\right)\right)
$$

371 This meant $v_{y}$ values could vary over three orders of magnitude (between 0.0313 and 32.0), while enabling models to converge with reasonable MCMC lengths. 
374 The precision parameter of the negative binomial distribution, $\phi$, was sampled from a uniform distribution. Where there is little evidence of overdispersion, $\phi$ will be large relative to $\mathbb{E}\left[d_{i, x}\right]$, whereas highly overdispersed data can be modelled with a smaller, albeit non-zero, $\phi$ value. Therefore, the prior distribution was chosen to be broad, but always positive:

Model parameters are summarised in Table 1. All models were implemented using $\mathrm{R}$ [58] and Rstan [59]. Each model was fitted using two Hamiltonian Markov chain Monte Carlo (MCMC) evaluations for 25,000 iterations. Convergence was assessed through analysing the MCMC traces, using the criterion of all $\hat{R}$ values below 1.05 , and no reports of divergent transitions in the sampling [56]. This was achieved using default MCMC sampling parameters for the serotype analyses, but the strain analyses required a smaller step size (0.01), higher acceptance probability (0.99) and larger tree depth (20). The data and code used for the analyses are available as an R package from https://github.com/nickjcroucher/progressionEstimation/.

\section{Model evaluation and comparison}

393 Models were compared using likelihoods, independent of priors, through approximate leave-one-out cross-validation with the loo package [60]. The marginal

395 likelihoods of different models, given the data, were compared with Bayes factors

396 calculated using the bridgesampling package [61]. The same number of iterations

397 were used to calculate the logarithmic marginal likelihoods as were used to fit the 
models. Model outputs were analysed and plotted with tidyverse and ggpubr packages $[62,63]$.

\section{S. pneumoniae serotype data}

402 The matched carriage and invasive pneumococcal disease serotype datasets were combined from two meta-analyses $[27,34]$. Twelve of the reported studies were omitted due to lack of publicly-available data [29,64-69]; difficultly in defining independent cross-sectional carriage samples [70,71]; small sample sizes once stratified by age [72], or study design biased towards particular serotypes [73]. If a

407 PCV were introduced during a study, then samples were divided into pre-PCV and post-PCV datasets. This generated 21 paired case and carrier datasets, each with substantial matched systematically-sampled and comprehensively serotyped asymptomatic carriage and disease samples (Table S1). Of these studies, 20

411 included data on child carriage and child IPD, and five included data on child

412 carriage and adult IPD.

414 Data that were only resolved to serogroup level, based on the currently-known serotypes, were omitted from the analysis, although the overall number of samples taken $\left(\eta_{i}\right)$ was not adjusted. However, data on serotypes in historical studies that are

417 now known to correspond to multiple serotypes (e.g. serotype 6A now being

418 resolved into $6 \mathrm{~A}$ and $6 \mathrm{C}$ [74]) were included unaltered. Additionally, isolates of serotypes $15 B$ and $15 C$ were combined into the single $15 B / C$ category. 
422 Analysis of variation of invasiveness between S. pneumoniae strains in children used

423 population genomic data from South Africa [35], a mixture of population genomic and

424 genotyped data from the USA [35], and genotyped data from Finland [71], Oxford

425 [29] and Stockholm [75]. The equivalent analysis of strain invasiveness in adults

426 used data from Portugal [52]. Some of the genotyped datasets were not as

427 thoroughly documented as the serotyped datasets, and therefore it was not

428 appropriate to fit models that lacked a study-specific scale factor that reduced their

429 reliance upon accurate carriage sample information (Text S1).

431 Results

433 Bayesian meta-analysis of S. pneumoniae serotype invasiveness

434 Twenty matched disease case and nasopharyngeal carrier datasets were used to 435 quantify S. pneumoniae serotype invasiveness in children (Table S1). From these, 4367,340 carriage isolates and 2,851 disease isolates were extracted, across 72 437 serotypes (Fig. S1). Multiple models of invasiveness were proposed to analyse these 438 data (see Methods). The null model assumed there was no systematic difference 439 between serotypes' invasiveness across datasets. The type-specific model assumed 440 each serotype had a characteristic invasiveness that was consistent across

441 locations. The study-adjusted null model assumed invasiveness did not vary across 442 serotypes, but could differ between studies. Finally, the study-adjusted type-specific 443 model allowed invasiveness to vary between both types and studies. All four 444 approaches to estimating the expected numbers of disease cases and carriage 445 isolates were fitted assuming the number of disease cases would follow a Poisson 
distribution, and allowing for overdispersion by fitting a negative binomial distribution

447 to these values, resulting in eight total models.

449 Datapoints at which both the count of both carriage and disease isolates were low for a given type in a study offered limited power for distinguishing the different model structures. Therefore only paired observations from an individual study in which either the number of carried or disease isolates was at least five were used for the model comparison. This reduced the dataset to 7,048 carriage isolates and 2,617 disease isolates across 45 serotypes (Fig. S2). The eight models were each fitted to the data using two Hamiltonian Markov chain Monte Carlo samplings, both run for 25,000 iterations. All chains appeared to have converged, based on the traces of the posterior probabilities (Fig. S3) and all $\hat{R}$ values being below 1.001 (Fig. S4).

Comparisons of the observed and predicted isolate counts showed all models could accurately reproduce the observations from carriage studies, with the exception of

460 the simplest null Poisson model (Fig. 1). However, only the most complex models,

461 adjusting for both S. pneumoniae serotype and study, were able to accurately reproduce the disease case counts.

464 These deviations can be quantified as root mean squared error (RMSE) values (Fig.

465 S5). These show the negative binomial models replicate the carriage values closely, 466 relative to the equivalent Poisson models, with correspondingly greater deviation 467 from the disease counts enabled by the overdispersion permitted by the negative 468 binomial distribution's precision parameter, $\phi$. The low $\phi$ values for the three simplest 469 negative binomial models suggest there is substantial unmodelled variation (Fig. S6). 470 However, for the study-adjusted type-specific models, the high $\phi$ value suggests little 
evidence of overdispersion, and the similar RMSE values for the Poisson and negative binomial versions of this model suggested adjusting for study and serotype enabled disease cases to be modelled using a Poisson distribution (Fig. S5).

The success of the study-adjusted type-specific models in reproducing the observations may represent overfitting by the most complex models. Therefore formal model comparisons were undertaken using leave-one-out cross validation [60]. Although this suggested the study-adjusted type-specific models were the most appropriate, the large number of model parameters meant the Pareto k statistic diagnostic values were too high for these comparisons to be reliable (Table S2) [76].

481 This was still true if the models were compared using only the likelihoods calculated

482 from the disease counts, which were more constrained than those calculated from the carriage data (Table S3). Hence models were instead compared using Bayes factors calculated from bridge sampling [61]. This found the null models to be the poorest fitting, and identified the study-adjusted type-specific Poisson model to be the most strongly favoured by the data (Table S4).

\section{Identification of highly invasive non-vaccine serotypes}

489 The study-adjusted type-specific model was therefore applied to the full dataset.

490 Both the MCMC traces and $\hat{R}$ statistics indicated the model fit converged after

49125,000 iterations (Fig. S7). This enabled the estimation of invasiveness for 72 serotypes (Fig. 2; Dataset S1), including all 24 included in formulations that are currently licensed or under development $[20,77,78]$. The analysis shows the serotypes associated with high invasiveness and narrow credibility intervals are the

495 three serotypes added to PCV7 to generate PCV10 (1, 5 and 7F), which are also 
present in higher-valency PCVs, and serotype 12F, included in PCV20. Other serotypes not included in current vaccine designs, but likely to be highly invasive, include 9L, 19C, 28A and 46. However, the credibility intervals of these estimates were substantial, resulting from small overall sample sizes.

The serotypes associated with low invasiveness and narrow credible intervals were 11A (included in PCV20), 6C, 21, 23A, 23B, 34, 35B and 35F. Many other serotypes

these estimates have wide credibility intervals. The higher uncertainty generally corresponded with lower sample sizes, although some of these serotypes had a total sample size above 50 (e.g. 10F, 35A, 42), but were nevertheless rare in IPD. The reference population for the model fit was the post-PCV7 sample from the Navajo nation [37], as this study contributed the largest number of isolates (Fig. S1). The model fits found the maximal progression rates were above $10^{-2}$ IPD cases per carrier per year, with the minimum point estimates approximately 10-4 IPD cases per

511 carrier per year. However, the incidence of IPD in the Navajo population is high, with excellent disease surveillance [79], and therefore other studies were expected to report lower disease cases per carriage episode. Correspondingly, the study-

514 adjustment scale factors were below one for most other datasets (Fig. S8),

515 suggesting most locations would expect to detect around half the number of IPD cases per carriage episode for the same carriage serotype composition.

518 The fitted study-adjustment scale factors were all associated with similarly narrow

519 credibility intervals, demonstrating there were enough shared types between

520 samples to robustly infer these parameters. For four locations, both pre-PCV and 
521 post-PCV samples were included in the meta-analysis, which might be expected to have similar scale factors, if the host population and disease surveillance were consistent across these eras. However, this was not the case for three locations

524 (Atlanta, Bogota and the Netherlands). The model's assumption that serotype invasiveness is constant across studies may be violated by a reduction in vaccine-

526 type invasiveness following PCV introduction, if vaccine-induced immunity inhibited progression from carriage to IPD. Therefore the study-adjusted type-specific Poisson model was refitted, treating vaccine-type serotypes as different types pre- and postPCV (including 6A as a PCV7 type, and 6C as a PCV13 type [80]; Fig. S9). The

530 point estimates of invasiveness for most vaccine serotypes dropped following PCV

531 introduction, with the evidence strongest for serotypes 14 and $7 \mathrm{~F}$ falling after the

532 introduction of PCV7 and PCV10, respectively (Fig. 2). This fit meant the scale factor credibility intervals for the Netherlands' pre-PCV7, post-PCV7 and post-PCV10

534 studies overlapped (Fig. S10). These data suggest PCVs can reduce the invasiveness of vaccine types before they are eliminated by herd immunity, and

536 therefore distinguishing between pre- and post-PCV invasiveness may help standardisation across meta-analyses.

\section{Comparison of Bayesian modelling with odds ratios}

540 The outputs of the adjusted type-specific Poisson model were compared to those

541 from estimating pneumococcal invasiveness from the same dataset using odds

542 ratios (Fig. 3). Odds ratios were combined across studies using either random (Fig.

543 3A) or fixed effects (Fig. 3B) models, and the results disaggregated based on the

544 total number of isolates, summed across carriage and disease, for each serotype.

545 Across all sample sizes, there was a significant positive correlation between the two 
measures of invasiveness. The range of invasiveness values extended over two

orders of magnitude for both methods. Hence the study-adjusted type-specific

Poisson model produced similar relative estimates of invasiveness to odds ratio

analyses, while having the advantage of providing both overall, and location-specific,

absolute estimates of these progression rates that can be used in quantitative analyses.

Fixed effects analyses assume there is a single invasiveness value across all

locations, whereas random effects analyses allow for variation in the underlying invasiveness estimate between studies. The identification of between-location heterogeneity typically suggests random effects models are more appropriate for analyses of pneumococcal invasiveness $[27,34,35]$. This variation may either reflect genuine differences in serotype behaviour, or arise from standardisation relative to a variable mix of serotypes between locations. By accounting for this variation, random effects models often calculate wider confidence intervals than fixed effect models (Fig. 3). Additionally, random effects models are typically not recommended where there are fewer than five studies in which a serotype features [81], and therefore meta-analyses of odds ratios may be a mixture of fixed- and random-effects models

564 [35]. By contrast, the Bayesian framework rejected the over-dispersed negative

565 binomial model in favour of the Poisson model (Fig. 1). This may reflect reduced

566 heterogeneity in invasiveness estimates, because standardisation does not use

567 differing mixtures of serotypes, as for odds ratios. This single, consistent model can be applied across serotypes, regardless of their frequency. 
570 Deviations between the methods in the rank order of invasiveness point estimates

571 were most evident at small sample sizes. This was most notable for serotypes $33 \mathrm{~A}$

572 and 36 , both of which were associated with relatively high log odds ratios (above

573 zero) and relatively low Bayesian progression rate estimates (below $10^{-3}$ cases per

574 carrier per year). Both were observed only in carriage: five isolates across four

575 studies for serotype 33A, and one isolate in each of three studies for serotype 36.

576 Whereas logarithmic odds ratio analyses necessarily generate symmetrical

577 confidence intervals, those from the Bayesian analysis were asymmetric, with long

578 tails spanning lower values representing the possibility that the invasiveness of these

579 serotypes may be negligible, as they were not observed to cause IPD. Hence the

580 Bayesian model estimates provide a more informative representation of the limited

581 available data.

582

583 At the upper end of the scale, the Bayesian model found the most highly invasive

584 serotype to be 46 , with credibility intervals indicating this serotype is unlikely to be of

585 intermediate invasiveness [28]. By contrast, the confidence intervals for the odds

586 ratios estimated using random effects spanned the full range of invasiveness point

587 estimates across the species. This serotype was observed in two studies, but never

588 isolated from carriage, and there is further circumstantial evidence that serotype 46

589 is likely to be highly invasive (see Discussion). Hence this Bayesian framework can

590 use case-carrier studies to provide informative estimates of invasiveness even from

591 small sample sizes.

593 Odds ratios were previously found to correlate with another measure of

594 invasiveness, the "attack rate", which in turn negatively correlated with carriage 
duration [18]. This could result from IPD being most common shortly after the acquisition of a novel serotype in the nasopharynx, which occurs more frequently for serotypes carried for only a short period in each host. The invasiveness values from child IPD data were compared with recent estimates of carriage duration from multistate modelling of longitudinally-sampled carriage studies in Maela, Thailand [55,82].

600 Although the highest invasiveness values were associated with short carriage

601 durations, likely as longer carriage duration is expected to result in higher crosssectional carriage prevalences, there was no strong overall relationship (Fig. S11).

\section{Differences in invasiveness between host age demographics}

605 Although S. pneumoniae primarily circulate between children, they frequently cause disease in adults. Five datasets were identified in which adult disease cases could be matched with child nasopharyngeal carrier datasets, to estimate serotype invasiveness in adults. Overall, 3,756 carriage isolates and 3,041 disease isolates were extracted across 53 serotypes (Fig. S12). As with the child IPD samples, this

610 dataset was filtered for observations where either the number of carriage or disease

611 isolates was at least five for the model comparison, to improve the power for

612 identifying the best fitting model. This filtering left in 3,704 carriage isolates and

6132,969 disease isolates across 40 serotypes (Fig. S13). As with the child dataset, two

614 Hamiltonian MCMC samplings for 25,000 iterations were used to fit the eight models,

615 which converged based on the traces of the posterior probability (Fig. S14) and $\hat{R}$

616 values being below 1.001 (Fig. S15). Similar to the analysis of invasiveness in

617 children, comparisons of the observed and predicted isolate counts again showed

618 that only the models adjusting for both S. pneumoniae serotype and study were able

619 to accurately reproduce the adult disease case counts (Fig. S16). Bayes factors 
concurred that the study-adjusted type-specific Poisson model was the most likely,

621 given the data (Table S5).

622

623 Thus, this model was applied to the complete adult disease dataset. MCMC traces

624 and $\hat{R}$ statistics again indicated the model fit converged after 25,000 iterations (Fig.

625 S17). Like the child analysis, the reference population for the model fit was the post-

626 PCV7 sample from the Navajo nation [37]. The high incidence of IPD in this

627 population is again evident in the adult population, and therefore the other studies

628 report lower study-adjustment scale factors (Fig. S18), with most locations expecting

629 to detect around a third or fewer the number of IPD cases per carriage episode for

630 the same carriage serotype composition.

631

632 This analysis therefore enabled the estimation of invasiveness of 53 serotypes in

633 adults (Fig. 4A; Dataset S2), including the 24 included in PCV formulations currently

634 licensed or under development. The analysis shows the non-vaccine serotypes

635 associated with high invasiveness and narrow credibility intervals were serotypes 8

636 and 12F, included in the PCV20 formulation, and the non-vaccine type serotype 13.

637 Other serotypes not included in current vaccine designs, but likely to be highly

638 invasive, include serotypes $9 \mathrm{~L}, 12 \mathrm{~B}$ and 29 . However, the credibility intervals of

639 these estimates were substantial, resulting from small overall sample sizes. The non-

640 PCV serotypes associated with low invasiveness (mean estimates $<10^{-3}$ disease

641 cases per carrier per year) and narrow credible intervals were serotypes 7C, 15A,

$64216 \mathrm{~F}, 23 \mathrm{~A}, 31,34,35 \mathrm{~A}, 35 \mathrm{~B}$ and $35 \mathrm{~F}$. 
644 Comparisons with the corresponding child invasiveness estimates (Fig. 4B) showed many PCV serotypes had similar invasiveness estimates in both children and adults

646 [37], with PCV7 and PCV10 types having mid-range and high invasiveness

647 estimates for both children and adults, respectively. Serotype 6C, which is affected

648 by PCV13-induced immunity against the 6A component, was low in both children and adults. The non-PCV serotype $9 \mathrm{~L}$ appears to be highly invasive in both populations, although this value was associated with considerable uncertainty. However, other non-PCV types showed a discrepancy between the two age groups. For example, serotypes 12B and 29 were highly invasive in adults but not children, though the credible interval ranges were large for both.

Serotypes included in the PCV15 and PCV20 formulations appeared to have midrange invasiveness in both age groups, except for the consistently highly invasive serotypes 8 and 12F. This suggests the removal of these two serotypes through herd immunity from higher-valency PCV infant immunisation programmes would likely be beneficial to the adult population $[83,84]$. However, this would concomitantly reduce the effectiveness of the current PPV23 adult vaccine, due to its overlap in serotype coverage with PCVs meaning it would protect against a lower proportion of the postvaccine S. pneumoniae population $[27,85]$. Its residual effect would be determined by the prevalence and invasiveness of the non-PCV PPV23 serotypes. Both serotypes 2 and 20 were estimated to be highly invasive for both age groups, albeit with broad credible intervals for adults for the former, due to it only being included in one adult dataset. Other PPV23 serotypes had elevated invasiveness compared to many non-vaccine types, suggesting that PPV23 may offer protection against a 
limited number of higher-risk serotypes following the implementation of PCV15 or PCV20 infant vaccination programmes.

\section{Invasiveness varies between pneumococcal strains and serotypes}

S. pneumoniae populations are genetically diverse, and can be divided into discrete strains $[50,86]$. Isolates of a particular serotype are often found across multiple strain backgrounds, and a single strain may be associated with multiple serotypes through switching [51]. To test how each of these characteristics affected pneumococcal progression rates, five different models of isolates' invasiveness were fitted using the study-adjusted type-specific Poisson framework (see Methods). These corresponded to the hypotheses that an isolate's invasiveness was determined by its serotype; by its strain background; primarily by its serotype, but modified by strain background; primarily by its strain background, but modified by its serotype; and determined by the combination of its serotype and strain background. All five models were fitted using Poisson and negative binomial distributions.

683

684 These ten models were used to conduct a meta-analysis of six studies in which both serotype and strain background could be determined, for at least some isolates (Fig. S19). Three of the studies (post-PCV7 and post-PCV13 South Africa; post-PCV7

687 USA) were modified versions of a comparison primarily conducted using genomic 688 data [35]. These were combined with pre-PCV genotyped studies from Oxford, UK [29]; Stockholm, Sweden [75], and Finland [71] (see Text S1 and Table S6). For each dataset $i$, isolates were grouped by both their serotype $j$ and strain $k$. Models

691 were fitted to a subset of these samples that excluded rare strain-serotypes (with a 692 maximum $c_{i, j, k}$ or $d_{i, j, k}$ below five; Fig. S20), leaving 38 serotypes, 74 strains, and 99 

estimates, as inferred from the traces of logarithmic posterior probability values (Fig. S21) and distribution of $\hat{R}$ values (Fig. S22). All models were able to generate reasonably accurate predictions (Fig. S23). There was little evidence of negative

697 binomial distributions improving the fit of these models, and the precision parameters were correspondingly high, albeit with evidence of greater overdispersion when serotype information was omitted from the model fit (Fig. S24). The lowest RMSEs were associated with the models that accounted for both strain background and serotype, either through modification, or when considered in combination (Fig. S25).

Model comparison with LOO-CV found the best-performing models were those that combined information on isolates' serotype and strain background (Tables S7 and S8), although the Pareto k statistic diagnostic values were again too high for this comparison to be reliable. Comparisons using Bayes factors agreed that the most

707 likely model was that in which invasiveness was determined individually for each 708 combination of strain and serotype (Table S9). Some carriage sample sizes had to be approximated in this analysis (for the Oxford and Finland studies in particular; see Text S1), but the study adjustment factors were robustly estimated and significantly

711 differed across studies, suggesting the model was able to compensate for this 712 aspect of the data (Fig. S26). To test whether these problems could have affected

713 relative model likelihoods, the model comparison was repeated with a 100-fold 714 change in the sample size values for those studies in which the precise number was not reported. The study-adjustment factor meant the comparisons were relatively

716 insensitive to these changes, and the same model was identified as the most likely, 
given the data (Table S10). Hence model comparisons demonstrated that neither serotype nor strain background alone determines a genotype's invasiveness.

\section{Identification of invasive pneumococcal genotypes}

721 The best-fitting model converged on a stable solution when applied to the full dataset

722 (Fig. S27). The invasiveness estimates can be plotted to analyse variation by serotype within strains (Fig. 5; Dataset S3). Some strains were uniformly low invasiveness (serotypes 11A, 15A and 20A within GPSC22), whereas others had consistently higher invasiveness estimates (serotypes 14, 9V, 19F and 19A within GPSC6). By contrast, 19A had an elevated invasiveness relative to 19F within GPSC1, and relative to serotype 15B/C in GPSC4. Similarly, serotypes 8 and 33F were substantially more invasive than $11 \mathrm{~A}$ within GPSC3. Hence there was considerable variation in estimated invasiveness both between, and within, strains.

The same invasiveness estimates were plotted grouped by serotype (Fig. 6). The meta-analysis identified significant evidence to support many of the observations of within-serotype invasiveness variation noted in the individual analyses (Table S11). Heterogeneity was most strongly evident within some of the traditional paediatric types [19] (including 6A, 6B, 14, 19F), as well as $16 \mathrm{~F}$ and $19 \mathrm{~A}$. This may represent

736 these common serotypes being found across a wider diversity of strain backgrounds.

737 However, the estimates for other low invasiveness serotypes disseminated across multiple backgrounds, such as 15B/C, 23F and 35B, were more consistent.

739 Furthermore, some serotypes (such as 1 and 12F) were similarly highly invasive in

740 multiple strains. This implies some serotypes may have a strong effect on an

741 isolate's invasiveness. 
743 The adjusted type-specific model was applied to the full dataset, including low

744 frequency types, to identify high-risk genotypes that might emerge as causes of IPD post-PCV (Fig. S28). The most invasive genotypes not targeted by current PCVs were mainly of serotypes typically considered invasive, such as 8 and 12F. Yet there were also examples of genotypes expressing serotypes regarded as less invasive (e.g. 10A, 16F, 23B and 35B) with high invasiveness point estimates, albeit with wide credibility intervals reflecting small sample sizes. Most of these are likely to remain rare, or regress to the population-wide mean as more data emerge, but ongoing surveillance to rapidly identify whether any represent a potentially problematic type post-PCV will be valuable.

754 An additional genotyped dataset from Portugal (Fig. S29), in which the majority of disease cases were isolated from adults [52], was analysed with the type-specific Poisson model in which invasiveness was specific to each combination of serotype and strain background (Fig. S30). There were few instances of multiple serotypes being isolated from the same strain, but several serotypes were distributed across multiple genetic backgrounds (Fig. S31). This found evidence of heterogeneity in invasiveness within serotypes 3, 14 and 23F. The elevated invasiveness of serotype 3 was associated with the GPSC6 strain, found to have high invasiveness when expressing multiple serotypes in children (Fig. 5). For serotypes 14 and 23F, this involved strains that did not substantially differ in the child dataset (Fig. 6), suggesting further within-serotype variation in invasiveness may emerge as studies include a greater diversity of host age groups. 


\section{Discussion}

768 This study describes novel models for using data from cases and carriers to estimate

769 the hazard of an asymptomatically carried pathogen causing a defined disease over

770 a time period, previously defined as a progression rate [2]. This quantity is crucial for

771 determining the efficacy of partial coverage vaccines, such as the PCVs [26,27], and

772 the flexible framework developed here should be applicable to any diverse microbial

773 population. These models calculate progression rates as absolute quantities, rather

774 than dimensionless ratios as with previous meta-analyses $[27,34,36]$. These

estimates can enable the translation of alterations in microbial population structures

776 to changes in disease incidence, which is crucial for understanding the

consequences of strain- or type-specific interventions [27]. Furthermore, given suitable datasets for multiple pathogens, these models could also be used to estimate changes in disease burdens for alterations across microbiota.

When applied to $S$. pneumoniae serotype data, the best-performing model structures were those in which type-specific progression rates were adjusted by datasetspecific scale factors. In principle, these scale factors should correlate with the burden of disease in a given host population, representing a combination of socioeconomic factors and co-morbidities that affect IPD incidence $[87,88]$. Yet in practice, they will also represent the probability of an isolate causing IPD being included in a study dataset. This is affected by multiple factors, including the probability of attending a hospital participating in the study, the efficiency of retrieving bacteria from blood cultures, and the consistency with which cultured isolates are collected by research centres [87]. 
792 These model structures facilitate comparisons across populations by standardising progression rate estimates between datasets using all common serotypes or strains shared between them. Existing methods for meta-analysis typically standardise data relative to a single type, required to be present in all datasets [34,36], or combine estimates derived from ratios calculated relative to variable mixes of types in different locations. The dataset-adjusted type-specific progression rate models are better suited to the extensive international variation in S. pneumoniae population structures $[35,38]$, particularly given their ongoing diversification following vaccine

800 introduction [32]. Comparison with odds ratios showed that estimates were

801 correlated at large sample sizes, demonstrating both methods converged on similar

802 values when data are available on many isolates. However, this comes with the caveat that 16 of the 21 studies in the meta-analysis originated from North America or Europe, with most collected prior to PCV introduction. Hence there is a pressing need for paired case and carrier studies from post-PCV settings, particularly from Asia and Africa. As more diverse populations are combined, the improved

807 standardisation across studies from these Bayesian analyses will become more 808 important.

810 At smaller sample sizes, the Bayesian models were able to produce more

811 informative estimates of invasiveness than odds ratios. Information on types that are

812 rare in individual datasets is particularly important for an opportunistic pathogen as

813 diverse as S. pneumoniae, in which serotypes can emerge and expand rapidly post-

814 PCV $[23,32,83]$. A recent meta-analysis using odds ratios highlighted the conclusion

815 that $12 \mathrm{~F}$ was the only non-PCV13 serotype to have an invasiveness higher than 19A

816 [34], the serotype responsible for much post-PCV7 IPD [32,89]. However, this 
817 previous study limited its results to 25 serotypes, omitting less common examples

818 that could rise in frequency when serotype replacement is driven by higher-valency

819 vaccines $[32,89]$. The Bayesian analysis described in this work identified rare

820 serotypes that may be highly invasive in adults (e.g. 9L, 12B and 29) and children

821 (e.g. 19C, 28A and 46), based on small sample sizes. Serotype 46 has already been observed causing child IPD post-PCV13 within the strain GPSC26, which is more commonly associated with the highly-invasive serotype 12F [31]. These two capsule types are structurally similar [90], which is common for serotypes expressed by isolates of the same strain [51]. Future post-PCV13 surveillance will likely show whether $12 \mathrm{~F}$ and 46 are truly similarly invasive. As higher-valency PCVs become available, with the potential to remove commonly-carried serotypes such as $11 \mathrm{~A}$ and $15 B / C[20,91]$, reducing the uncertainty in invasiveness estimates for remaining nonvaccine types will be of great importance in understanding the vaccine-associated changes in the incidence of IPD.

832 The need for meta-analysis of multiple datasets is exacerbated by the model comparison in this study that concluded that invasiveness is most accurately

834 quantified at the level of strain-serotype combination. This conclusion is consistent with the results of some individual studies [35,52,53], although not all [29]. Such a

836 result raises the spectre of separately estimating invasiveness for multiple serotypes

837 within the hundreds of known S. pneumoniae strains, many of which are rare in 838 individual populations $[35,86]$. However, that such models fit better than those using

839 only strain or serotype as a predictor only implies that neither factor alone

840 determines an isolate's invasiveness. The improved fit might simply represent the

841 benefit of more precise classification of bacterial genotypes, and therefore remains 
842 possible that some other component of the S. pneumoniae genome that varies over

843 short, within-strain timescales may additionally affect, or entirely determine, isolates'

844 invasiveness $[50,92,93]$. This could explain the heterogeneity of invasiveness within

845 strain GPSC3, where the serotypes are separated into distinct clades

846 (https://microreact.org/project/gpsGPSC3), in contrast to the comparative

847 homogeneity of invasiveness within GPSC6 (containing the PMEN3, or Spain ${ }^{9 V_{-}}$,

848 lineage), where a single lineages dominates the strain's structure [94].

850 However, it seems unlikely that serotypes and invasiveness are not causally linked.

851 Some serotypes (e.g. 1, 12F) exhibited high invasiveness across multiple strain

852 backgrounds, whereas others were consistently low (e.g. 15B/C, 35F). This is consistent with the model fitting to serotype data, in which there was not a substantial improvement of model fitting when using negative binomial versions of the models. Additionally, the associated precision parameters were large when dataset-adjusted models were fitted (Fig. S6). If other loci were strongly affecting

857 invasiveness, then a greater degree of overdispersion in the observed incidence of 858 IPD might be expected, unless they were in linkage disequilibrium with the locus determining serotype.

861 By contrast, some paediatric serotypes exhibited a more heterogeneous distribution

862 of invasiveness values. This may reflect these capsules having little effect on invasiveness, or their greater prevalence in the pre-PCV pneumococcal population

864 providing greater power to detect variation between strains [30]. Heterogeneity has

865 previously been noted in serotype 14, with both GPSC6 [52,71] and GPSC18 [29,35]

866 identified as highly invasive clones (Table S11). In this analysis, both were found to 
867 be more invasive than GPSC9 within the same serotype. This analysis estimated

868 high invasiveness values for all serotypes within GPSC6, including an elevated

869 invasiveness within serotype 3 in the Portuguese dataset. Similarly, invasiveness

870 was consistently low for serotypes 14 and 15A for GPSC9. This could result in

871 heterogeneous vaccine impacts between regions, as elimination of serotype 14 by

872 PCVs will likely have a greater benefit across Europe and South America, where the

873 highly-invasive GPSC6 is mainly distributed

874 (https://microreact.org/project/gpsGPSC6), rather than Africa and India, where the

875 less invasive GPSC9 is common (https://microreact.org/project/gpsGPSC9).

876

877 Whether these models are useful long-term, or will ultimately be superseded by

878 alternatives based on genome-wide association studies, will depend on the extent to

879 which progression rates are affected by interactions between genetic loci [95]. It may

880 prove possible to explain a high proportion of the variation in invasiveness between

881 microbes through a tractable number of polymorphic loci that each independently

882 contribute to a microbe's invasiveness using genome-wide association studies [45-

$88348]$. If so, then the individual estimates for each of the multitude of subtype

884 categorisations can be replaced with a simpler genome-based approach, which

885 would be capable of predicting the invasiveness of previously unseen genotypes.

886 However, if invasiveness depends on combinations of loci [95], it may only be

887 possible to estimate progression rates for extant common types from epidemiological

888 studies. Other alternative model structures include random effects models and

889 multivariate regression analyses, which can incorporate information on the host

890 population characteristics $[2,37,96]$. However, these models typically require

891 comprehensive surveillance of disease and detailed information on host populations, 
which limits the range of studies that can be combined in meta-analyses of diverse bacterial populations.

895 Even using more conventional approaches to estimating invasiveness, whole

896 genome sequencing clearly represents an important tool in future case-carrier

897 studies of opportunistic pathogen invasiveness. In addition to assigning isolates to

898 strains, genomic data is a reliable and cost-effective means of classifying microbes according to their capsular structures $[97,98]$. Furthermore, it also enables the extraction of additional clinically-relevant information, such as antibiotic resistance

901 loci $[94,99]$, that may be incorporated into future extensions of these models.

902 However, the use of genomic data exacerbates an underlying problem with these models, as high-quality genome assemblies are not necessarily generated from all isolates recovered from carriage. The model assumes there are no false negative swabs in carriage studies, meaning there is an expectation that all carriage samples will be present in the genomic data. Hence the omission of genomic data adds to a

907 false negative rate that, even with serotype data, already reflects the imperfect 908 detection of colonisation by nasopharyngeal swabbing. This can be the consequence 909 of all resident bacteria being missed, or the difficulty of detecting lower prevalence

910 types in instances of multiple carriage [100]. Unless there is variation in the ability to

911 detect carriage of different types, the underestimation of carriage means all

912 progression rates will be uniformly overestimated. However, if only a subset of

913 datasets in a meta-analysis has a lower sensitivity for detecting carriage, the model

914 will adjust for this by increasing the associated scale factors. Hence the model

915 structure is sufficiently flexible to account for such differences. This is necessary, as

916 even with standard protocols for detecting colonisation, the population-wide 
917 estimates for carriage rates for a location will depend on the exact demographics

918 sampled.

919

920 Some of these problems with detecting colonisation can be addressed using new

921 techniques with improved sensitivity for detecting multiple serotypes in carriage

922 [101]. However, to simultaneously obtain the genotyping information needed to most

923 precisely characterise an isolate's invasiveness, deep genome sequencing, or

924 similar high-sensitivity molecular genotyping techniques, will be necessary. Such

925 data will not only improve the input to epidemiological models, such as those

926 outlined here, but also potential future models based on combinations of genetic loci.

927 Yet meta-analyses of case-carrier studies can also be improved by simple changes

928 to reporting, without any alterations to current procedures. The data and models

929 described in this work are made available for re-use, modification, and application to

930 other multi-strain microbes (see Methods). The fitting of the model to new datasets

931 will require studies to report their raw data in a standard format, and include the total

932 number of swabs included in the carriage study, as well as an informed estimate of

933 the size of the population under surveillance for IPD. To improve comparability

934 between future studies, it would also be ideal for studies to stratify these data by age

935 category, to enable specific subsets to be employed in different meta-analyses

936 studying specific demographics. Therefore, as the repertoire of vaccines against

937 diverse pathogens expands, we can hope to monitor and understand their impact on

938 population-wide microbial invasiveness using improved models, advances in

939 sequencing technology, and greater transparency of reporting. 
942 We thank Raquel Sá-Leão, Mário Ramirez, Bill Hanage and Birgitta Henriques-

943 Normark for providing further information on case-carrier datasets, and Daniel

944 Weinberger for helpful discussions on model structure and fitting. AL was funded by

945 an investigator-initiated grant from GSK to NJC. NJC was supported by the UK

946 Medical Research Council and Department for International Development (grants

947 MR/R015600/1 and MR/T016434/1) and a Sir Henry Dale Fellowship, jointly funded

948 by Wellcome and the Royal Society (grant no. 104169/Z/14/A). The funders had no

949 role in study design, data collection and analysis, decision to publish, or preparation

950 of the manuscript.

951

952 Competing interests

953 We have read the journal's policy and the authors of this manuscript have the

954 following competing interests: this work was partially funded by GSK, who

955 manufacture the PCV10 vaccine, although they had no role in study design, data

956 collection or analysis.

957

958 Data Availability

959 All data and code used for the described analyses are available in a GitHub

960 repository at https://github.com/nickjcroucher/progressionEstimation/. This repository

961 has been assigned the DOI 10.5281/zenodo.5154066. 


\section{References}

963

964 1. Brown SP, Cornforth DM, Mideo N. Evolution of virulence in opportunistic pathogens: generalism, plasticity, and control. Trends Microbiol. 2012;20: 336-

966 342. doi:10.1016/j.tim.2012.04.005

967

2. Lewnard JA, Givon-Lavi N, Weinberger DM, Lipsitch M, Dagan R. Panserotype reduction in progression of Streptococcus pneumoniae to otitis media after rollout of pneumococcal conjugate vaccines. Clin Infect Dis. 2017;65: 1853-1861. doi:10.1093/cid/cix673

3. Didelot X, Bowden R, Wilson DJ, Peto TEA, Crook DW. Transforming clinical microbiology with bacterial genome sequencing. Nat Rev Genet. 2012;13: 601-612. doi:10.1038/nrg3226

4. Feil EJ, Enright MC. Analyses of clonality and the evolution of bacterial pathogens. Curr Opin Microbiol. 2004;7: 308-313. doi:10.1016/j.mib.2004.04.002

5. Lees JA, Harris SR, Tonkin-Hill G, Gladstone RA, Lo S, Weiser JN, et al. Fast and flexible bacterial genomic epidemiology with PopPUNK. Genome Res. 2019;29: 304-316. doi:10.1101/360917

6. Cartman ST, Heap JT, Kuehne SA, Cockayne A, Minton NP. The emergence of "hypervirulence" in Clostridium difficile. Int J Med Microbiol. 2010;300: 387395. doi:10.1016/j.ijmm.2010.04.008

983 7. Fearnley C, Manning G, Bagnall M, Javed MA, Wassenaar TM, Newell DG. Identification of hyperinvasive Campylobacter jejuni strains isolated from poultry and human clinical sources. J Med Microbiol. 2008;57: 570-580. 
8. Knol MJ, Hahné SJM, Lucidarme J, Campbell H, de Melker HE, Gray SJ, et al. serogroup $\mathrm{W}$ and $\mathrm{C}$ disease in the Netherlands and England: an observational cohort study. Lancet Public Heal. 2017;2: e473-e482. doi:10.1016/S24682667(17)30157-3

992

9. Lynskey NN, Jauneikaite E, Li HK, Zhi X, Turner CE, Mosavie M, et al. increased scarlet fever activity in England: a population-based molecular epidemiological study. Lancet Infect Dis. 2019;19: 1209-1218. doi:10.1016/S1473-3099(19)30446-3

10. Du P, Zhang Y, Chen C. Emergence of carbapenem-resistant hypervirulent Klebsiella pneumoniae. Lancet Infect Dis. 2018;18: 23-24. doi:10.1016/S14733099(17)30625-4

11. Ganaie F, Saad JS, McGee L, van Tonder AJ, Bentley SD, Lo SW, et al. A new pneumococcal capsule type, $10 \mathrm{D}$, is the 100th serotype and has a large cps fragment from an oral streptococcus. MBio. 2020;11: e00937-20. doi:10.1128/mBio.00937-20

12. Ganaie F, Maruhn K, Li C, Porambo RJ, Elverdal PL, Abeygunwardana C, et al. Structural, genetic, and serological elucidation of Streptococcus pneumoniae serogroup 24 serotypes: Discovery of a new serotype, $24 \mathrm{C}$, with a variable capsule structure. J Clin Microbiol. 2021; JCM.00540-21. doi:10.1128/JCM.00540-21

13. Geno KA, Gilbert GL, Song JY, Skovsted IC, Klugman KP, Jones C, et al. 
1012 14. Nelson AL, Roche AM, Gould JM, Chim K, Ratner AJ, Weiser JN. Capsule enhances pneumococcal colonization by limiting mucus-mediated clearance. Infect Immun. 2007;75: 83-90. doi:10.1128/IAI.01475-06

15. Hyams C, Camberlein E, Cohen JM, Bax K, Brown JS. The Streptococcus pneumoniae capsule inhibits complement activity and neutrophil phagocytosis by multiple mechanisms. Infect Immun. 2009/12/02. 2010;78: 704-715. doi:IAI.00881-09 [pii]10.1128/IAI.00881-09 [doi]

16. Barker J, Gratten M, Riley M, Lehmann D, Montgomery J, Kajoi M, et al. Pneumonia in children in the eastern highlands of Papua New Guinea: A bacteriologic study of patients selected by standard clinical criteria. J Infect Dis. 1989;159: 348-352. doi:10.1093/infdis/159.2.348

17. Eyre JW, Washbourn JW. Varities and virulence of the pneumococcus. Lancet.

18. Sleeman KL, Griffiths D, Shackley F, Diggle L, Gupta S, Maiden MC, et al. Capsular serotype-specific attack rates and duration of carriage of Streptococcus pneumoniae in a population of children. J Infect Dis. 2006;194:

19. Hausdorff WP, Feikin DR, Klugman KP. Epidemiological differences among pneumococcal serotypes. Lancet Infect Dis. 2005;5: 83-93. doi:10.1016/S1473-3099(05)01280-6

20. Croucher NJ, Løchen A, Bentley SD. Pneumococcal Vaccines: Host Interactions, Population Dynamics, and Design Principles. Annu Rev Microbiol. 2018;72: 521-549. doi:10.1146/annurev-micro-090817-062338 serotype replacement 4 years after seven-valent pneumococcal conjugate 
vaccination in England and Wales: An observational cohort study. Lancet Infect Dis. 2011;11: 760-68. doi:10.1016/S1473-3099(11)70090-1

22. Weinberger DM, Malley R, Lipsitch M. Serotype replacement in disease after pneumococcal vaccination. The Lancet. 2011. pp. 1962-1973. doi:10.1016/S0140-6736(10)62225-8

23. Lewnard JA, Hanage WP. Making sense of differences in pneumococcal serotype replacement. Lancet Infect Dis. 2019. doi:10.1016/s1473$3099(18) 30660-1$

1045

1046

1047

1048

1049

1050

1051

1052

1053

1054

1055

1056

1057

1058 The rise and fall of pneumococcal serotypes carried in the PCV era. Vaccine. 2017;35: 1293-1298. doi:10.1016/j.vaccine.2017.01.035

25. Southern J, Andrews N, Sandu P, Sheppard CL, Waight PA, Fry NK, et al. Pneumococcal carriage in children and their household contacts six years after introduction of the 13-valent pneumococcal conjugate vaccine in England. PLoS One. 2018;13: e0195799. doi:10.1371/journal.pone.0195799

26. Nurhonen M, Auranen K. Optimal Serotype Compositions for Pneumococcal Conjugate Vaccination under Serotype Replacement. PLoS Comput Biol. 2014;10: e1003477. doi:10.1371/journal.pcbi.1003477

27. Colijn C, Corander J, Croucher NJ. Designing ecologically optimized pneumococcal vaccines using population genomics. Nat Microbiol. 2020;5: 473-485. doi:10.1038/s41564-019-0651-y

28. Smith T, Lehmann D, Montgomery J, Gratten M, Riley ID, Alpers MP. Acquisition and invasiveness of different serotypes of Streptococcus pneumoniae in young children. Epidemiol Infect. 1993;111: 27-39. doi:10.1017/S0950268800056648 
1062

1063

1064

1065

1066

1067

1068

1069

1070

1071

1072

1073

1074

1075

1076

1077

1078

1079

1080

1081

1082

1083

1084

1085

1086

29. Brueggemann AB, Griffiths DT, Peto T, Meats E, Crook DW, Spratt BG. Clonal Relationships between Invasive and Carriage Streptococcus pneumoniae and Serotype- and Clone-Specific Differences in Invasive Disease Potential. J Infect Dis. 2003;187: 1424-32. doi:10.1086/374624

30. Johnson HL, Deloria-Knoll M, Levine OS, Stoszek SK, Hance LF, Reithinger $\mathrm{R}$, et al. Systematic evaluation of serotypes causing invasive pneumococcal disease among children under five: The pneumococcal global serotype project. PLoS Med. 2010;7: e1000348. doi:10.1371/journal.pmed.1000348

31. Lo SW, Gladstone RA, van Tonder AJ, Lees JA, du Plessis M, Benisty R, et al. Pneumococcal lineages associated with serotype replacement and antibiotic resistance in childhood invasive pneumococcal disease in the post-PCV13 era: an international whole-genome sequencing study. Lancet Infect Dis. 2019;19: 759-769. doi:10.1016/S1473-3099(19)30297-X

32. Løchen A, Croucher NJ, Anderson RM. Divergent serotype replacement trends and increasing diversity in pneumococcal disease in high income settings reduce the benefit of expanding vaccine valency. Sci Rep. 2020;10: 18977. doi:10.1038/s41598-020-75691-5

33. Hanage WP, Auranen K, Syrjanen R, Herva E, Makela PH, Kilpi T, et al. Ability of pneumococcal serotypes and clones to cause acute otitis media: implications for the prevention of otitis media by conjugate vaccines. Infect Immun. 2004;72: 76-81.

34. Balsells E, Dagan R, Yildirim I, Gounder PP, Steens A, Muñoz-Almagro C, et al. The relative invasive disease potential of Streptococcus pneumoniae among children after PCV introduction: A systematic review and metaanalysis. J Infect. 2018;77: 368-378. doi:10.1016/j.jinf.2018.06.004 
35. Gladstone RA, Lo SW, Lees JA, Croucher NJ, van Tonder AJ, Corander J, et al. International genomic definition of pneumococcal lineages, to contextualise disease, antibiotic resistance and vaccine impact. EBioMedicine. 2019;43: 338-346. doi:10.1016/j.ebiom.2019.04.021

36. Brueggemann AB, Peto TEA, Crook DW, Butler JC, Kristinsson KG, Spratt BG. Temporal and Geographic Stability of the Serogroup-Specific Invasive Disease Potential of Streptococcus pneumoniae in Children. J Infect Dis. 2004/09/04. 2004;190: 1203-1211. doi:10.1086/423820

37. Weinberger DM, Grant LR, Weatherholtz RC, Warren JL, O'Brien KL, Hammitt LL. Relating Pneumococcal Carriage among Children to Disease Rates among Adults before and after the Introduction of Conjugate Vaccines. Am J Epidemiol. 2016;183: 1055-62. doi:10.1093/aje/kwv283

38. Corander J, Fraser C, Gutmann MU, Arnold B, Hanage WP, Bentley SD, et al. Frequency-dependent selection in vaccine-associated pneumococcal population dynamics. Nat Ecol Evol. 2017;1: 1950-1960. doi:10.1038/s41559017-0337-x

39. Weinberger DM, Bruden DT, Grant LR, Lipsitch M, O’Brien KL, Pelton SI, et al. Using pneumococcal carriage data to monitor postvaccination changes in invasive disease. Am J Epidemiol. 2013;178: 1488-1495. doi:10.1093/aje/kwt156

40. Zwahlen A, Winkelstein JA, Moxon ER. Surface Determinants of Haemophilus influenzae Pathogenicity: Comparative Virulence of Capsular Transformants in Normal and Complement-Depleted Rats. J Infect Dis. 1983;148: 385-394. doi:10.1093/infdis/148.3.385

41. Kelly T, Dillard JP, Yother J. Effect of genetic switching of capsular type on 
virulence of Streptococcus pneumoniae. Infect Immun. 1994;62: 1813-1819. Available: https://iai.asm.org/content/iai/62/5/1813.full.pdf

42. Hathaway LJ, Grandgirard D, Valente LG, Täuber MG, Leib SL. Streptococcus pneumoniae capsule determines disease severity in experimental pneumococcal meningitis. Open Biol. 2016;6: 150269. doi:10.1098/rsob.150269

43. Hu FZ, Eutsey R, Ahmed A, Frazao N, Powell E, Hiller NL, et al. In vivo capsular switch in Streptococcus pneumoniae - Analysis by whole genome sequencing. PLoS One. 2012;7: e47983-e47983. doi:10.1371/journal.pone.0047983

44. Mizrachi Nebenzahl Y, Porat N, Lifshitz S, Novick S, Levi A, Ling E, et al. Virulence of Streptococcus pneumoniae may be determined independently of capsular polysaccharide. FEMS Microbiol Lett. 2004;233: 147-152. doi:10.1016/j.femsle.2004.02.003

45. Obert C, Sublett J, Kaushal D, Hinojosa E, Barton T, Tuomanen El, et al. Identification of a candidate Streptococcus pneumoniae core genome and regions of diversity correlated with invasive pneumococcal disease. Infect Immun. 2006;74: 4766-4777. doi:10.1128/IAI.00316-06

46. Blomberg C, Dagerhamn J, Dahlberg S, Browall S, Fernebro J, Albiger B, et al. pneumoniae. J Infect Dis. 2009;199: 1032-1042. doi:10.1086/597205 
48. Cremers AJ, Mobegi F, van der Gaast -de Jongh C, van Weert M, van Opzeeland F, Vehkala M, et al. The contribution of genetic variation of Streptococcus pneumoniae to the clinical manifestation of invasive pneumococcal disease. Clin Infect Dis. 2019;68: 61-69. doi:10.1101/169722

49. Donati C, Hiller NL, Tettelin H, Muzzi A, Croucher NJ, Angiuoli S V, et al. Structure and dynamics of the pan-genome of Streptococcus pneumoniae and closely related species. Genome Biol. 2010;11: R107-R107. doi:10.1186/gb-

50. Croucher NJ, Coupland PG, Stevenson AE, Callendrello A, Bentley SD, 2010-11-10-r107 Hanage WP. Diversification of bacterial genome content through distinct mechanisms over different timescales. Nat Commun. 2014;5: 5471.

51. Croucher NJ, Kagedan L, Thompson CM, Parkhill J, Bentley SD, Finkelstein JA, et al. Selective and Genetic Constraints on Pneumococcal Serotype Switching. PLoS Genet. 2015;11: e1005095. doi:10.1371/journal.pgen.1005095

52. Sá-Leao R, Pinto F, Aguiar S, Nunes S, Carriço JAJA, Frazao N, et al. Analysis of invasiveness of pneumococcal serotypes and clones circulating in Portugal before widespread use of conjugate vaccines reveals heterogeneous behavior of clones expressing the same serotype. J Clin Microbiol. 2011;49: 1369-75. doi:10.1128/jcm.01763-10

53. Browall S, Norman M, Tångrot J, Galanis I, Sjöström K, Dagerhamn J, et al. Intraclonal Variations Among Streptococcus pneumoniae Isolates Influence the Likelihood of Invasive Disease in Children. J Infect Dis. 2014;209: 377-388. doi:10.1093/infdis/jit481

54. Fraser C, Hanage WP, Spratt BG. Neutral microepidemic evolution of bacterial 
pathogens. Proc Natl Acad Sci U S A. 2005;102: 1968-1973. doi:10.1073/pnas.0406993102

55. Lees JA, Croucher NJ, Goldblatt D, Nosten F, Parkhill J, Turner C, et al. Genome-wide identification of lineage and locus specific variation associated with pneumococcal carriage duration. Elife. 2017;6: e26255. doi:10.7554/eLife. 26255

56. Stan Development Team. Stan User's Guide, Version 2.27. In: Interaction Flow Modeling Language [Internet]. 2020 p. 23.7. Available: https://mc-

57. Wahl B, O’Brien KL, Greenbaum A, Majumder A, Liu L, Chu Y, et al. Burden of Streptococcus pneumoniae and Haemophilus influenzae type b disease in children in the era of conjugate vaccines: global, regional, and national estimates for 2000-15. Lancet Glob Heal. 2018;6: E744-E757. doi:10.1016/S2214-109X(18)30247-X

58. R Core Team. R: A Language and Environment for Statistical Computing. $R$ Found Stat Comput. 2019. doi:10.1007/978-3-540-74686-7

1178 59. Stan Development Team. RStan: the R interface to Stan. 2020.

60. Vehtari A, Gelman A, Gabry J. Practical Bayesian model evaluation using leave-one-out cross-validation and WAIC. Stat Comput. 2017;27: 1413-1432. doi:10.1007/s11222-016-9696-4

1182 61. Gronau QF, Singmann H, Wagenmakers EJ. Bridgesampling: An R package for estimating normalizing constants. J Stat Softw. 2020;92: 1-29. doi:10.18637/jss.v092.i10

62. Wickham H, Averick M, Bryan J, Chang W, McGowan L, François R, et al. 
doi:10.21105/joss.01686

63. Kassambara A. ggpubr: "ggplot2" Based Publication Ready Plots. 2020. Available: https://cran.r-project.org/package=ggpubr

64. Valles X, Roca A, Lozano F, Morais L, Suarez B, Casals F, et al. Serotypespecific pneumococcal disease may be influenced by mannose-binding lectin deficiency. Eur Respir J. 2010;36: 856-863. doi:10.1183/09031936.00171409

65. Principi N, Marchisio P. Epidemiology of Streptococcus pneumoniae in Italian

66. Smart LE, Platt DJ, Timbury MC. A comparison of the distribution of pneumococcal types in systemic disease and the upper respiratory tract in adults and children. Epidemiol Infect. 1987;98: 203-209.

67. Mogdasy MC, Camou T, Fajardo C, Hortal M. Colonizing and invasive strains of Streptococcus pneumoniae in Uruguayan children: type distribution and patterns of antibiotic resistance. Pediatr Infect Dis J. 1992;11: 648-652.

68. Scott J, Hall A, Hannington A, Edwards R, Mwarumba S, Lowe B, et al. Serotype distribution and prevalence of resistance to benzylpenicillin in three representative populations of Streptococcus pneumoniae isolates from the coast of Kenya. Clin Infect Dis. 1998;27: 1442-50.

69. Levidiotou S, Vrioni G, Tzanakaki G, Pappa C, Gesouli H, Gartzonika C, et al. Serotype distribution of Streptococcus pneumoniae in north-western Greece and implications for a vaccination programme. FEMS Immunol Med Microbiol.

70. Azzari C, Cortimiglia M, Nieddu F, Moriondo M, Indolfi G, Mattei R, et al. carrier children in Italy: Should we expect herd protection of adults through 
infants' vaccination? Hum Vaccin Immunother. 2016;12: 344-350. doi:10.1080/21645515.2015.1102811

1214 71. Hanage WP, Kaijalainen TH, Syrjänen RK, Auranen K, Leinonen M, Mäkelä $\mathrm{PH}$, et al. Invasiveness of serotypes and clones of Streptococcus pneumoniae

72. Cullotta AR, Kalter HD, Delgado J, Gilman RH, Facklam RR, Velapatino B, et al. Antimicrobial susceptibilities and serotype distribution of Streptococcus pneumoniae isolates from a Low socioeconomic area in Lima, Peru. Clin Diagn Lab Immunol. 2002;9: 1328-1331.

73. Takala AK, Vuopio-Varkila J, Tarkka E, Leinonen M, Musser JM. Subtyping of common pediatric pneumococcal serotypes from invasive disease and pharyngeal carriage in Finland. J Infect Dis. 1996;173: 128-135.

74. In HP, Pritchard DG, Cartee R, Brandao A, Brandileone MCC, Nahm MH.

Streptococcus pneumoniae. J Clin Microbiol. 2007;45: 1225-1233. doi:10.1128/JCM.02199-06

75. Browall S, Backhaus E, Naucler P, Galanis I, Sjöström K, Karlsson D, et al. Clinical manifestations of invasive pneumococcal disease by vaccine and nonvaccine types. Eur Respir J. 2014;44: 1646-57. doi:10.1183/09031936.00080814

76. Vehtari A, Simpson D, Gelman A, Yao Y, Gabry J. Pareto Smoothed Importance Sampling. arXiv. 2021; 1507.02646v7.

1235 77. Stacey HL, Rosen J, Peterson JT, Williams-Diaz A, Gakhar V, Sterling TM, et al. Safety and immunogenicity of 15 -valent pneumococcal conjugate vaccine 
(PCV-15) compared to PCV-13 in healthy older adults. Hum Vaccines Immunother. 2019;15: 530-539. doi:10.1080/21645515.2018.1532249

78. Hurley D, Griffin C, Young M, Scott DA, Pride MW, Scully IL, et al. Safety, Tolerability, and Immunogenicity of a 20-Valent Pneumococcal Conjugate Vaccine (PCV20) in Adults 60 to 64 Years of Age. Clin Infect Dis. 2020; ciaa1045. doi:10.1093/cid/ciaa1045

79. O’Brien KL, Shaw J, Weatherholtz R, Reid R, Watt J, Croll J, et al. in the era before use of conjugate pneumococcal vaccines, 1989-1996. Am J Epidemiol. 2004;160: 270-8. doi:10.1093/aje/kwh191

80. Ladhani SN, Collins S, Djennad A, Sheppard CL, Borrow R, Fry NK, et al. Rapid increase in non-vaccine serotypes causing invasive pneumococcal disease in England and Wales, 2000-17: a prospective national observational cohort study. Lancet Infect Dis. 2018;18: 441-451. doi:10.1016/S1473$3099(18) 30052-5$

81. Bolker BM, Brooks ME, Clark CJ, Geange SW, Poulsen JR, Stevens MHH, et al. Generalized linear mixed models: a practical guide for ecology and

82. Chewapreecha C, Harris SR, Croucher NJ, Turner C, Marttinen P, Cheng L, et al. Dense genomic sampling identifies highways of pneumococcal recombination. Nat Genet. 2014;46: 305-309. doi:10.1038/ng.2895

83. Feikin DR, Kagucia EW, Loo JD, Link-Gelles R, Puhan MA, Cherian T, et al. 
doi:10.1371/journal.pmed.1001517

1263 84. Shiri T, Datta S, Madan J, Tsertsvadze A, Royle P, Keeling MJ, et al. Indirect effects of childhood pneumococcal conjugate vaccination on invasive pneumococcal disease: a systematic review and meta-analysis. Lancet Glob Heal. 2017;5: e51-e59. doi:10.1016/S2214-109X(16)30306-0

85. José RJ, Brown JS. Adult pneumococcal vaccination: advances, impact, and unmet needs. Curr Opin Pulm Med. 2017;23.

86. Harrow GL, Lees JA, Hanage WP, Lipsitch M, Corander J, Colijn C, et al.

Negative frequency-dependent selection and asymmetrical transformation stabilise multi-strain bacterial population structures. ISME J. 2021;15: 15231538. doi:10.1038/s41396-020-00867-w

87. Fedson DS, Anthony J, Scott G. The burden of pneumococcal disease among adults in developed and developing countries: what is and is not known.

88. Torres A, Blasi F, Dartois N, Akova M. Which individuals are at increased risk of pneumococcal disease and why? Impact of COPD, asthma, smoking, diabetes, and/or chronic heart disease on community-acquired pneumonia and invasive pneumococcal disease. Thorax. 2015;70: 984 LP - 989. doi:10.1136/thoraxjnl-2015-206780

89. Kyaw MH, Lynfield R, Schaffner W, Craig AS, Hadler J, Reingold A, et al. Effect of Introduction of the Pneumococcal Conjugate Vaccine on DrugResistant Streptococcus pneumoniae. N Engl J Med. 2006;354: 1455-1463. doi:10.1056/NEJMoa051642

90. Mavroidi A, Aanensen DM, Godoy D, Skovsted IC, Kaltoft MS, Reeves PR, et 
al. Genetic relatedness of the Streptococcus pneumoniae capsular biosynthetic loci. J Bacteriol. 2007;189: 7841-7855. doi:10.1128/JB.00836-07

91. Croucher NJ, Finkelstein JA, Pelton SI, Mitchell PK, Lee GM, Parkhill J, et al. Population genomics of post-vaccine changes in pneumococcal epidemiology. Nat Genet. 2013;45: 656-663. doi:10.1038/ng.2625

92. Manso AS, Chai MH, Atack JM, Furi L, De Ste Croix M, Haigh R, et al. A random six-phase switch regulates pneumococcal virulence via global epigenetic changes. Nat Commun. 2014;5: 5055. doi:10.1038/ncomms6055

93. Kwun MJ, Oggioni MR, De Ste Croix M, Bentley SD, Croucher NJ. Excisionreintegration at a pneumococcal phase-variable restriction-modification locus drives within- and between-strain epigenetic differentiation and inhibits gene acquisition. Nucleic Acids Res. 2018;46: 11438-11453. doi:10.1093/nar/gky906

94. D'Aeth JC, van der Linden MPG, McGee L, de Lencastre H, Turner P, Song J$H$, et al. The role of interspecies recombination in the evolution of antibioticresistant pneumococci. Elife. 2021;10: e67113. Available:

95. Skwark MJ, Croucher NJ, Puranen S, Chewapreecha C, Pesonen M, Xu YY, et al. Interacting networks of resistance, virulence and core machinery genes

96. Lewnard JA, Givon-Lavi N, Tähtinen PA, Dagan R. Pneumococcal Phenotype and Interaction with Nontypeable Haemophilus influenzae as Determinants of Otitis Media Progression. Infect Immun. 2018;86: e00727-17. 
1312 97. Epping L, van Tonder AJ, Gladstone RA, Bentley SD, Page AJ, Keane JA. SeroBA: rapid high-throughput serotyping of Streptococcus pneumoniae from whole genome sequence data. Microb Genomics. 2018;4:

98. Kapatai G, Sheppard CL, Al-Shahib A, Litt DJ, Underwood AP, Harrison TG, et al. Whole genome sequencing of Streptococcus pneumoniae: development, evaluation and verification of targets for serogroup and serotype prediction using an automated pipeline. PeerJ. 2016;4: e2477. doi:10.7717/peerj.2477

99. Li Y, Metcalf BJ, Chochua S, Li Z, Gertz RE, Walker H, et al. Penicillin-Binding Protein Transpeptidase Signatures for Tracking and Predicting $\beta$-Lactam Resistance Levels in Streptococcus pneumoniae. MBio. 2016;7: e00756-16. doi:10.1128/mbio.00756-16

100. Huebner RE, Dagan R, Porath N, Wasas AD, T M, Klugman KP. Lack of utility of serotyping multiple colonies for detection of simultaneous nasopharyngeal

101. Turner P, Hinds J, Turner C, Jankhot A, Gould K, Bentley SD, et al. Improved detection of nasopharyngeal cocolonization by multiple pneumococcal serotypes by use of latex agglutination or molecular serotyping by microarray. J Clin Microbiol. 2011;49: 1784-1789. doi:10.1128/JCM.00157-11 et al. Temporal Changes in Pneumococcal Colonization in HIV-infected and HIV-uninfected Mother-Child Pairs Following Transitioning from 7-valent to 13valent Pneumococcal Conjugate Vaccine, Soweto, South Africa. J Infect Dis. 2015. doi:10.1093/infdis/jiv167 
103. Madhi SA, Nzenze SA, Nunes MC, Chinyanganya L, Van Niekerk N, Kahn K, et al. Residual colonization by vaccine serotypes in rural South Africa four years following initiation of pneumococcal conjugate vaccine immunization. Expert Rev Vaccines. 2020;19: 383-393. doi:10.1080/14760584.2020.1750377

104. Nzenze SA, Shiri T, Nunes MC, Klugman KP, Kahn K, Twine R, et al. Temporal changes in pneumococcal colonization in a rural African community with high HIV prevalence following routine infant pneumococcal immunization. Pediatr Infect Dis J. 2013;32: 1270-1278. doi:10.1097/01.inf.0000435805.25366.64

105. Statistics South Africa. Mid-year population estimates: 2009-2013. 2013.

106. Chang Q, Stevenson AE, Croucher NJ, Lee GM, Pelton SI, Lipsitch M, et al. Stability of the pneumococcal population structure in Massachusetts as PCV13 was introduced. BMC Infect Dis. 2015;15: 68. doi:10.1186/s12879-015-0797-z

107. Centres for Disease Prevention and Control. Active Bacterial Core surveillance matrix. 2018. Available: https://www.cdc.gov/abcs/downloads/abcssurveillance-matrix.pdf

108. Enright MC, Spratt BG. A multilocus sequence typing scheme for Streptococcus pneumoniae: Identification of clones associated with serious invasive disease. Microbiology. 1998;144: 3049-3060. doi:10.1099/00221287$144-11-3049$

109. Syrjänen RK, Kilpi TM, Kaijalainen TH, Herva EE, Takala AK. Nasopharyngeal carriage of Streptococcus pneumoniae in Finnish children younger than 2 years old. J Infect Dis. 2001;184: 451-459. doi:10.1086/322048

110. Sleeman KL, Daniels L, Gardiner M, Griffiths D, Deeks JJ, Dagan R, et al. 
Acquisition of Streptococcus pneumoniae and nonspecific morbidity in infants and their families: A cohort study. Pediatr Infect Dis J. 2005;24: 121-127. doi:10.1097/01.inf.0000151030.10159.b1

111. Normark BH, Christensson B, Sandgren A, Noreen B, Sylvan S, Burman LG, et al. Clonal Analysis of Streptococcus pneumoniae Nonsusceptible to Penicillin at Day-Care Centers with Index Cases, in a Region with Low Incidence of Resistance: Emergence of an Invasive Type 35B Clone among Carriers. Microb Drug Resist. 2003;9: 337-344.

112. Galanis I, Lindstrand A, Darenberg J, Browall S, Nannapaneni P, Sjöström K, et al. Effects of PCV7 and PCV13 on invasive pneumococcal disease and carriage in Stockholm, Sweden. Eur Respir J. 2016;47: 1208-1218. doi:10.1183/13993003.01451-2015

113. Mato R, Santos Sanches I, Simas C, Nunes S, Carriço JA, Sousa NG, et al. Natural history of drug-resistant clones of Streptococcus pneumoniae colonizing healthy children in Portugal. Microb Drug Resist. 2005;11: 309-322. doi:10.1089/mdr.2005.11.309

114. Gibson C. Population of the 100 Largest Cities and Other Urban Places In The United States: 1790 to 1990. 1998. Available: https://www.census.gov/library/working-papers/1998/demo/POPtwps0027.html

115. Gray BM, Converse GM, Dillon HC. Serotypes of Streptococcus pneumoniae causing disease. J Infect Dis. 1979;140: 979-83. doi:10.1093/infdis/140.6.979

116. Sharma D, Baughman W, Holst A, Thomas S, Jackson D, Da Gloria Carvalho $\mathrm{M}$, et al. Pneumococcal carriage and invasive disease in children before 
introduction of the 13-valent conjugate vaccine: Comparison with the era before 7-valent conjugate vaccine. Pediatr Infect Dis J. 2013;32: e45-53. doi:10.1097/INF.0b013e3182788fdd

117. Parra EL, De La Hoz F, Díaz PL, Sanabria O, Realpe ME, Moreno J. Changes in Streptococcus pneumoniae serotype distribution in invasive disease and nasopharyngeal carriage after the heptavalent pneumococcal conjugate vaccine introduction in Bogotá, Colombia. Vaccine. 2013;31: 4033-8. doi:10.1016/j.vaccine.2013.04.074

118. Instituto Nacional de Estadistica Venezuela. Censo Nacional de Poblacion y Vivienda. 2011. Available: http://www.redatam.ine.gob.ve/Censo2011/index.html

119. Rivera-Olivero IA, Del Nogal B, Sisco MC, Bogaert D, Hermans PWM, De Waard JH. Carriage and invasive isolates of Streptococcus pneumoniae in Caracas, Venezuela: The relative invasiveness of serotypes and vaccine

120. Czech Statistical Office. Age Distribution of the Population of the Czech Republic - 2005. 2005. Available: https://www.czso.cz/csu/czso/4003-06-2005$01 n$

121. Zemlickova H, Jakubu V, Urbaskova P, Motlova J, Musilek M, Adamkova V. Serotype-specific invasive disease potential of Streptococcus pneumoniae in Czech children. J Med Microbiol. 2010;59: 1079-83. doi:10.1099/jmm.0.018390-0

122. Trotter CL, Waight P, Andrews NJ, Slack M, Efstratiou A, George R, et al. 
era: England and Wales, 1996-2006. J Infect. 2010;60: 200-8. doi:10.1016/j.jinf.2009.12.008

123. Papua New Guinea National Statistical Office. National Population and Housing Census Ward Population Profile: Highlands Region. 2011. Available: https://www.nso.gov.pg/index.php/population-and-social/otherindicators\#highlands-region

124. Plan H-C au. Annuaire statistique de la région Rabat-Salé-Zemmour-Zaër, 2010. 2012. Available: https://www.hcp.ma/downloads/Annuaires-statistiquesregionaux_t11956.html

125. Jroundi I, Mahraoui C, Benmessaoud R, Moraleda C, Munoz Almagro C, Seffar M, et al. Streptococcus pneumoniae carriage among healthy and sick pediatric patients before the generalized implementation of the 13-valent pneumococcal vaccine in Morocco from 2010 to 2011. J Infect Public Health.

127. Vissers $M$, Wijmenga-Monsuur AJ, Knol MJ, Badoux $P$, van Houten MA, van der Ende A, et al. Increased carriage of non-vaccine serotypes with low invasive disease potential four years after switching to the 10-valent pneumococcal conjugate vaccine in The Netherlands. PLoS One. 2018;13: 115. doi:10.1371/journal.pone.0194823

128. Statistics Canada. Data tables, 1996. 1996. Available: https://www.statcan.gc.ca/

129. Instituto Nacionalde Estadistica Portugal. Censos 2001. 2002. 
130. Statistics Sweden. Population by region, marital status, age and sex. Year 1968 - 2018. Available: http://www.statistikdatabasen.scb.se/pxweb/en/ssd/START_BE_BE0101_ BE0101A/BefolkningNy/?rxid=e550e75b-4cef-4e77-b5e5-83adcc09c97e

131. Sandgren A, Christensson B, Samuelsson A, Olsson-Liljequist B, Sjöström K, Kronvall G, et al. Effect of Clonal and Serotype-Specific Properties on the Invasive Capacity of Streptococcus pneumoniae. J Infect Dis. 2004;189: 78596. doi:10.1086/381686

132. del Amo E, Brotons $P$, Monsonis $M$, Triviño $M$, Iñigo $M$, Selva $L$, et al. High invasiveness of pneumococcal serotypes included in the new generation of conjugate vaccines. Clin Microbiol Infect. 2014;20: 684-9. doi:10.1111/14690691.12422

133. Institut National de la Statistique et des Etudes Economiques. Age pyramid 2020 - France and metropolitan France. 2008.

134. Varon E, Cohen R, Béchet S, Doit C, Levy C. Invasive disease potential of pneumococci before and after the 13-valent pneumococcal conjugate vaccine implementation in children. Vaccine. 2015;33: 6178-85.

doi:10.1016/j.vaccine.2015.10.015

135. Yildirim I, Hanage WP, Lipsitch M, Shea KM, Stevenson A, Finkelstein J, et al. Serotype specific invasive capacity and persistent reduction in invasive pneumococcal disease. Vaccine. 2010/10/30. 2010;29: 283-288. doi:S0264410X(10)01502-1 [pii]10.1016/j.vaccine.2010.10.032 [doi]

136. Scott JR, Millar E V., Lipsitch M, Moulton LH, Weatherholtz R, Perilla MJ, et al. Impact of more than a decade of pneumococcal conjugate vaccine use on carriage and invasive potential in native American communities. J Infect Dis. 
2012. doi:10.1093/infdis/jir730

1463 137. Statistics Finland. Tilastokeskus. 2021.

1464 138. Office for National Statistics. Mid-1998 Population Estimates: Single year of age and sex for local authorities in England and Wales; estimated resident population. 2004.

139. Huang SS, Hinrichsen VL, Stevenson AE, Rifas-Shiman SL, Kleinman K, Pelton SI, et al. Continued Impact of Pneumococcal Conjugate Vaccine on Carriage in Young Children. Pediatrics. 2009;124: e1-11. doi:10.1542/peds.2008-3099

1471 140. Wroe PC, Lee GM, Finkelstein JA, Pelton SI, Hanage WP, Lipsitch M, et al. Pneumococcal carriage and antibiotic resistance in young children before 13valent conjugate vaccine. Pediatr Infect Dis J. 2012;31: 249-254. 
bioRxiv preprint doi: https://doi.org/10.1101/2021.09.01.458483; this version posted September 1,2021 . The copyright holder for this

preprint (which was not certified by peer review) is the author/funder, who has granted bioRxiv a license to display the preprint in perpetuity. It is made available under aCC-BY 4.0 International license.

\section{Figures}


bioRxiv preprint doi: https://doi.org/10.1101/2021.09.01.458483; this version posted September 1, 2021. The copyright holder for this

preprint (which was not certified by peer review) is the author/funder, who has granted bioRxiv a license to display the preprint in perpetuity. It is made available under aCC-BY 4.0 International license.
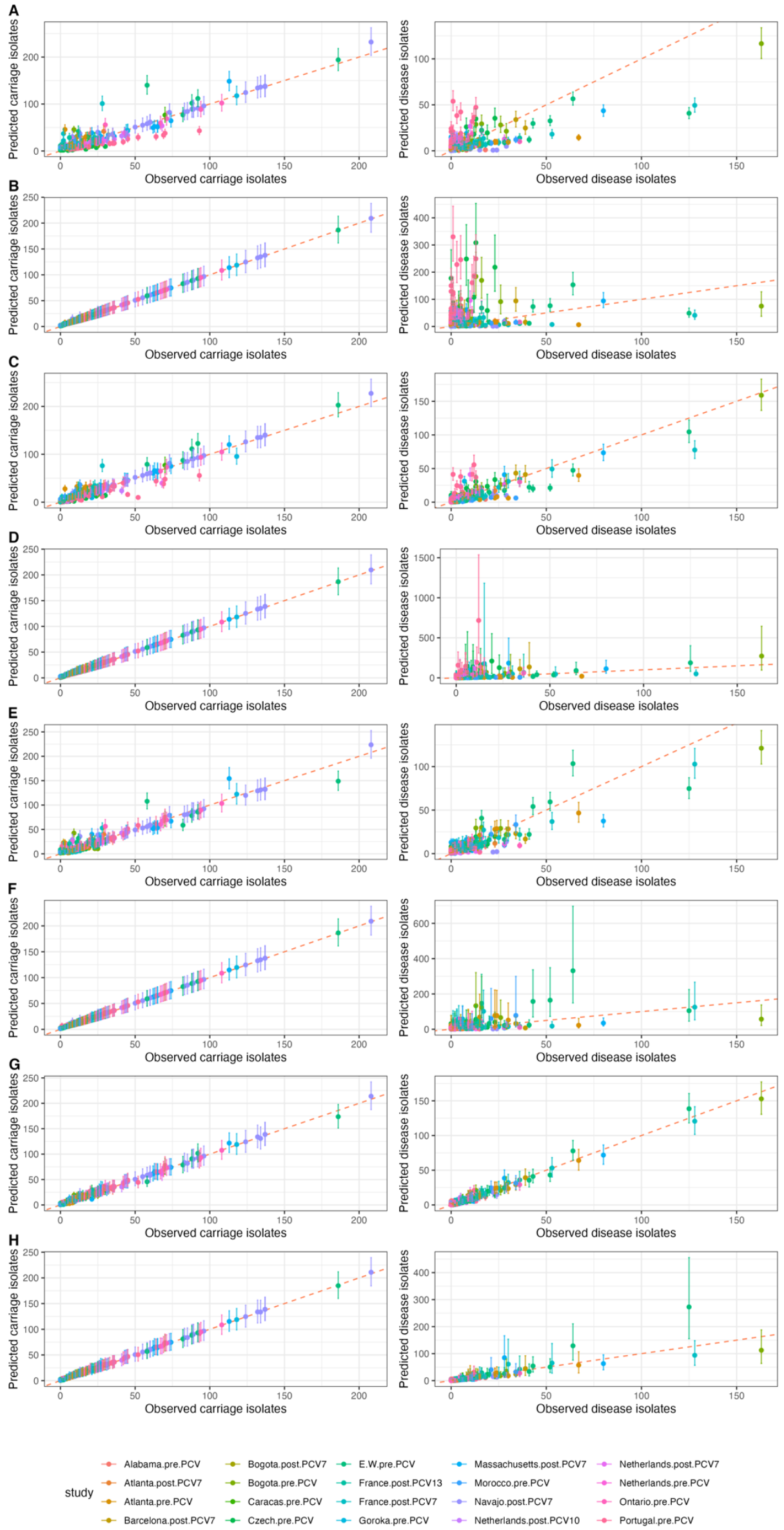
1478 Figure 1 Comparison of observed and predicted counts of each serotype within each 1479 study of $S$. pneumoniae invasiveness in children. The points are coloured by the 1480 study to which they correspond, and show the observed value on the horizontal axis, and the mean predicted value on the vertical axis. The error bars show the $95 \%$ credibility intervals. The red dashed line shows the line of identity, corresponding to a perfect match between prediction and observation. The left column shows the correspondence for carriage data (values of $c_{i, j}$ ), and the right column shows the correspondence for disease isolates (values of $d_{i . j}$ ). Each row corresponds to a different model: $(A)$ null Poisson model; $(B)$ null negative binomial model; (C) typespecific Poisson model; (D) type-specific negative binomial model; (E) studyadjusted Poisson model; (F) study-adjusted negative binomial model; (G) studyadjusted type-specific Poisson model; $(\mathrm{H})$ study-adjusted type-specific negative binomial model. 

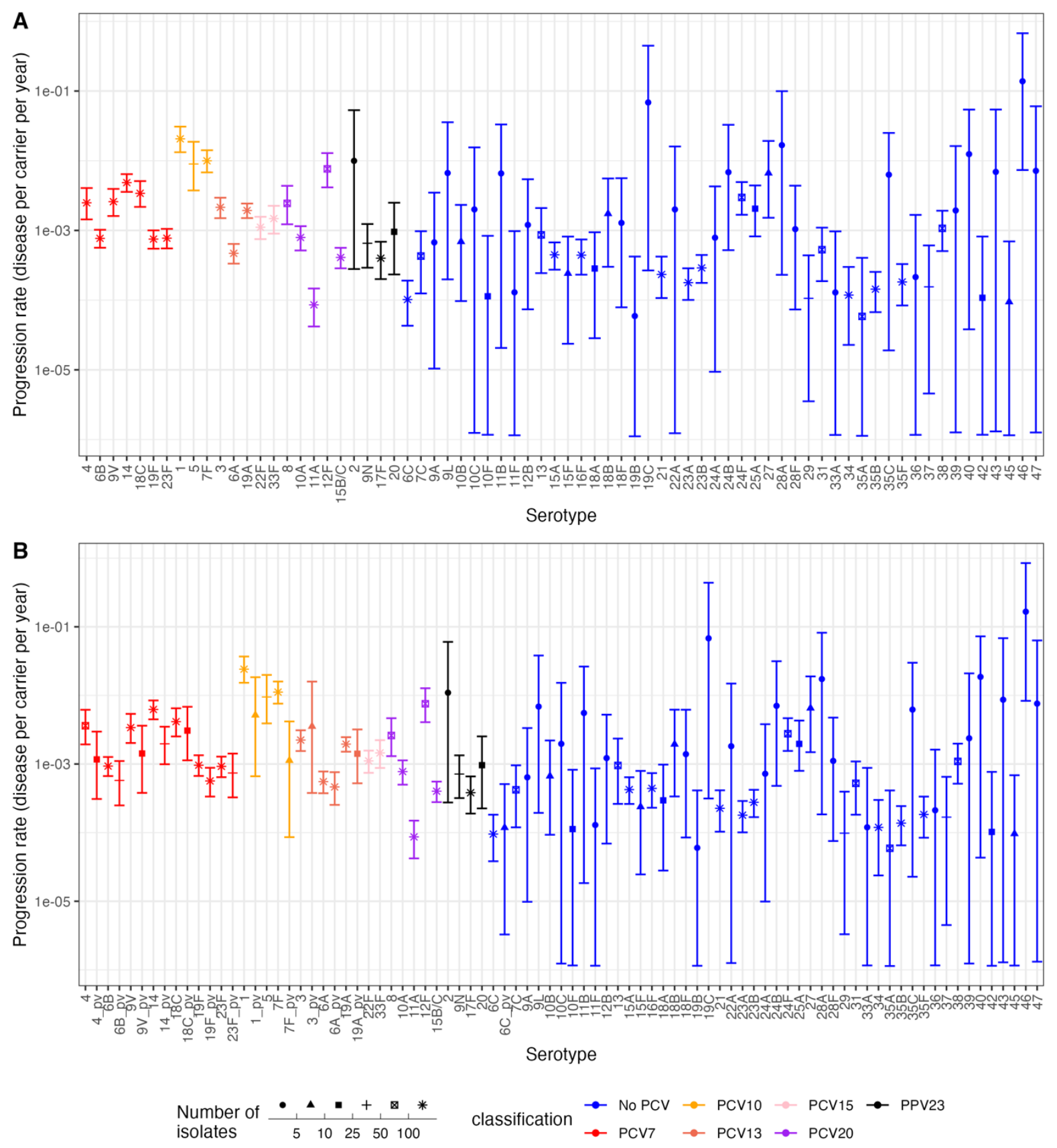

Figure 2 Invasiveness estimates for S. pneumoniae serotypes from the studyadjusted type-specific Poisson model applied to the full dataset of serotypes from child carriage and disease. Points represent the mean estimate, and are coloured according to the vaccine formulation in which they are found; all higher valency formulations encompass the serotypes found in lower valency formulations, with the exception of 6A not being present in PPV23. The point shape represents the sample size, summed across disease and carriage isolates from all studies, on which the estimates are based. The error bars show the 95\% credibility intervals. (A) Estimates for all 72 serotypes in the full dataset. (B) Estimates when distinguishing between vaccine-type serotypes in unvaccinated and vaccinated populations. Vaccine serotypes in vaccinated populations are denoted with the suffix “_pv". 
bioRxiv preprint doi: https://doi.org/10.1101/2021.09.01.458483; this version posted September $1,2021$. The copyright holder for this

preprint (which was not certified by peer review) is the author/funder, who has granted bioRxiv a license to display the preprint in perpetuity. It is made available under aCC-BY 4.0 International license.

A
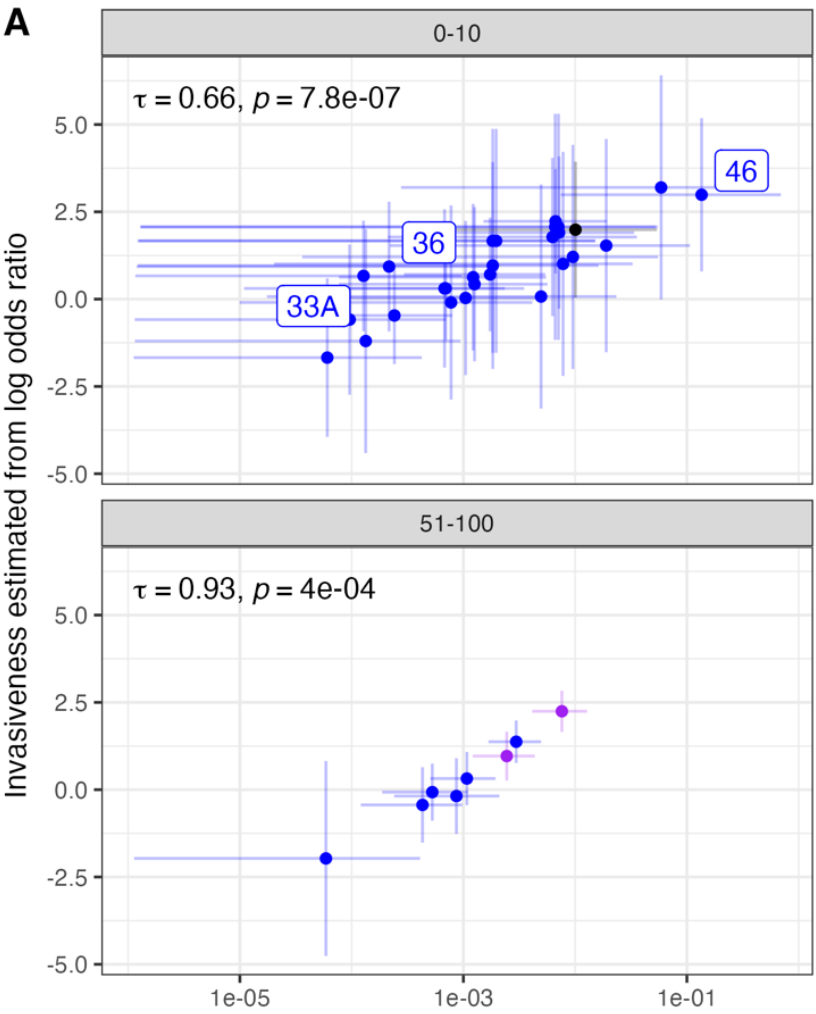

Invasivess estimate from adjusted type-specific Poisson (cases per carrier per year)
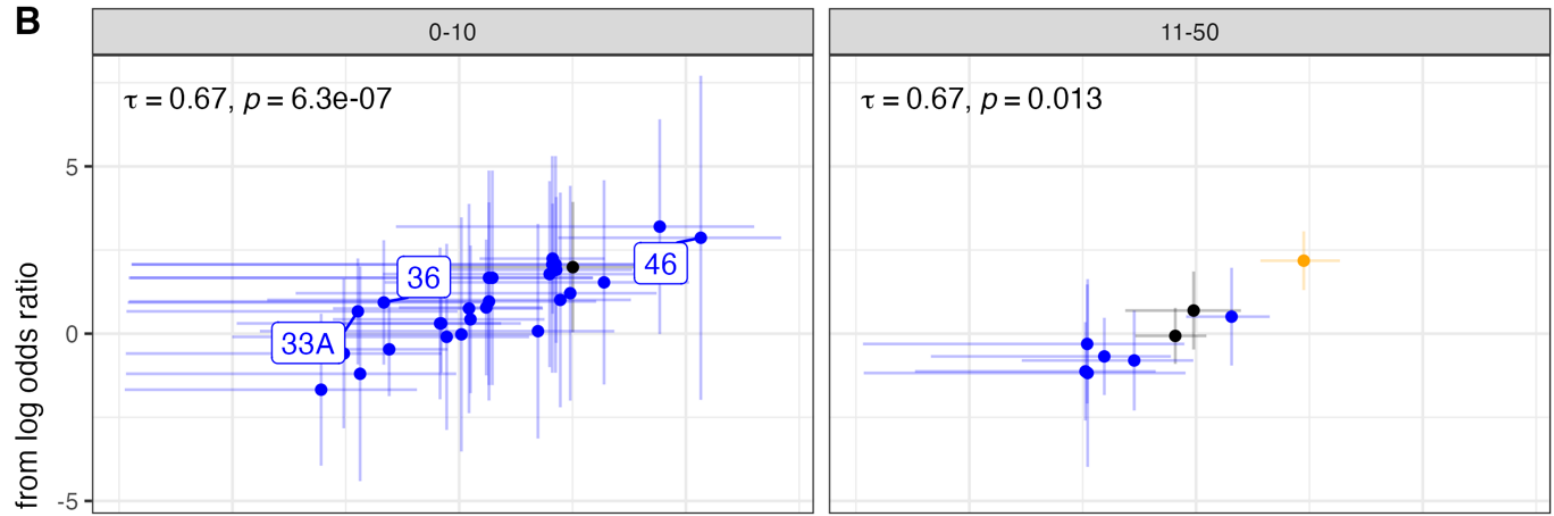

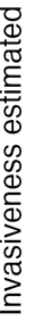


1506 Figure 3 Comparison of the serotype invasiveness estimates from the study-

1507 adjusted type-specific Poisson model with those from meta-analyses of the same 1508 dataset calculated as logarithmic odds ratios combined using $(A)$ fixed effects models and $(B)$ random effects models. Points are coloured based on the vaccine formulations in which serotypes are found. The horizontal error bars are the $95 \%$ credibility intervals from the Bayesian model, and the vertical error bars show the $95 \%$ confidence intervals from the logarithmic odds ratio analyses. Each plot is divided based on the sample size associated with each serotype, calculated as the sum of isolates from carriage and disease across all studies. The correlation between the two estimates is summarised as Kendall's $\mathrm{T}$ on each panel, with an

1516 associated $p$ value. 

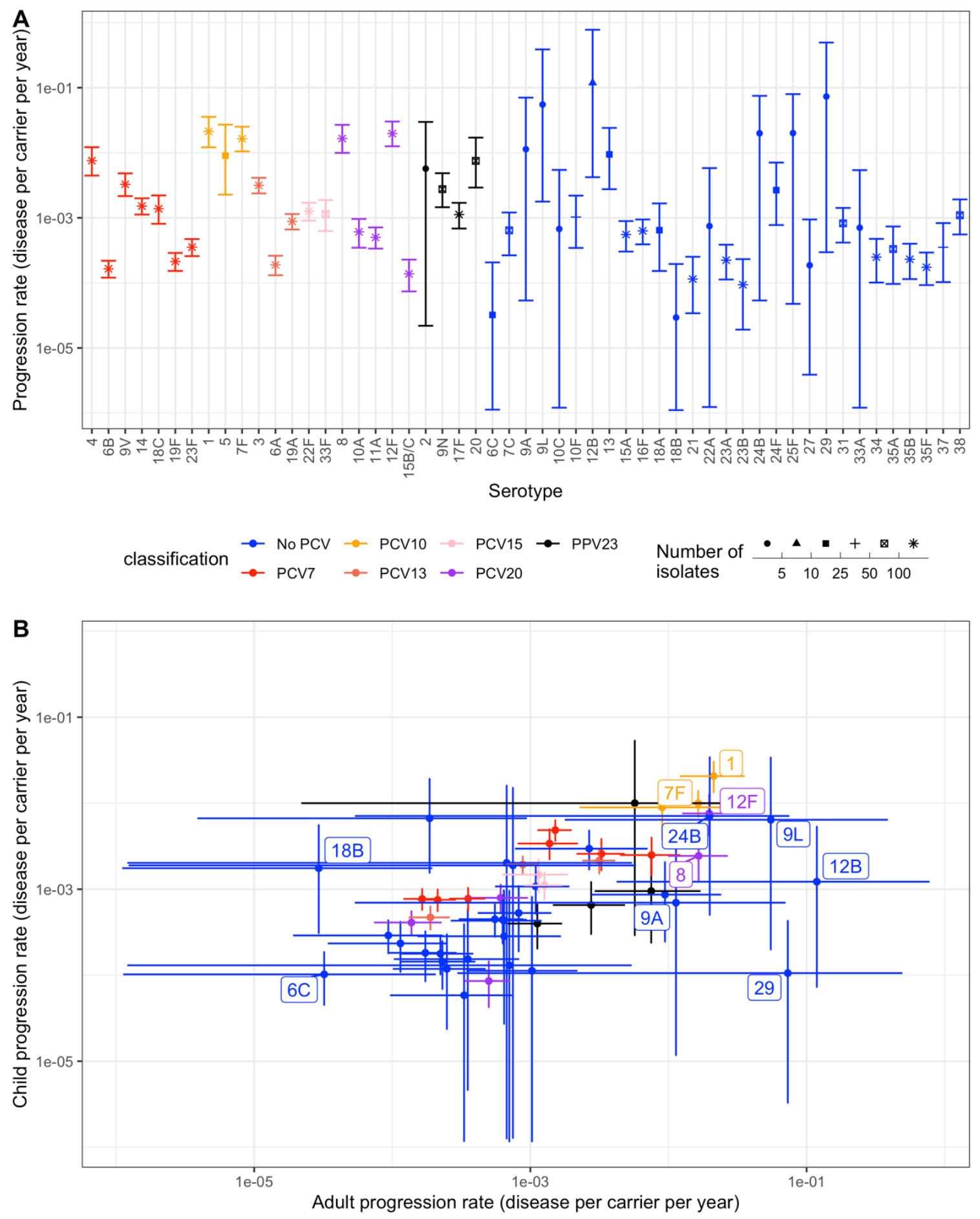

1519 Figure 4 Invasiveness estimates for S. pneumoniae serotypes from the study1520 adjusted type-specific Poisson model applied to the full dataset of serotypes from child carriage and adult disease. Points represent the mean estimate, and are coloured according to the vaccine formulation in which they are found; all higher valency formulations encompass the serotypes found in lower valency formulations, with the exception of $6 \mathrm{~A}$ not being present in PPV23. The error bars show the $95 \%$ credibility intervals. (A) Estimates for all 53 serotypes in the full dataset. The point shape represents the sample size, summed across disease and carriage isolates from all studies, on which the estimates are based. (B) Scatterplot comparing the invasiveness estimates for adults and children. 

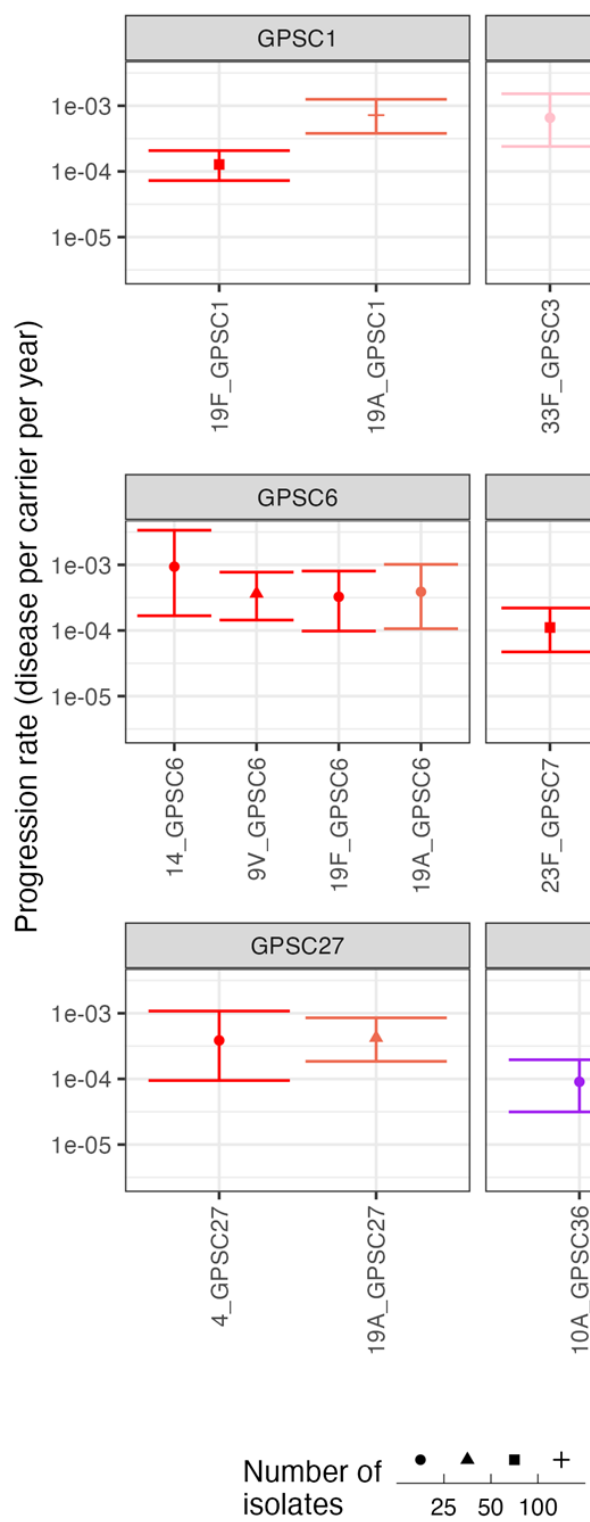
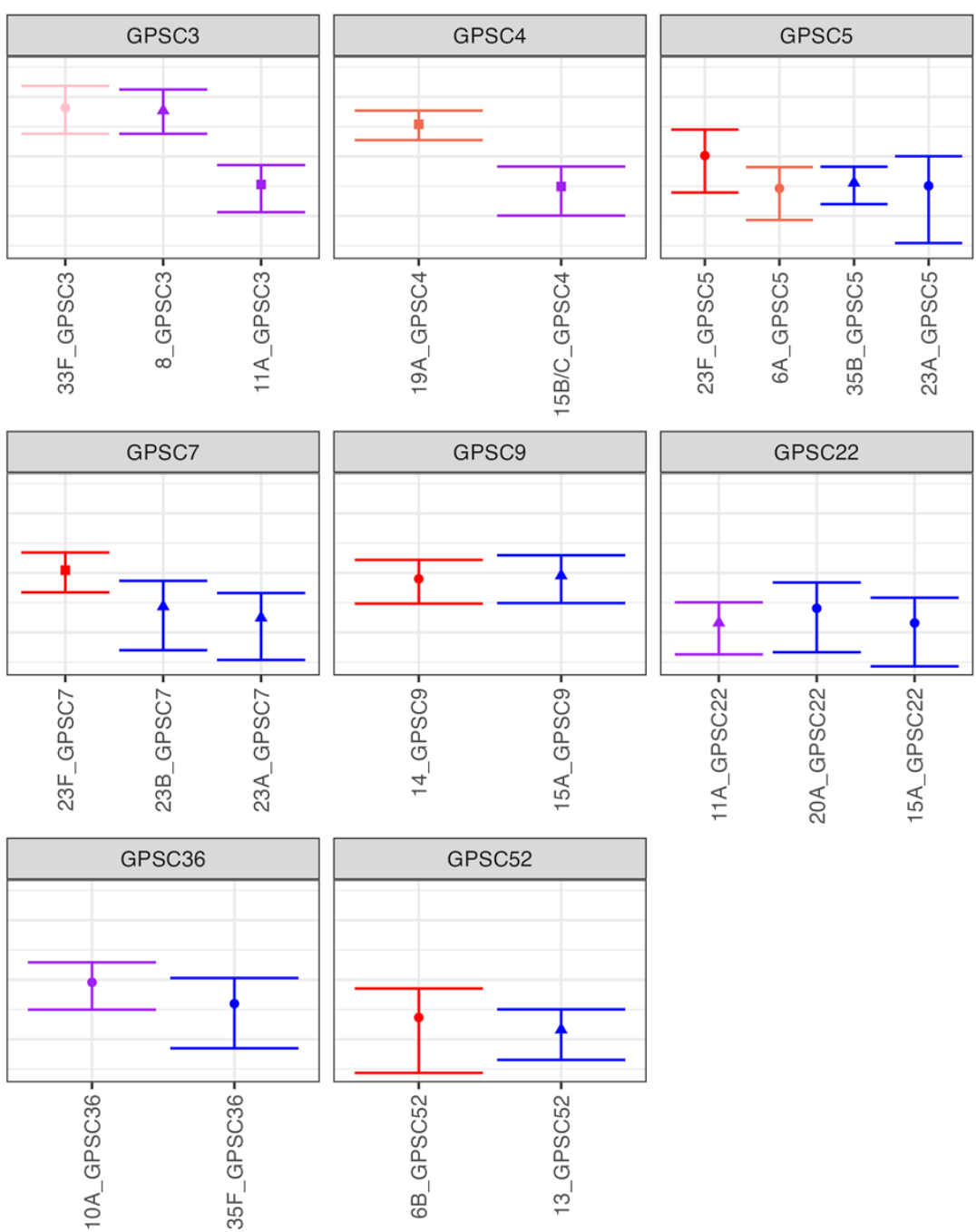

Serotype
Figure 5 Estimates of within- and between-strain variation in invasiveness for strain and serotype combinations represented by at least ten isolates across the studies with genotype information. Points represent the mean estimate, and are coloured by the vaccine formulations in which the corresponding serotype is present. The shape of the point represents the sample size on which the estimate is based. Estimates are grouped by strain. Only strains for which estimates of multiple strain and serotype combinations were possible are displayed. 

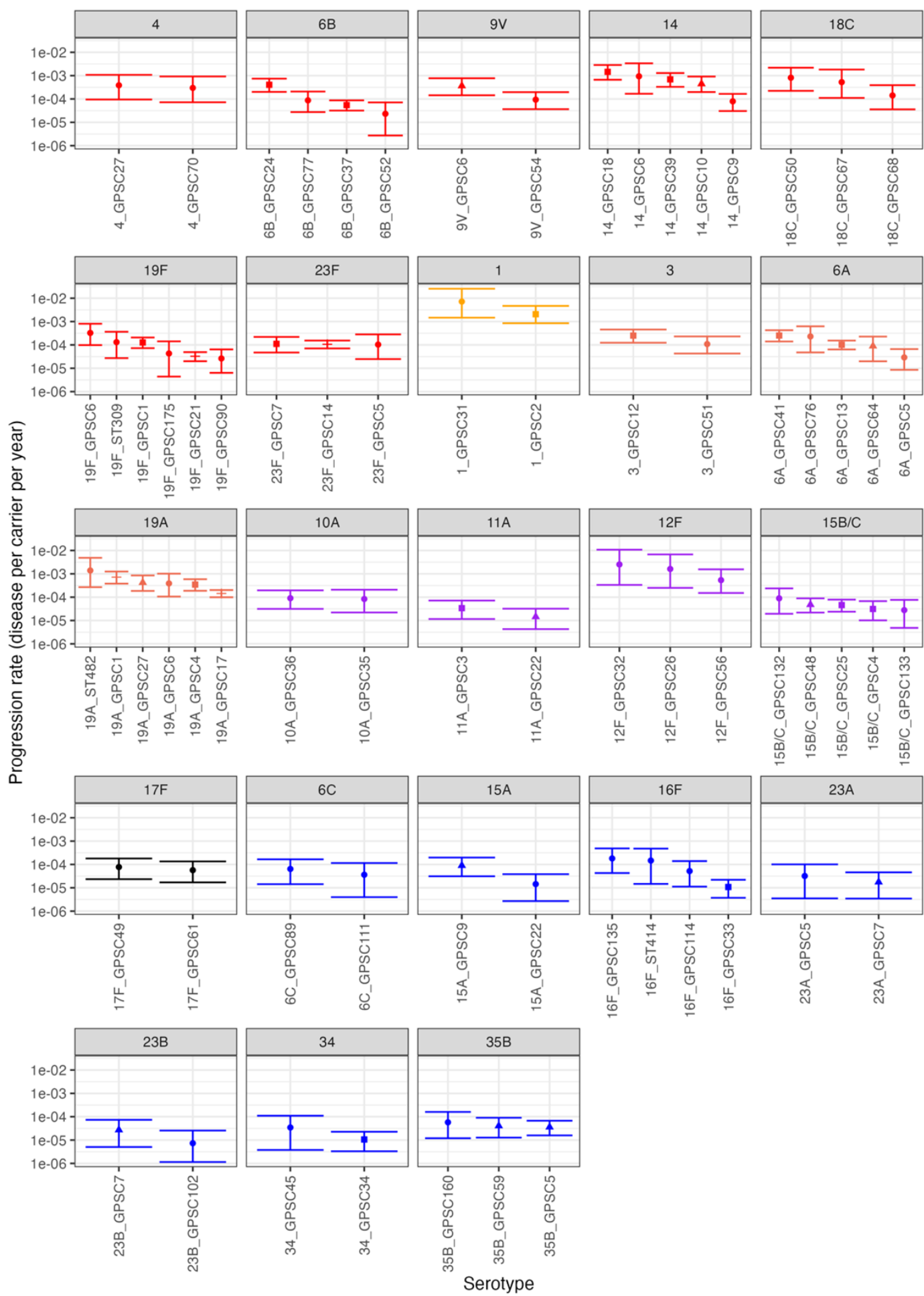

Figure 6 Estimates of within- and between-serotype variation in invasiveness for strain and serotype combinations represented by at least ten isolates across the included studies. Points represent the mean estimate, and are coloured by the vaccine formulations in which the corresponding serotype is present. The shape of the point represents the sample size on which the estimate is based. Estimates are grouped by serotype. Only serotypes for which estimates of multiple strain and serotype combinations were possible are displayed. 
Tables

\begin{tabular}{|c|c|c|}
\hline Parameter & Description & $\begin{array}{l}\text { Value or prior } \\
\text { distribution }\end{array}$ \\
\hline$i$ & Index denoting study & 1..(number of studies) \\
\hline$j$ & Index denoting type & 1..(number of types) \\
\hline$k$ & Index denoting strain & 1..(number of strains) \\
\hline$x$ & Generic index for type or strain & - \\
\hline$y$ & $\begin{array}{l}\text { Generic index of type or strain that } \\
\text { modifies the invasiveness of a genotype }\end{array}$ & - \\
\hline c & $\begin{array}{l}\text { Number of isolates detected in carriage } \\
\text { study }\end{array}$ & - \\
\hline$d$ & $\begin{array}{l}\text { Number of isolates detected in disease } \\
\text { surveillance }\end{array}$ & - \\
\hline$\rho$ & Carriage prevalence & $\rho \sim \operatorname{Beta}(1,1)$ \\
\hline$\eta$ & $\begin{array}{l}\text { Total number of positive and negative } \\
\text { samples in carriage study }\end{array}$ & $\begin{array}{l}\text { From previous } \\
\text { publications }\end{array}$ \\
\hline$N$ & $\begin{array}{l}\text { Number of individuals of the specified } \\
\text { demographic under disease surveillance }\end{array}$ & $\begin{array}{l}\text { From previous } \\
\text { publications }\end{array}$ \\
\hline$t$ & Duration of disease surveillance & $\begin{array}{l}\text { From previous } \\
\text { publications }\end{array}$ \\
\hline$v$ & Progression rate & $\begin{array}{l}\log _{10}(v) \sim U(-6,1) \text { or } \\
\text { truncated Cauchy }\left(\mu_{\text {mod }},\right. \\
\left.\mathrm{T}_{\text {mod }}\right) ; \text { see below }\end{array}$ \\
\hline V & Study-specific scale parameters & $\begin{array}{l}1 \text { or } \log _{10}(\gamma) \sim \\
\text { Cauchy }\left(\mu_{\text {study }}, T_{\text {study }}\right)\end{array}$ \\
\hline$\phi$ & $\begin{array}{l}\text { Precision parameter of negative binomial } \\
\text { distribution }\end{array}$ & $\log _{10}(\phi) \sim U(-3,3)$ \\
\hline$\Gamma_{\mathrm{i}}$ & $\begin{array}{l}\text { Random variable for sampling from the } \\
\text { Cauchy distribution for the study-specific } \\
\text { scale parameters }\end{array}$ & $\Gamma_{\mathrm{i}} \sim U(-0.5 \pi, 0.5 \pi)$ \\
\hline$\mu_{\text {study }}$ & $\begin{array}{l}\text { Location parameter of the Cauchy } \\
\text { distribution for the study-specific scale } \\
\text { parameters }\end{array}$ & 0 \\
\hline$T_{\text {study }}$ & $\begin{array}{l}\text { Scale parameter of the Cauchy } \\
\text { distribution for the study-specific scale } \\
\text { parameters }\end{array}$ & 2 \\
\hline $\mathrm{Y}_{\mathrm{y}}$ & $\begin{array}{l}\text { Random variable for sampling from the } \\
\text { truncated Cauchy distribution for the } \\
\text { invasiveness modification terms }\end{array}$ & $\mathrm{Y}_{\mathrm{y}} \sim U(-1.25,1.25)$ \\
\hline$\mu_{\bmod }$ & $\begin{array}{l}\text { Location parameter of the truncated } \\
\text { Cauchy distribution for the invasiveness } \\
\text { modification terms }\end{array}$ & 0 \\
\hline$T_{\text {mod }}$ & $\begin{array}{l}\text { Scale parameter of the truncated Cauchy } \\
\text { distribution for the invasiveness } \\
\text { modification terms }\end{array}$ & 0.5 \\
\hline
\end{tabular}

1548 Table 1 Summary of parameters used in the models. 


\section{Supporting Information}

1550

1551

1552 Analysing pneumococcal invasiveness using Bayesian models of pathogen

1553 progression rates

1554

1555 Alessandra Løchen, James E. Truscott and Nicholas J. Croucher

1556

$1557 \quad$ Text S1

1558 Figures S1-S31

1559 Tables S1-11

1560 Datasets S1-S3 (legends only) 
1561 Text S1: Sample descriptions for genomic and genotyped datasets

1562 The S. pneumoniae population was previously divided into strains by the Global

1563 Pneumococcal Sequencing project [31] using PopPUNK [5]. Previous estimation of

1564 the effect of strain background on invasiveness by Gladstone et al [35] used two

1565 study populations. The first combined two carriage studies from Agincourt and

1566 Soweto, in South Africa, with nationwide surveillance of IPD by the National Institute

1567 for Communicable Diseases. After excluding carriage and disease isolates from

1568 individuals reported as being HIV positive, genomes were available for 1,089

1569 carriage isolates and 855 IPD isolates from children under seven years old. Model

1570 fitting required calculating the number of swabs taken from HIV negative children under seven in the carriage studies. In Soweto, the reported age stratification meant

1572 this number could only be calculated for children under five [102], and therefore four carriage isolates from children aged five or six were excluded from the study. In Agincourt, the reported age stratification meant 33 isolates from children aged six were excluded [103]. As the prevalence of HIV was low in infants in the Agincourt study [104], and the exact number of swabs from HIV positive children was not reported, no adjustment was made to the sampling based on HIV status. The population of children under surveillance for IPD was estimated from nationwide census data between 2009-2013 [105]. All samples were stratified into the postPCV7 (2009-2011) and post-PCV13 (2012-2013) periods [31].

1582 The second study population combined a carriage survey from Massachusetts, USA and isolates from the Active Bacterial Core Surveillance (ABCS) of IPD across several states. Isolates were collected over the sampling periods of $2000-2001$, 2003-2004, 2006-2007 and 2008-2009. As only 51 IPD samples were available for 
the earliest two periods, and the population was changing rapidly over these years

1587 [91], only samples from the more stable post-PCV7 2006-2009 period were studied

1588 [106]. This included 405 IPD isolates, modelled as coming from a time interval of two

1589 years (as samples only came from 2007 and 2009) from a population size calculated

1590 from the ABCS population matrix [107]. Of the carriage isolates, 280 were assigned

1591 to strains from genomic data, while 291 were only associated with multi-locus sequence typing (MLST) genotypes [108]. Gladstone et al assigned these isolates to strains using the close relationship between MLST and PopPUNK population

1594 classifications [5,35].

1596 As these studies were estimating odds ratios across samples stratified by year,

1597 Gladstone et al randomly subsampled isolates to ensure an even ratio of disease and carriage at each sampling timepoint [35]. This correction is unnecessary with the models described in this study, as the $\gamma_{i}$ scaling parameters can adjust for differing

1600 levels of surveillance between samples (incorporating variation in both the samples 1601 collected, and the subset sequenced). Furthermore, such subsampling would distort the inferred $\rho_{i, x}$.

MLST genotypes were also available for isolates from the studies of serotype

1605 invasiveness from Stockholm [75], Finland [71,109] and Oxford, UK [29]. Where

1606 possible, these were assigned to GPS strains using the isolate's MLST data, or the

1607 clonal complex to which they belonged at the time of publication [4]. If an isolate

1608 could not be assigned to a GPS strain, then its MLST sequence type was used to

1609 designate its genotype instead. Isolates that could not be unequivocally assigned a

1610 strain, serotype and source (carriage or disease) were omitted. 
1612 For the Oxford study, these criteria meant 84 of the 150 disease isolates, and 113 of

1613 the 351 carriage isolates, could be analysed. The carriage isolates were assembled

1614 from three different surveys, only one of which could be linked to a more detailed

1615 published description of the total carriage sample size [110]. As the isolates in this

1616 study were recovered from 213 individuals, and the Oxford study attempted to

1617 minimise multiple sampling from any one host [29], the overall carriage sample size

1618 for the three studies was approximated as three times the number of individuals in

1619 this published study (639).

1620

1621 For the Finland study, the criteria described above meant 143 of the 224 disease

1622 isolates, and 102 of the 217 carriage isolates, could be analysed. The carriage

1623 isolates were recovered from ten longitudinal samples from each of 329 individuals

1624 [33]. As the Finland study sought to avoid multiple sampling of the same carriage

1625 episode [71], the host population size was used as the carriage sample size.

1626

1627 For the Stockholm study, the criteria described above meant 65 of the 165 disease

1628 isolates, and 178 of the 550 carriage isolates, could be analysed. The carriage

1629 isolates were recovered from studies conducted between 1997 and 2004. Two

1630 published descriptions of the original carriage studies reported the recovery of 506

1631 isolates from 1,330 individuals $[111,112]$. As this accounted for over $90 \%$ of the nasopharyngeal isolates, this number was used as the carriage sample size.

1634 An additional study from Portugal used a collection of disease isolates primarily

1635 recovered from adults [52]. Applying the same criteria as to the child disease studies 
1636 allowed unambiguous assignation of genotype and serotype to 463 of the 769

1637 carriage isolates, and 152 of the 475 of the disease isolates. The carriage isolates

1638 were a subset of a previous study [113], and originated from 1,170 nasopharyngeal

1639 swabs (R. Sá-Leão, personal communication). 


\section{Supplementary Figures}

2
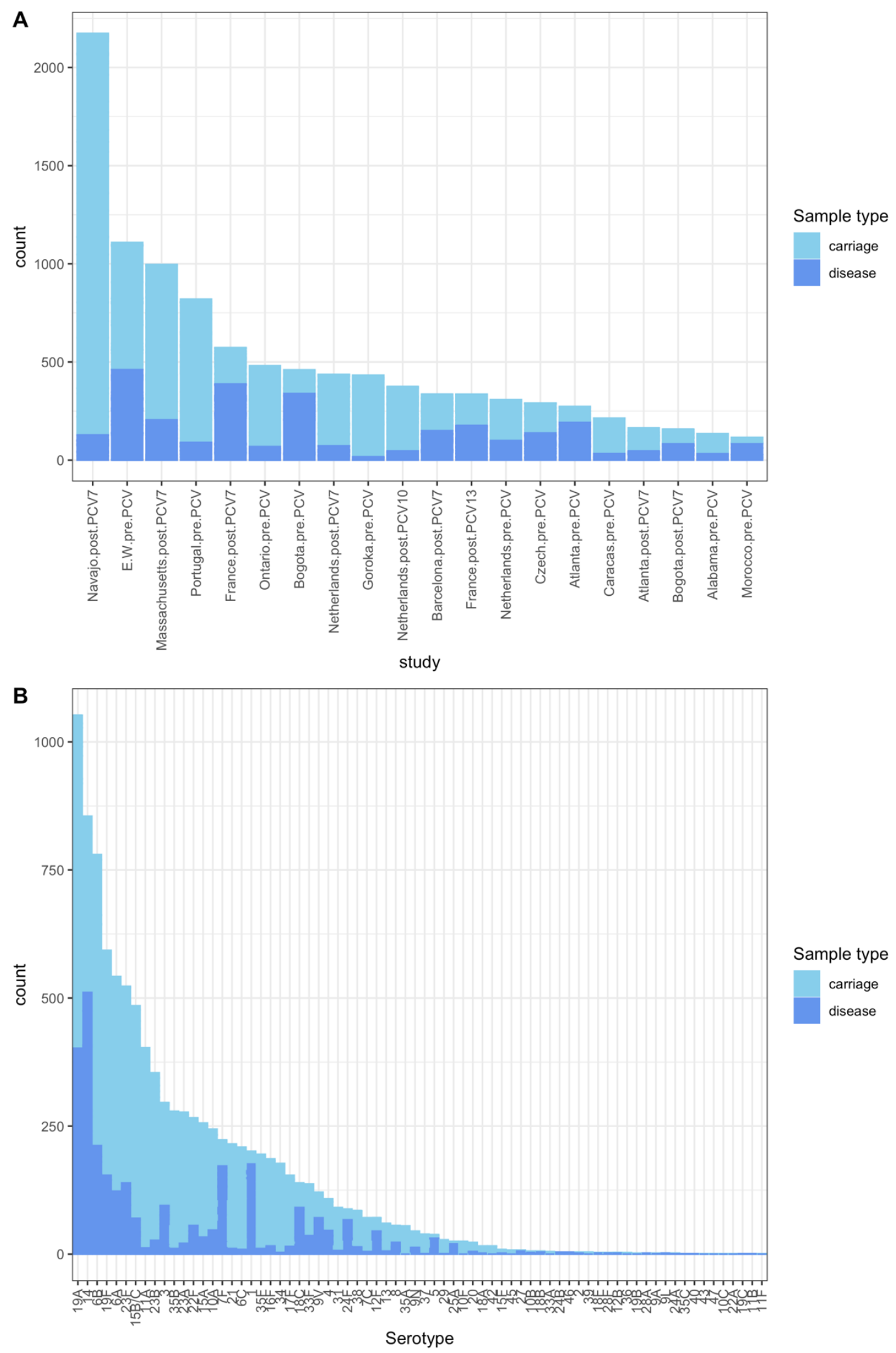

4 Figure S1 Properties of the child serotype dataset. (A) Stacked bar plot showing the 5 distribution of carriage and disease isolates between studies. (B) Stacked bar plot 6 showing the distribution of carriage and disease isolates between serotypes. 

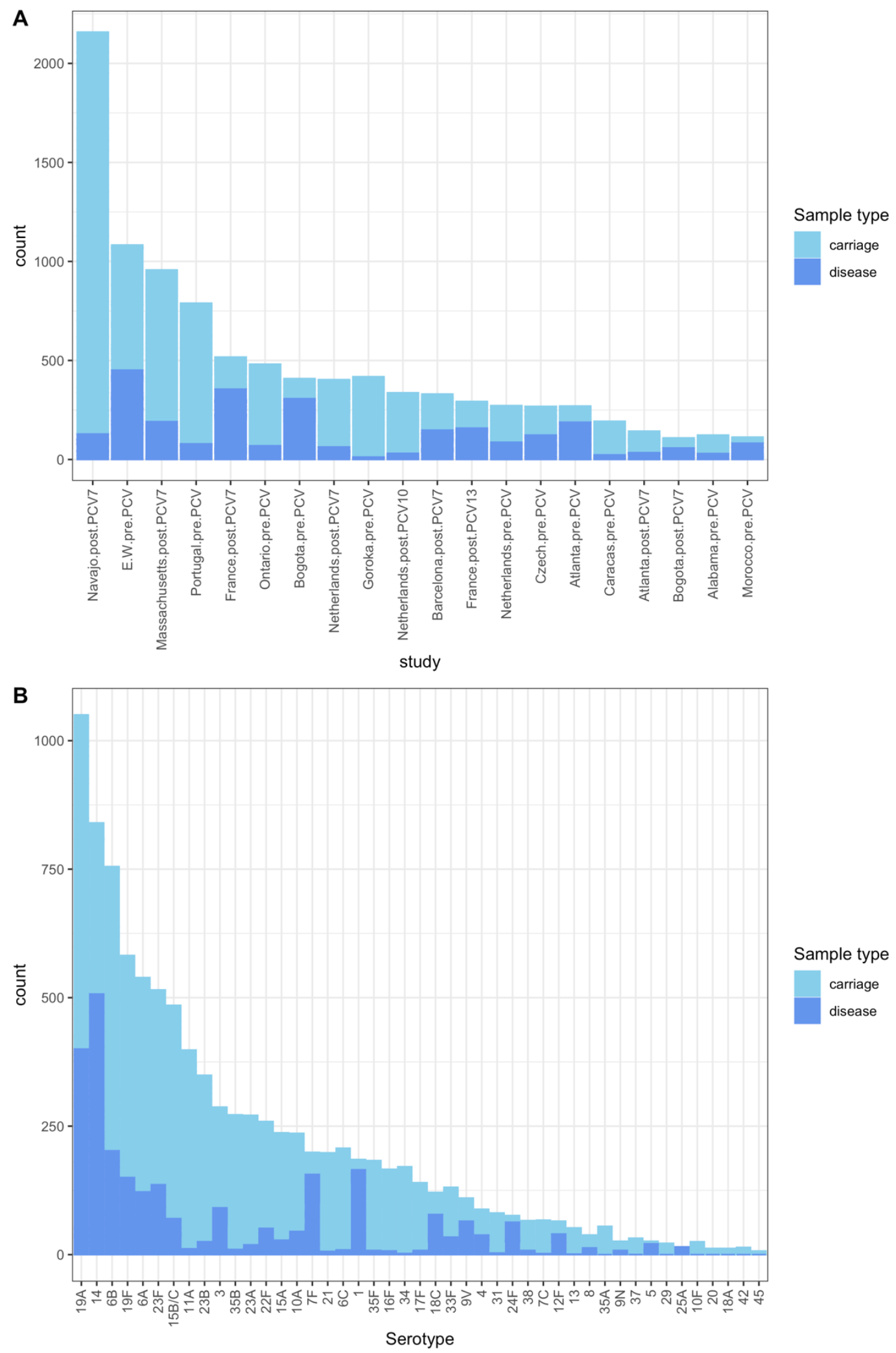

Figure S2 Properties of the child serotype dataset after removing datapoints in which fewer than five isolates of a serotype were recorded from both carriage and disease in a given study. (A) Stacked bar plot showing the distribution of carriage and disease isolates between studies. (B) Stacked bar plot showing the distribution of carriage and disease isolates between serotypes. 

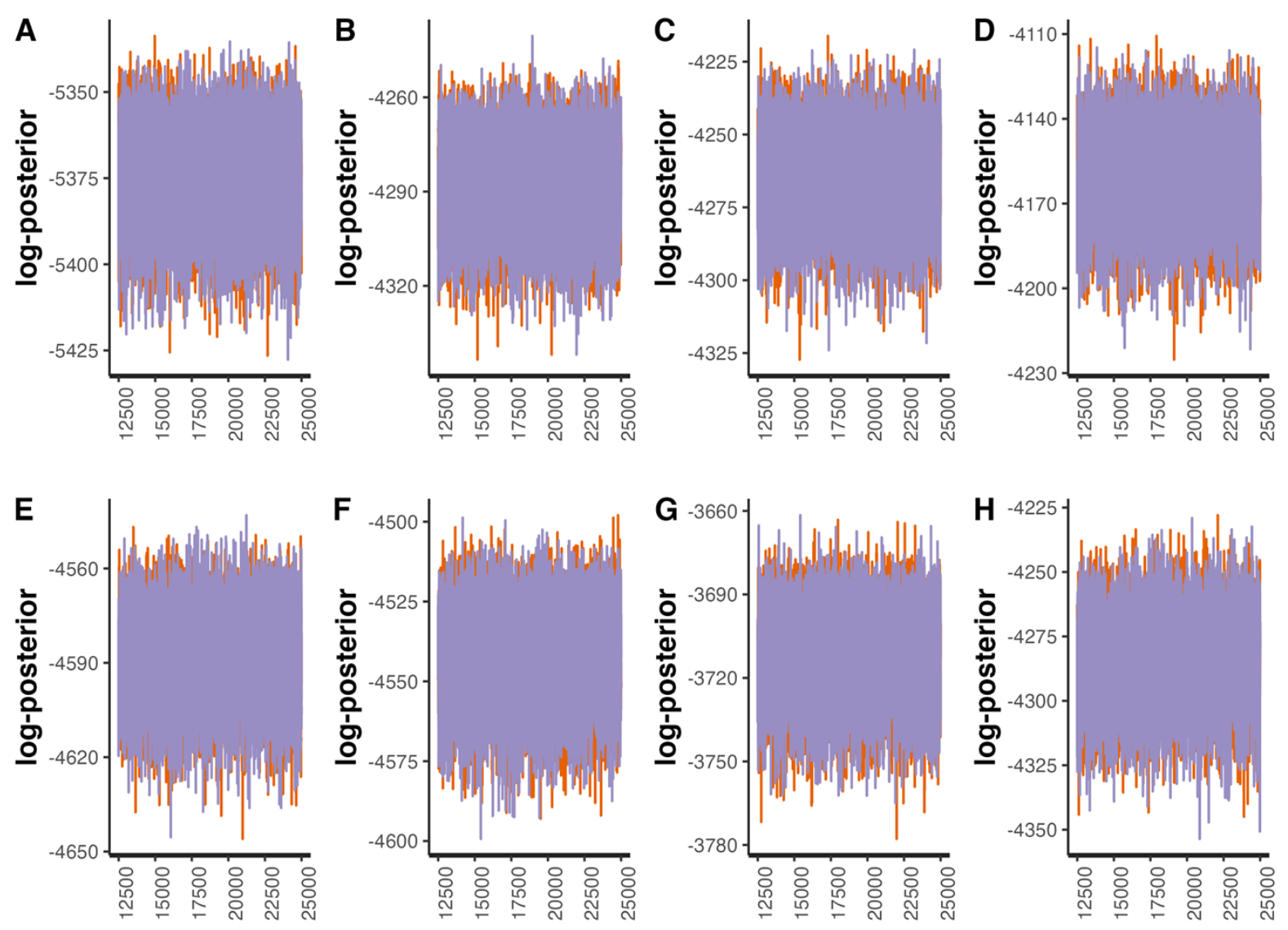

Figure S3 Line plots showing the post-warmup MCMC traces for the logarithmic posterior probabilities across two independent chains for models fitted to the filtered serotype data from child carriage and disease. The horizontal axis shows the generation of the MCMC, with values for the two chains shown by orange and purple lines. Each panel corresponds to a different model: (A) null Poisson model; (B) null negative binomial model; (C) type-specific Poisson model; (D) type-specific negative binomial model; (E) study-adjusted Poisson model; (F) study-adjusted negative binomial model; (G) study-adjusted type-specific Poisson model; $(\mathrm{H})$ study-adjusted

10 type-specific negative binomial model. 


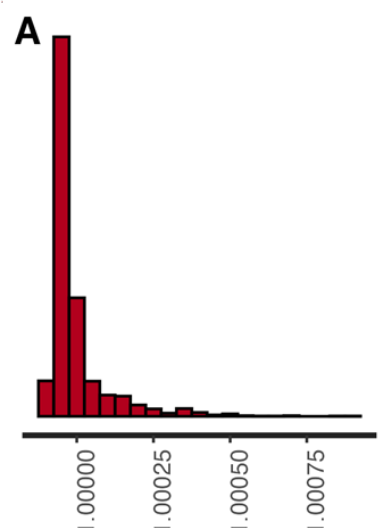

Rhat statistic

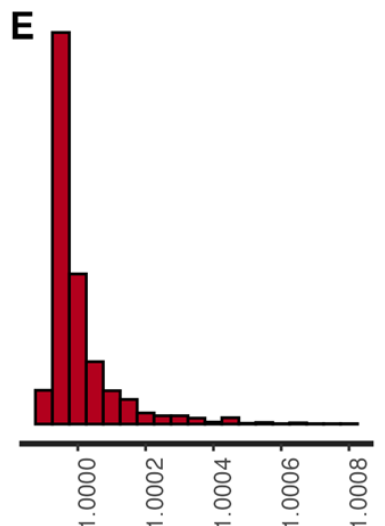

Rhat statistic

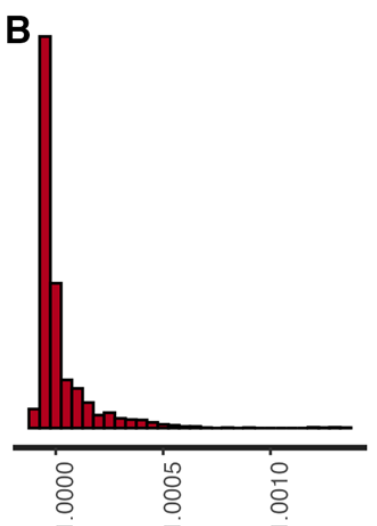

Rhat statistic

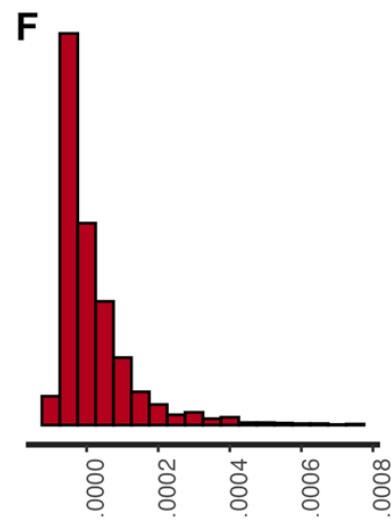

Rhat statistic

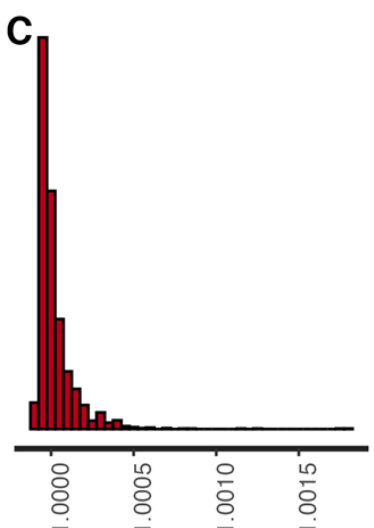

Rhat statistic

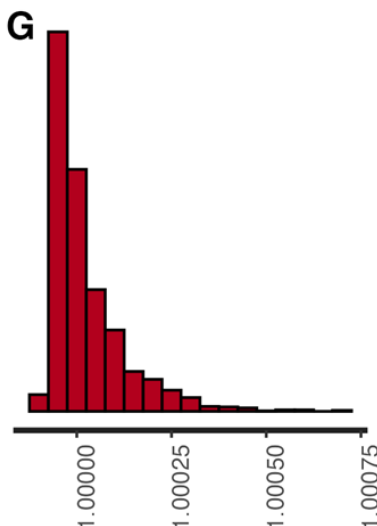

Rhat statistic

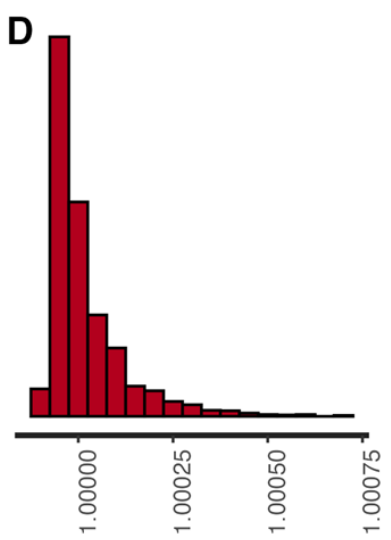

Rhat statistic

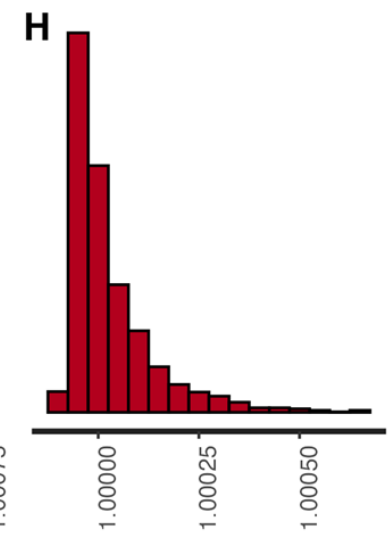

Rhat statistic

Figure S4 Histograms of Rhat values calculated from the paired MCMCs for models fitted to the filtered serotype data from child carriage and disease. Each panel corresponds to a different model: $(A)$ null Poisson model; $(B)$ null negative binomial model; (C) type-specific Poisson model; (D) type-specific negative binomial model; (E) study-adjusted Poisson model; (F) study-adjusted negative binomial model; $(\mathrm{G})$ study-adjusted type-specific Poisson model; $(\mathrm{H})$ study-adjusted type-specific negative binomial model. 


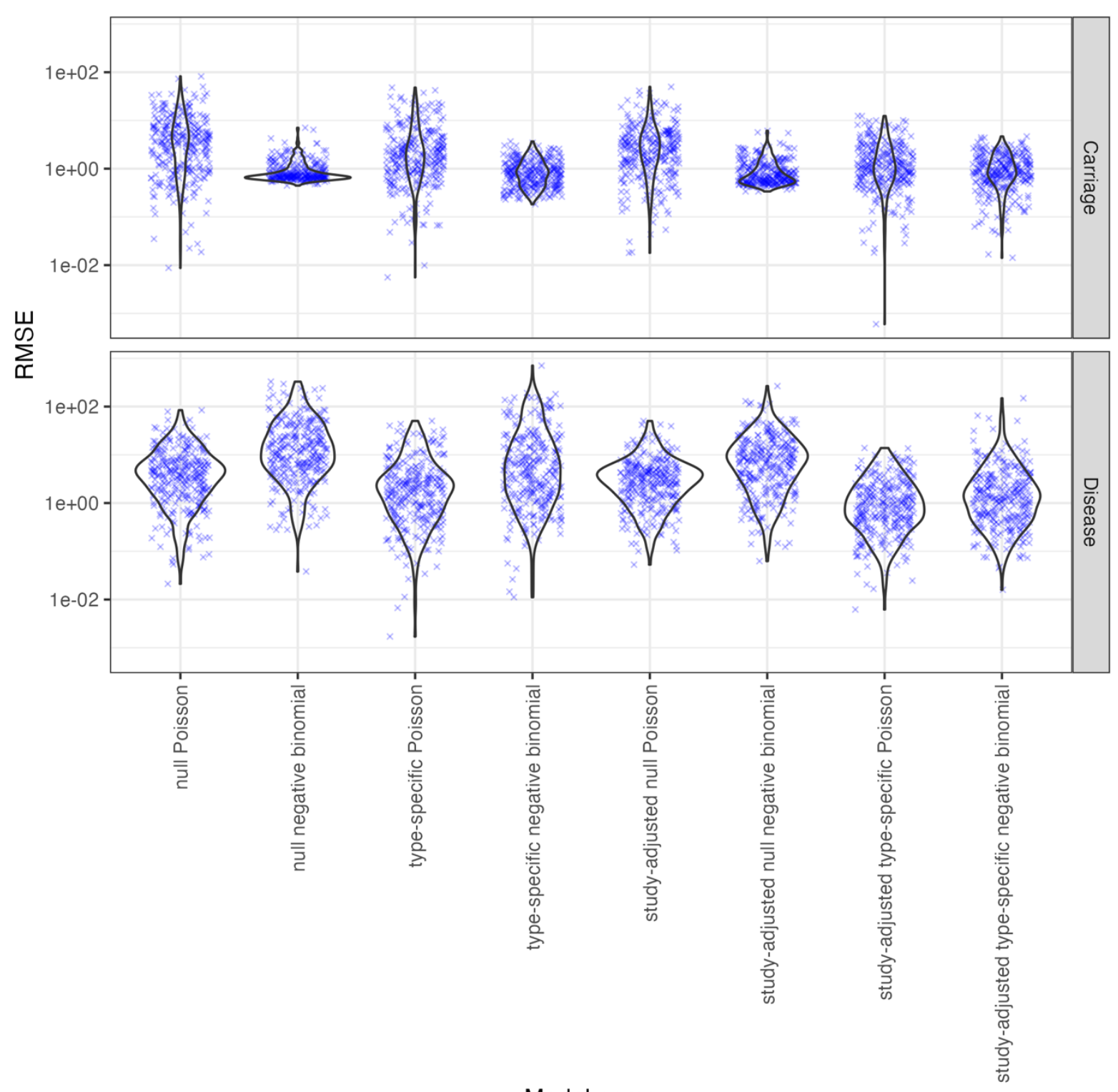

Model name

Figure S5 Violin plots showing the root mean square error between observed and predicted values across model fits to the filtered serotype data from child carriage and disease. Blue crosses represent the individual observations. 


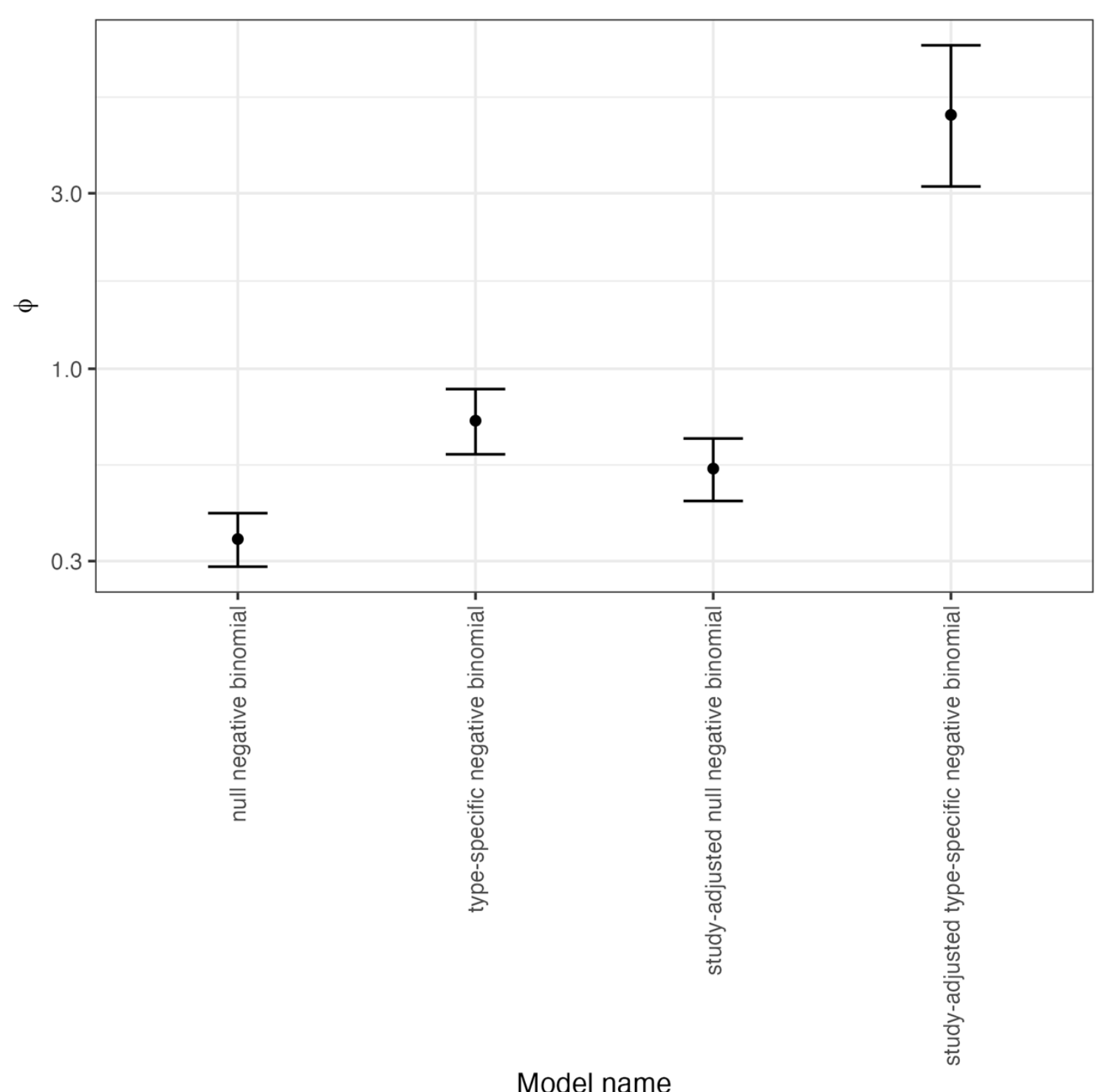

Figure S6 Graph showing the values of the negative binomial distribution's precision parameter, $\phi$, from model fits to the filtered serotype data from child carriage and disease. The points represent the mean estimate from the MCMCs, and the error 5 bars show the $95 \%$ credibility interval. 
A

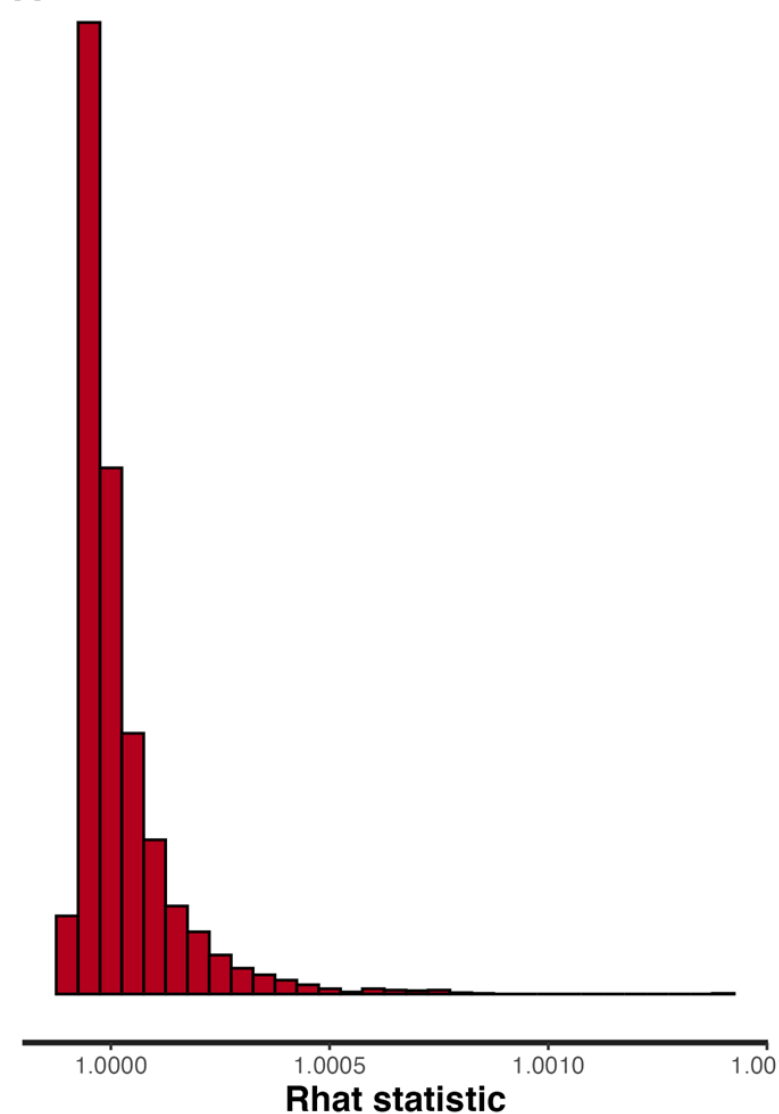

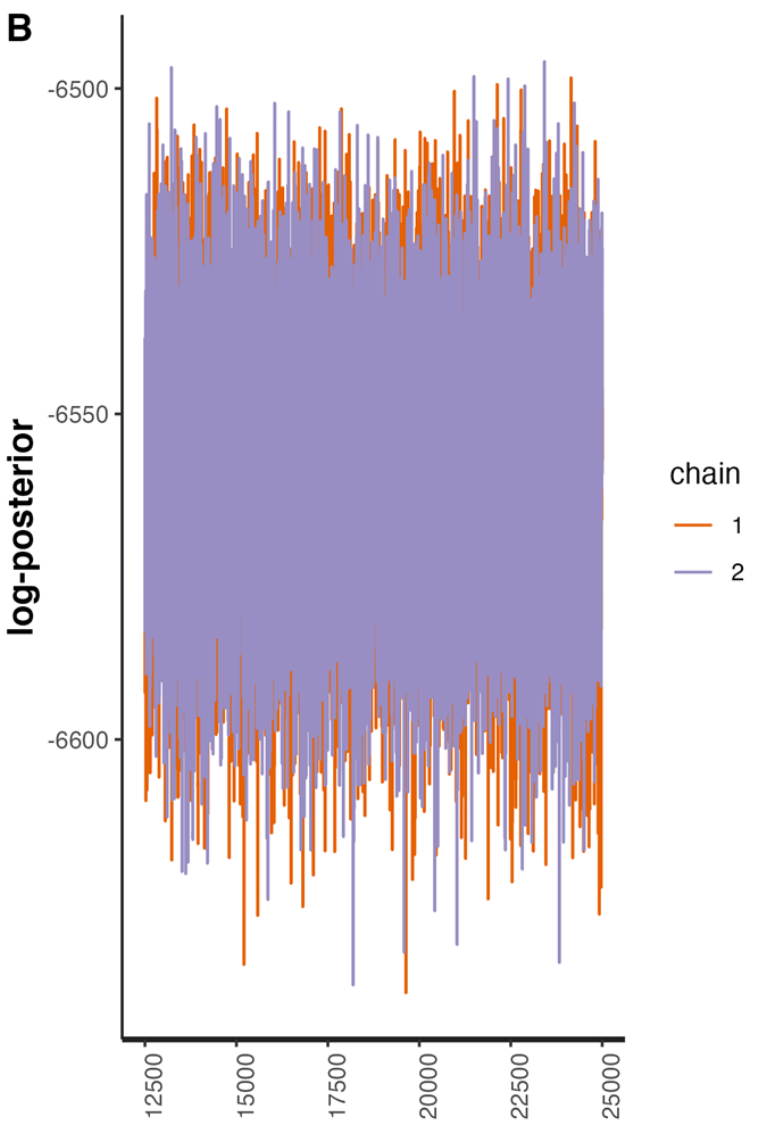

B

Figure S7 Plots validating the fit of the study-adjusted type-specific Poisson model to the full serotype data from child carriage and disease. (A) Histogram showing the distribution of Rhat values. (B) Post-warmup MCMC traces of the log posterior probability. 


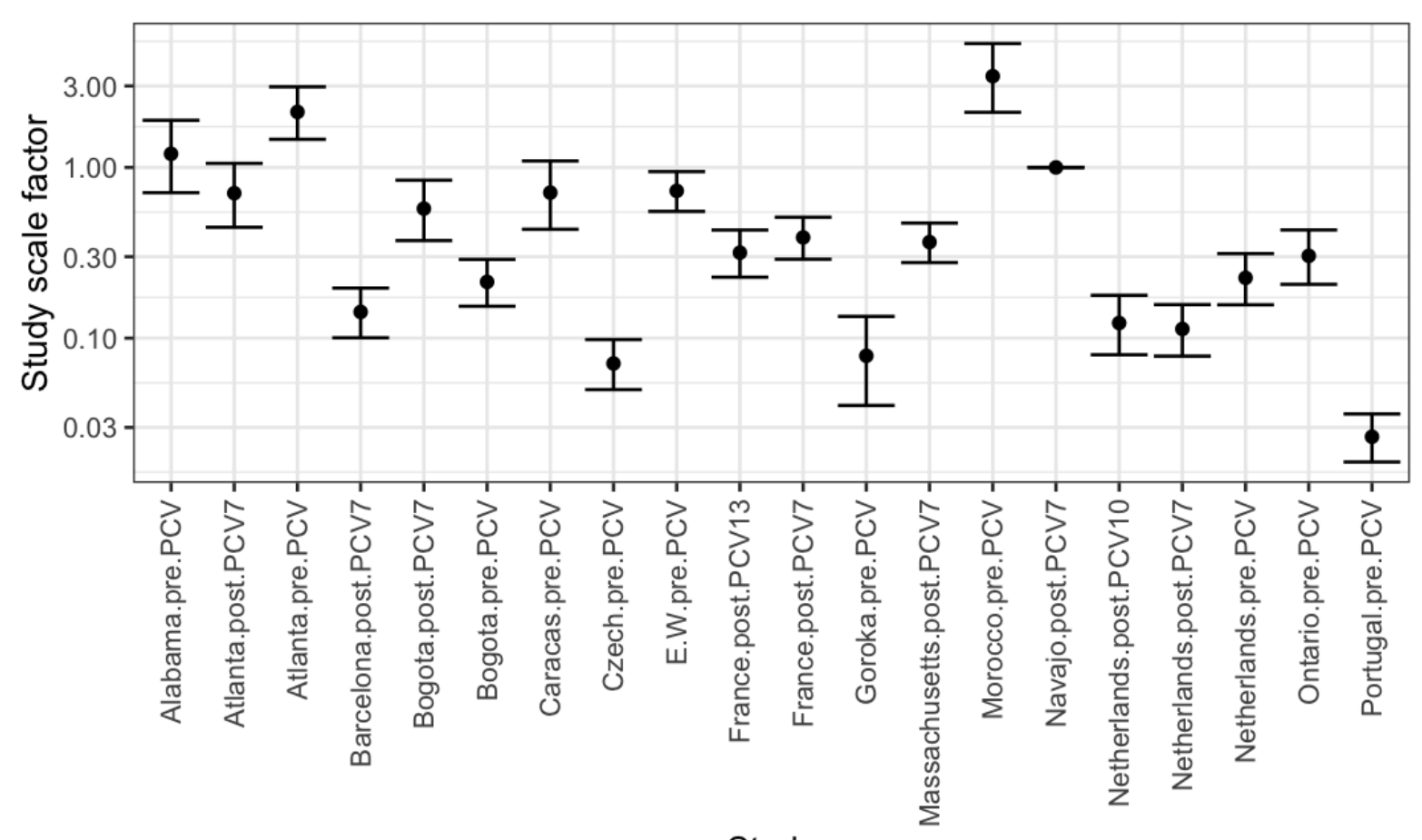

Study

Figure $\mathbf{S 8}$ Study-adjustment scale factors from the study-adjusted type-specific Poisson model fitted to the full serotype data from child carriage and disease. The reference study, for which the value was fixed at one, was the Navajo post-PCV7 dataset, which had the greatest sample size in this meta-analysis (Fig. S1). 
A

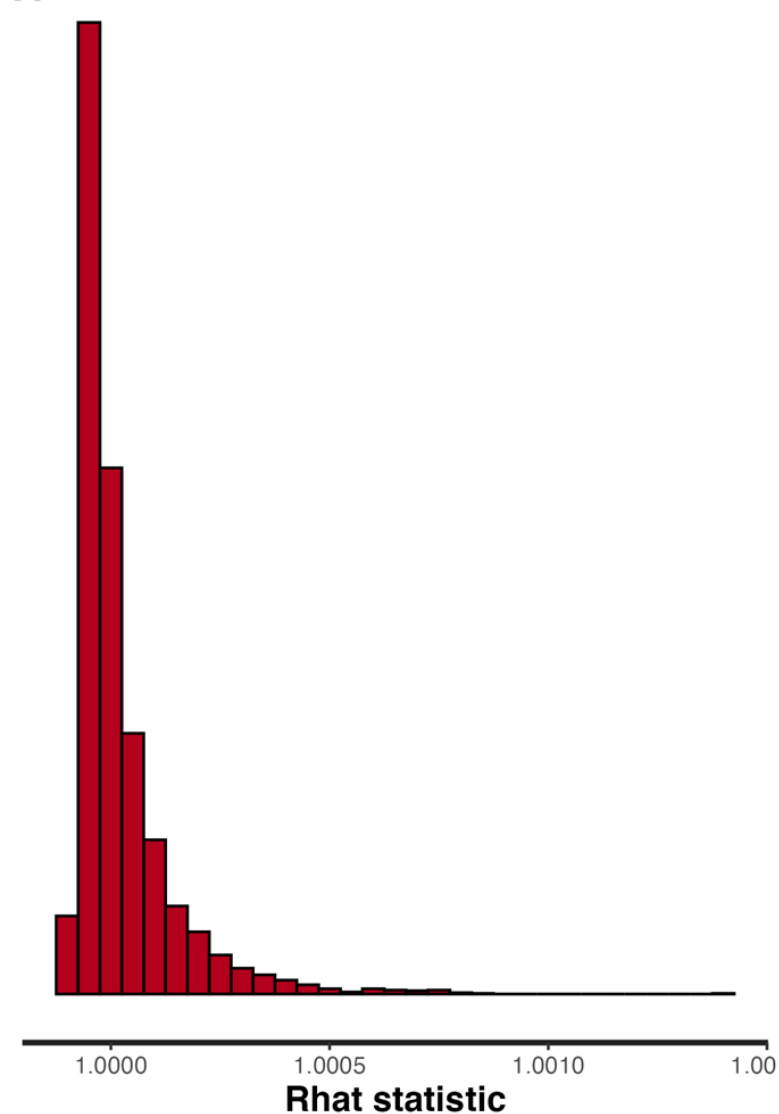

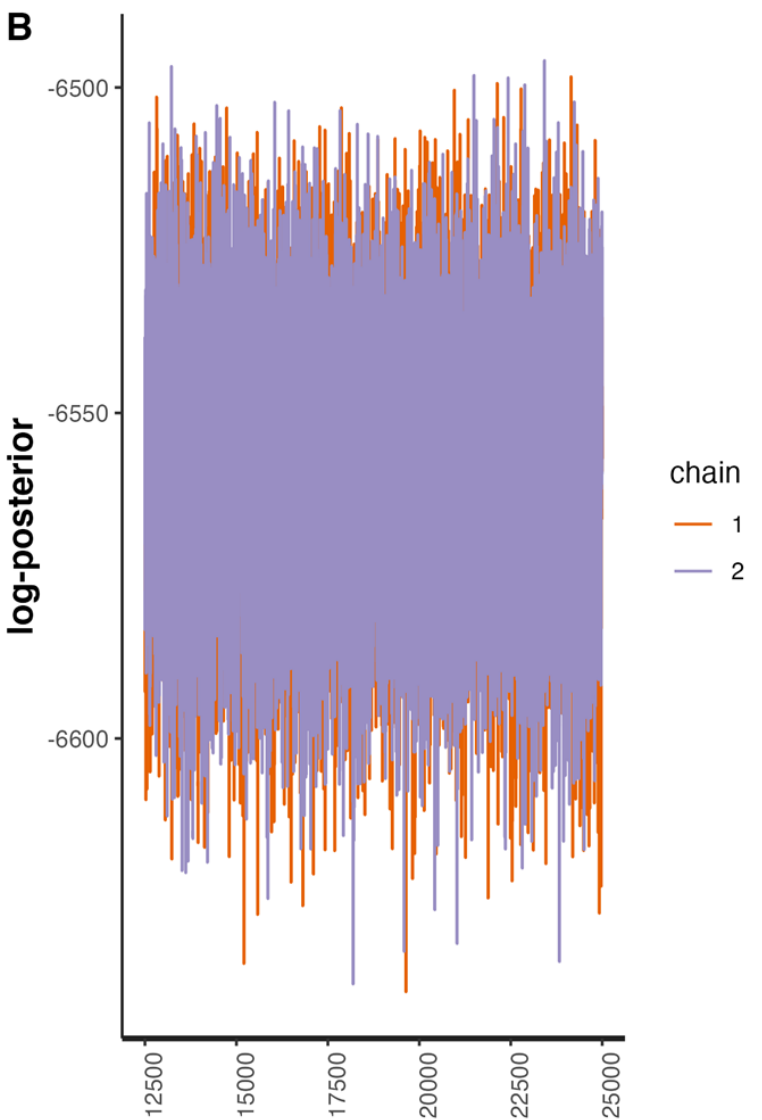

B

Figure S9 Plots validating the fit of the study-adjusted type-specific Poisson model to the full serotype data from child carriage and disease, when distinguishing between vaccine-type serotypes pre- and post-PCV. (A) Histogram showing the distribution of Rhat values. (B) Post-warmup MCMC traces of the log posterior probability. 


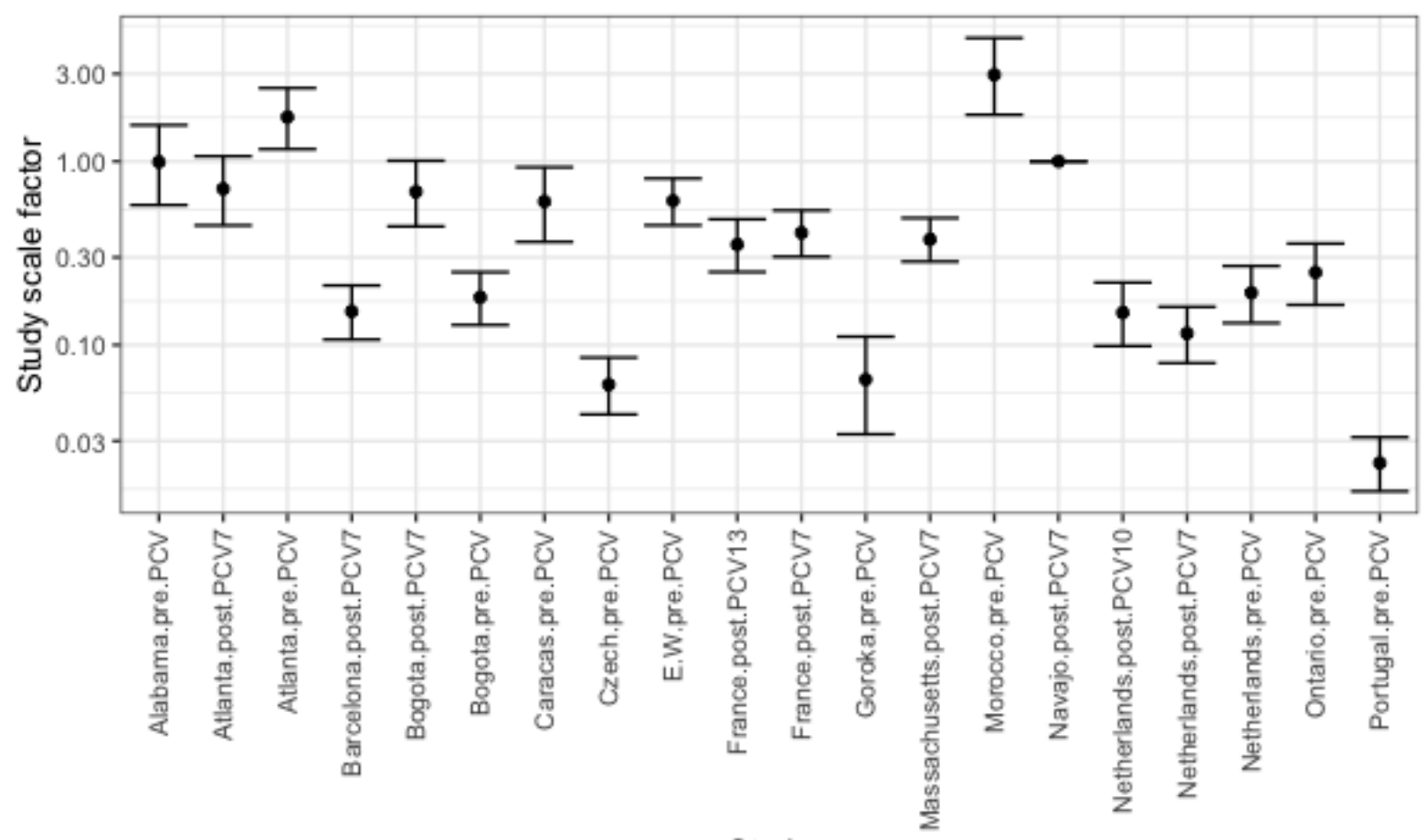

Study

Figure S10 Study-adjustment scale factors from the study-adjusted type-specific Poisson model fitted to the full serotype data from child carriage and disease, when distinguishing between vaccine-type serotypes pre- and post-PCV. The reference study, for which the value was fixed at one, was the Navajo post-PCV7 dataset, which had the greatest sample size in this meta-analysis (Fig. S1). 


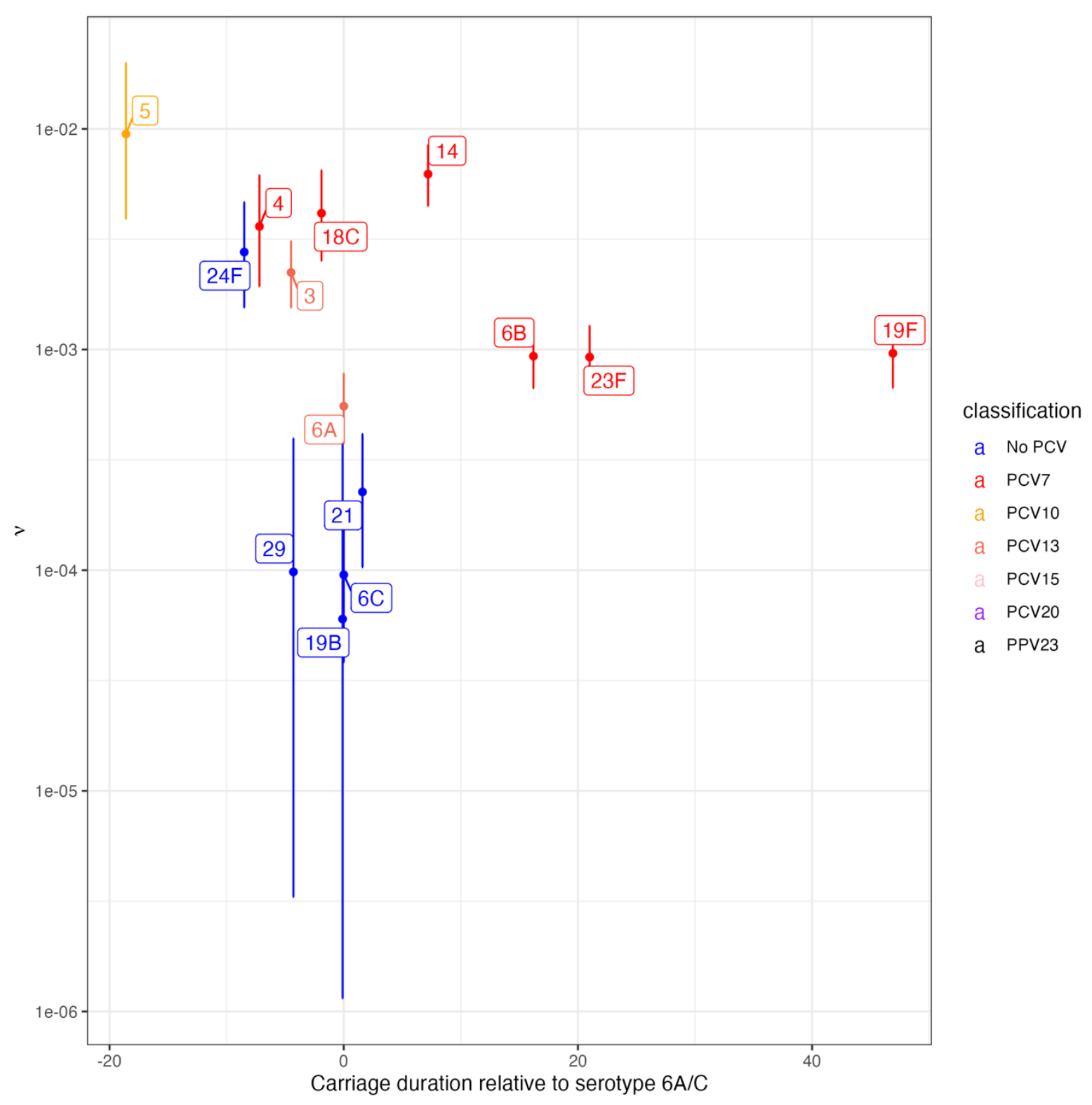

Figure S11 Relationship between serotype invasiveness in children (as shown in 3 Fig. 2) and carriage duration in a study of infant colonisation in Maela, Thailand. The carriage duration estimates were derived from a multi-variate lasso regression that included both serotype and antibiotic resistance phenotypes. Values were available 6 for 14 serotypes, all relative to the carriage duration of serotype $6 \mathrm{~A} / \mathrm{C}$, which was 7 therefore assigned a value of zero days. 

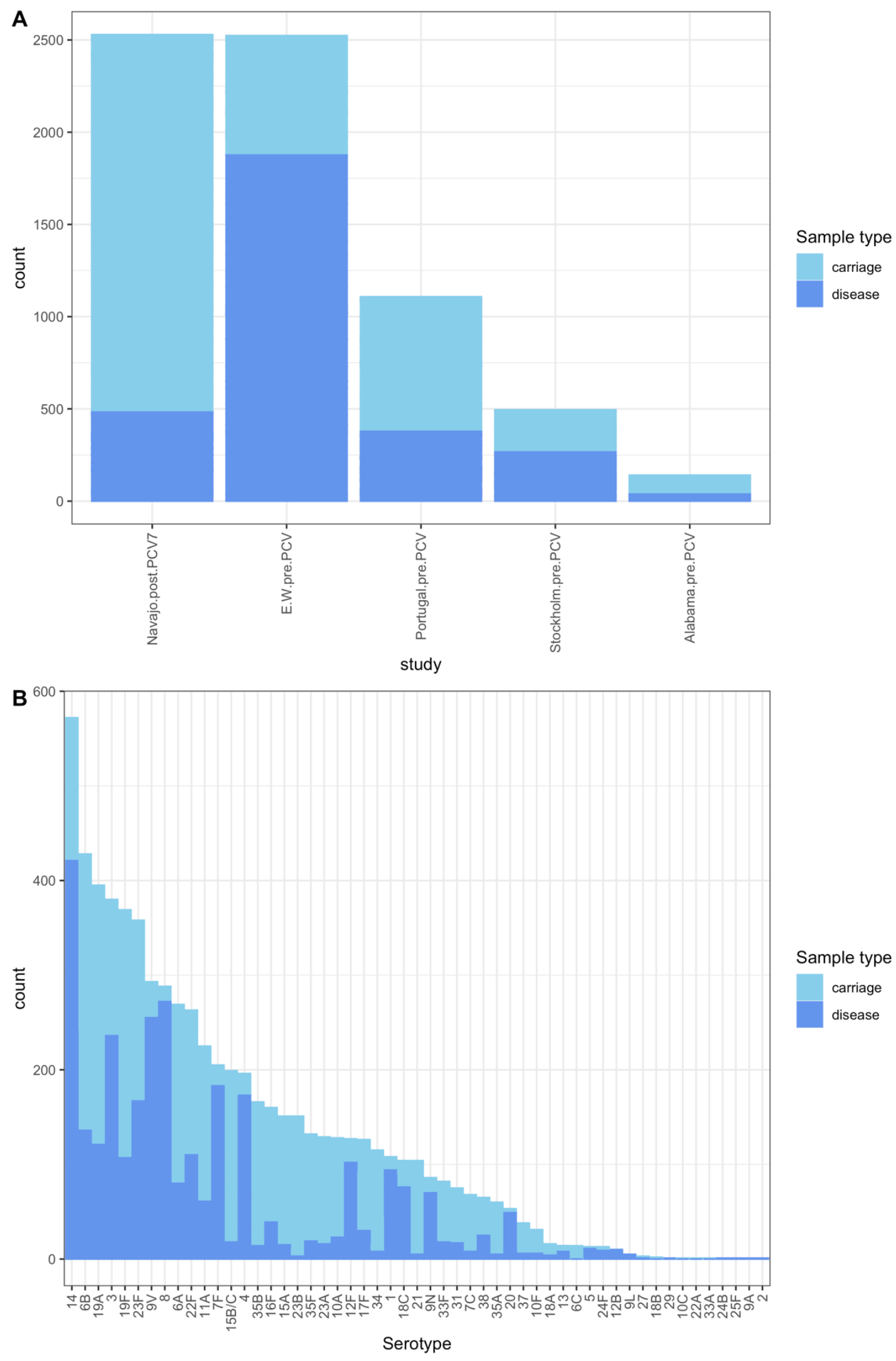

2 Figure S12 Properties of the adult serotype dataset. (A) Stacked bar plot showing 3 the distribution of carriage and disease isolates between studies. (B) Stacked bar 4 plot showing the distribution of carriage and disease isolates between serotypes. 

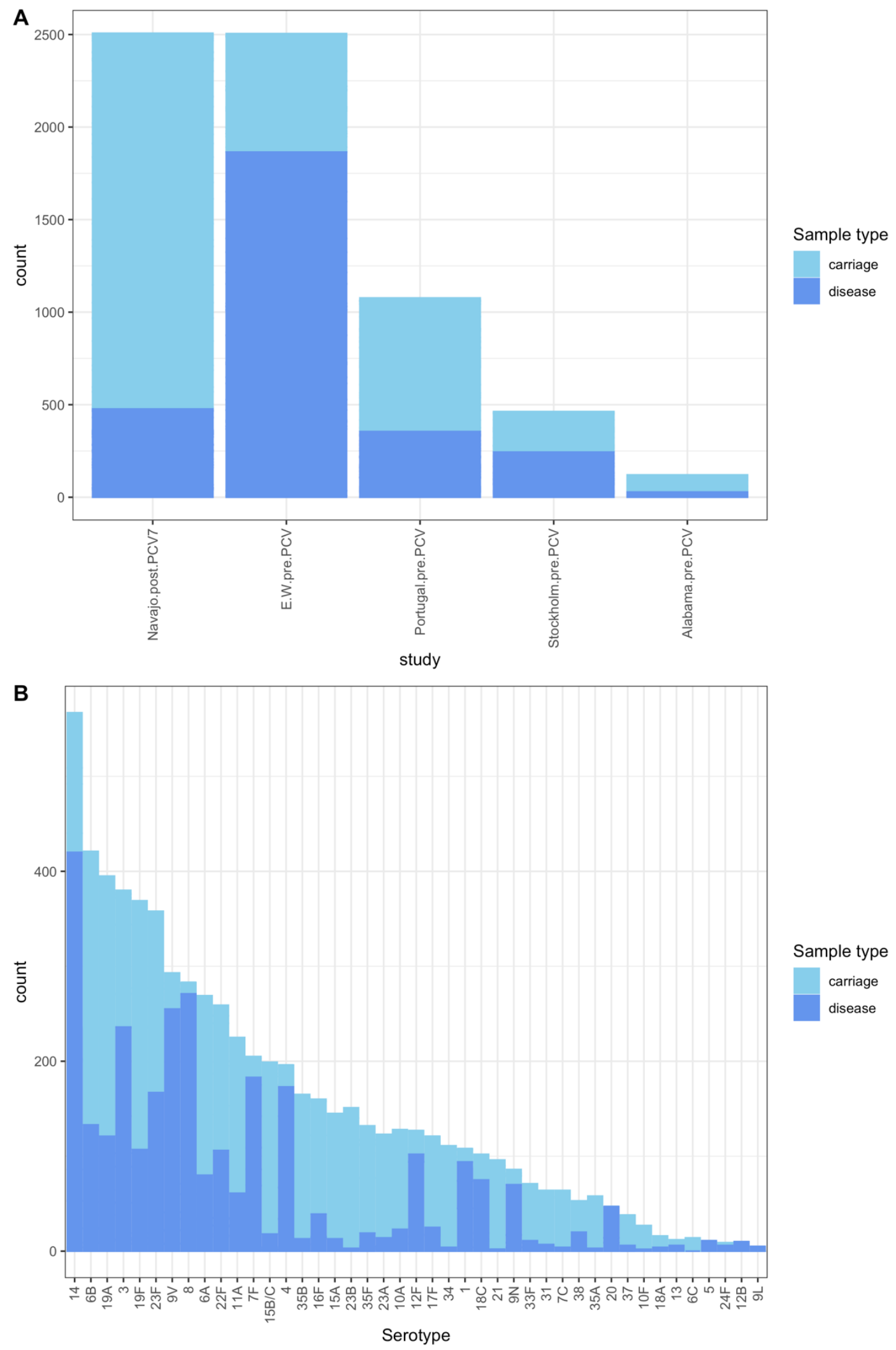

Figure S13 Properties of the adult serotype dataset after removing datapoints in which fewer than five isolates of a serotype were recorded from both carriage and disease in a given study. (A) Stacked bar plot showing the distribution of carriage and disease isolates between studies. (B) Stacked bar plot showing the distribution of carriage and disease isolates between serotypes. 

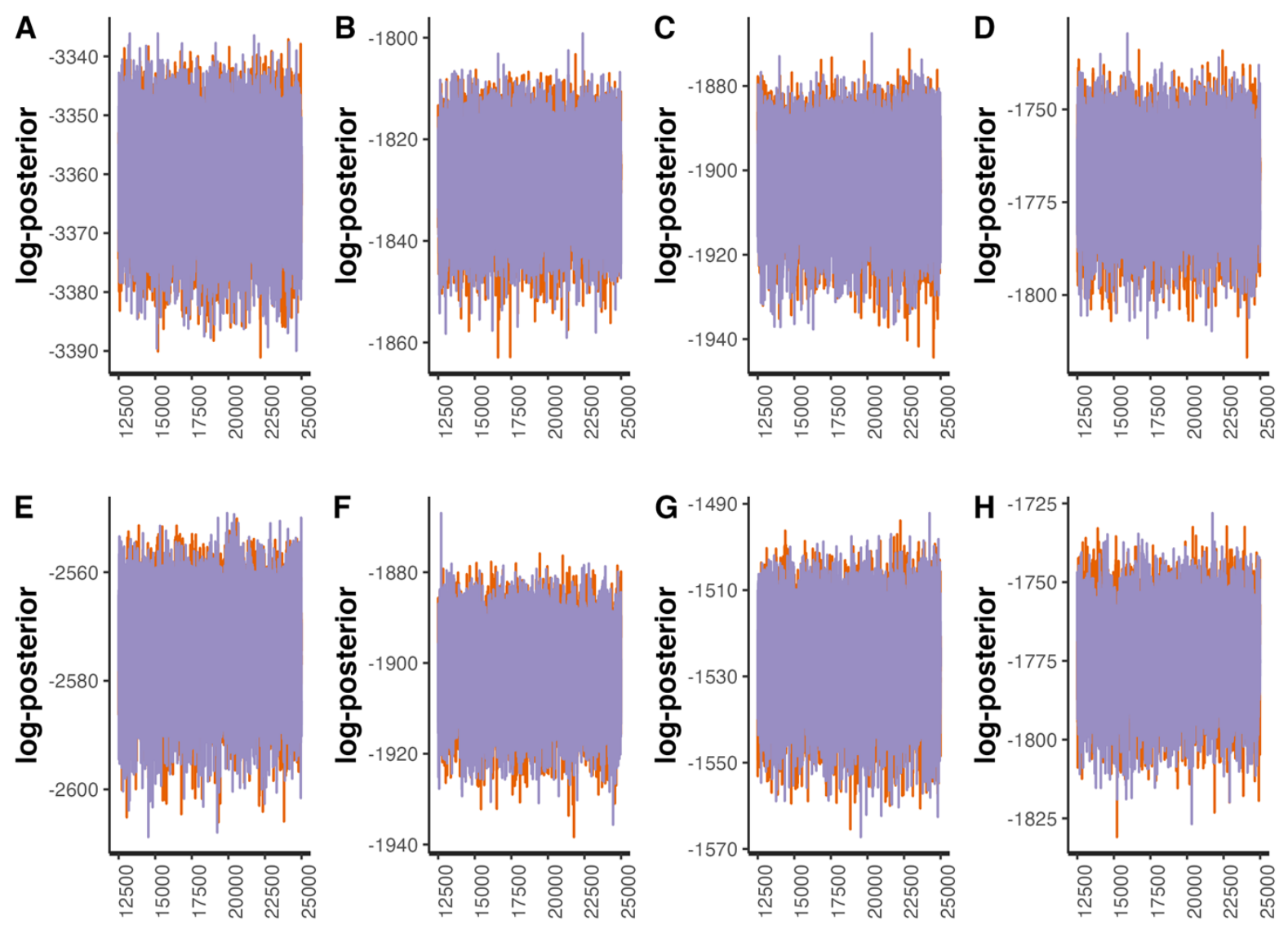

Figure S14 Line plots showing the post-warmup MCMC traces for the logarithmic posterior probabilities across two independent chains for models fitted to the filtered serotype data from child carriage and adult disease. The horizontal axis shows the generation of the MCMC, with values for the two chains shown by orange and purple lines. Each panel corresponds to a different model: (A) null Poisson model; (B) null negative binomial model; (C) type-specific Poisson model; (D) type-specific negative binomial model; (E) study-adjusted Poisson model; (F) study-adjusted negative binomial model; (G) study-adjusted type-specific Poisson model; $(\mathrm{H})$ study-adjusted type-specific negative binomial model. 


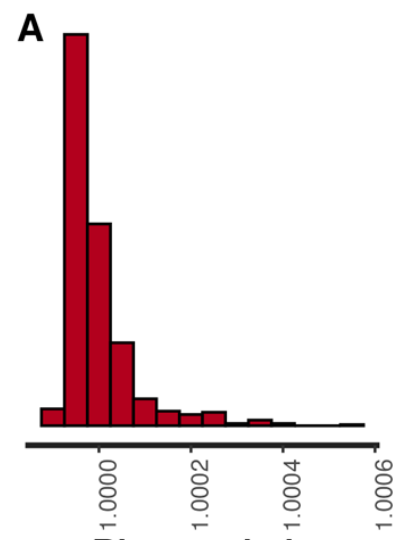

Rhat statistic

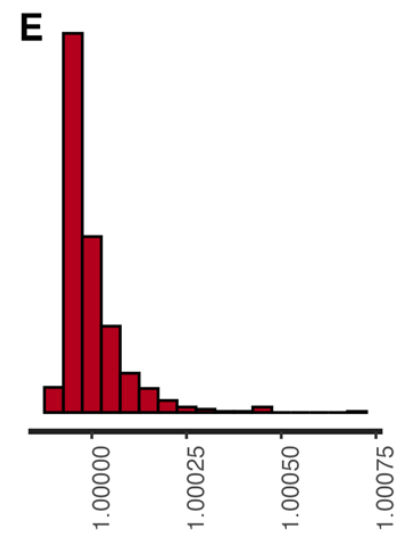

Rhat statistic
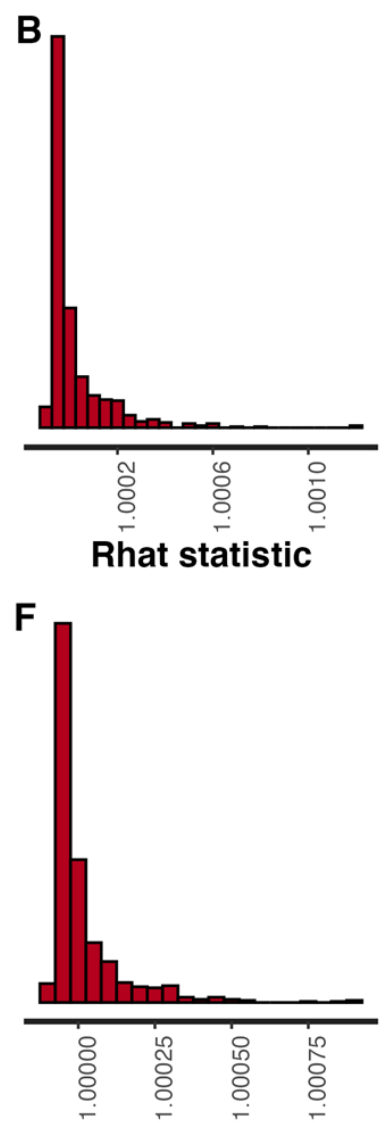

Rhat statistic
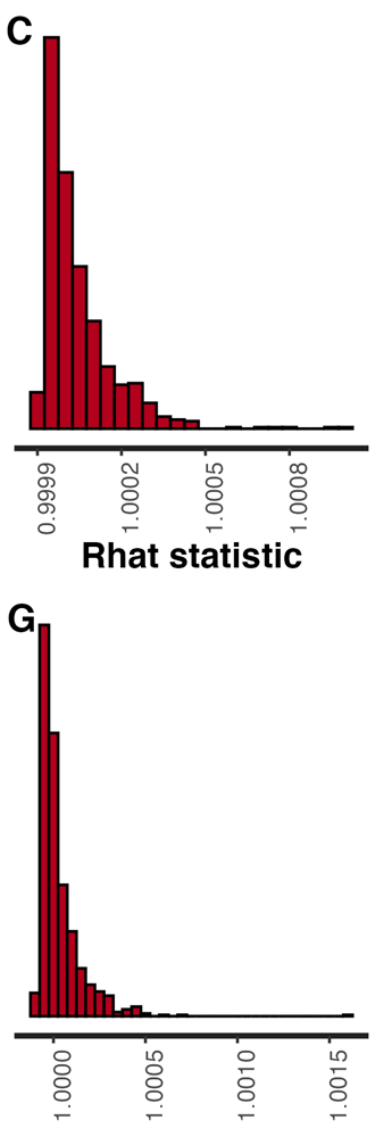

Rhat statistic

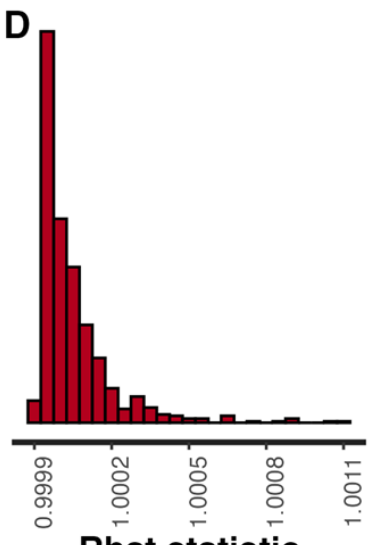

Rhat statistic

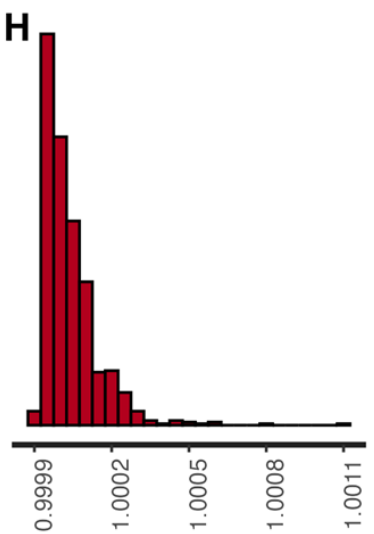

Rhat statistic

Figure S15 Histograms of Rhat values calculated from paired MCMCs for models fitted to the filtered serotype data from child carriage and adult disease. Each panel corresponds to a different model: $(A)$ null Poisson model; $(B)$ null negative binomial model; (C) type-specific Poisson model; (D) type-specific negative binomial model; (E) study-adjusted Poisson model; (F) study-adjusted negative binomial model; $(G)$ study-adjusted type-specific Poisson model; $(\mathrm{H})$ study-adjusted type-specific negative binomial model. 
bioRxiv preprint doi: https://doi.org/10.1101/2021.09.01.458483; this version posted September 1, 2021. The copyright holder for this preprint (which was not certified by peer review) is the author/funder, who has granted bioRxiv a license to display the preprint in perpetuity. It is made available under aCC-BY 4.0 International license.
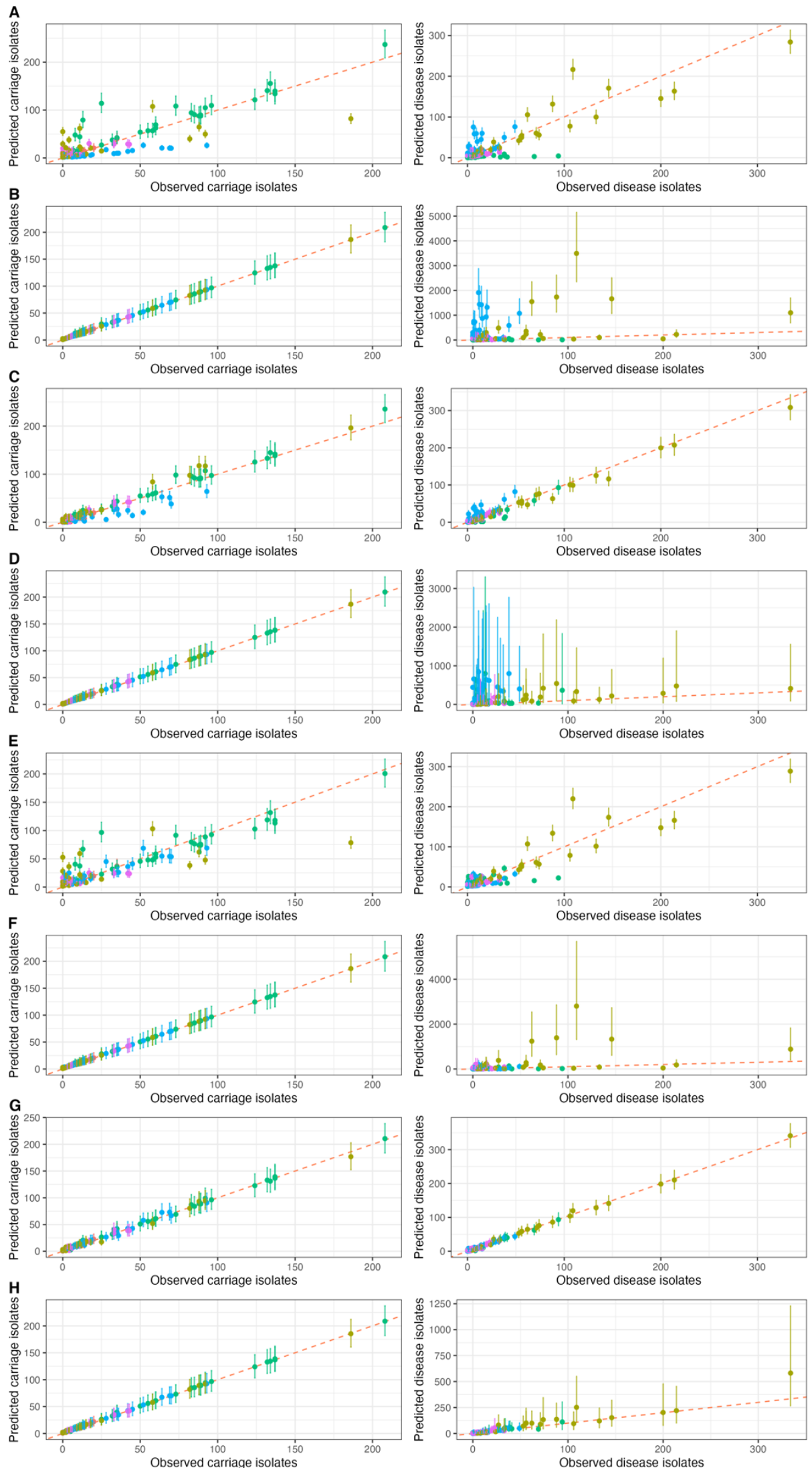

study $\rightarrow$ Alabama.pre.PCV $\rightarrow$ E.W.pre.PCV $\rightarrow$ Navajo.post.PCV7 $\rightarrow$ Portugal.pre.PCV $\leftrightarrow$ Stockholm.pre.PCV 
$1 \quad$ Figure S16 Comparison of observed and predicted counts of each serotype within 2 each adult study. The points are coloured by the study to which they correspond, 3 and represent the observed value on the horizontal axis, and the mean predicted value on the vertical axis. The error bars show the $95 \%$ credibility intervals. The red dashed line shows the line of identity, corresponding to a perfect match between prediction and observation. The left column shows the correspondence for carriage data (values of $c_{i, j}$ ), and the right column shows the correspondence for disease isolates (values of $d_{i . j}$ ). Each row corresponds to a different model: (A) null Poisson model; (B) null negative binomial model; (C) type-specific Poisson model; (D) type-

10 specific negative binomial model; (E) study-adjusted Poisson model; (F) study-

11 adjusted negative binomial model; $(G)$ study-adjusted type-specific Poisson model;

$12(\mathrm{H})$ study-adjusted type-specific negative binomial model. 
A

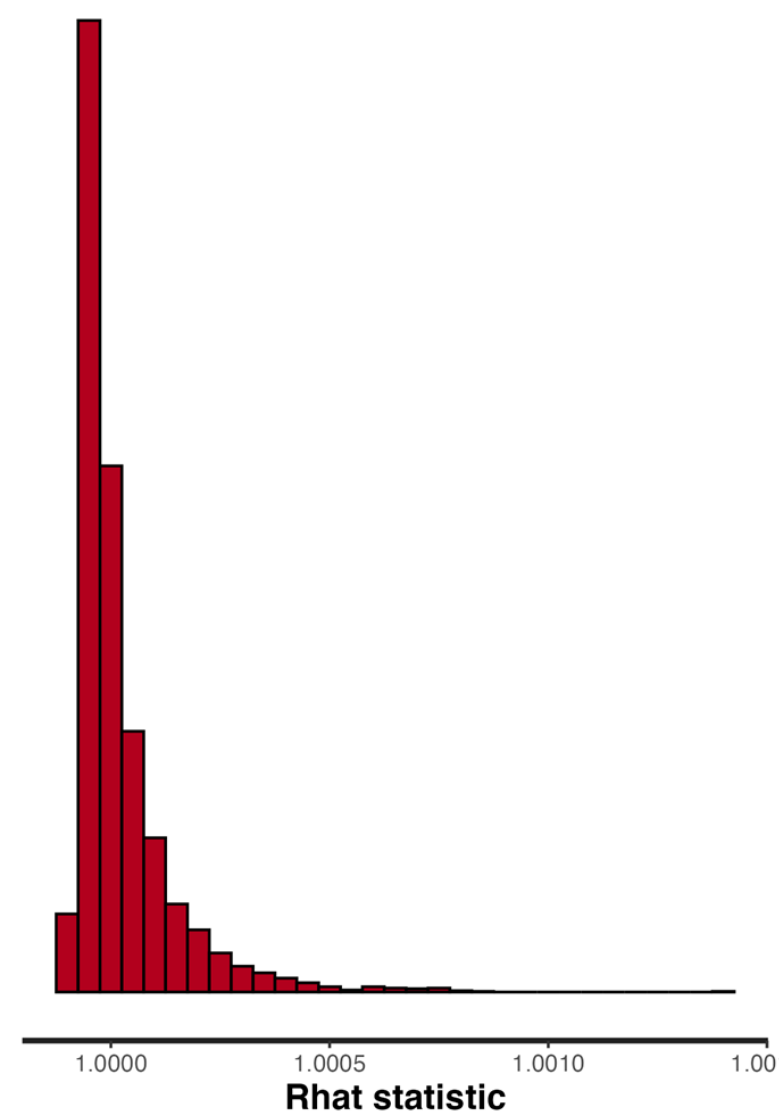

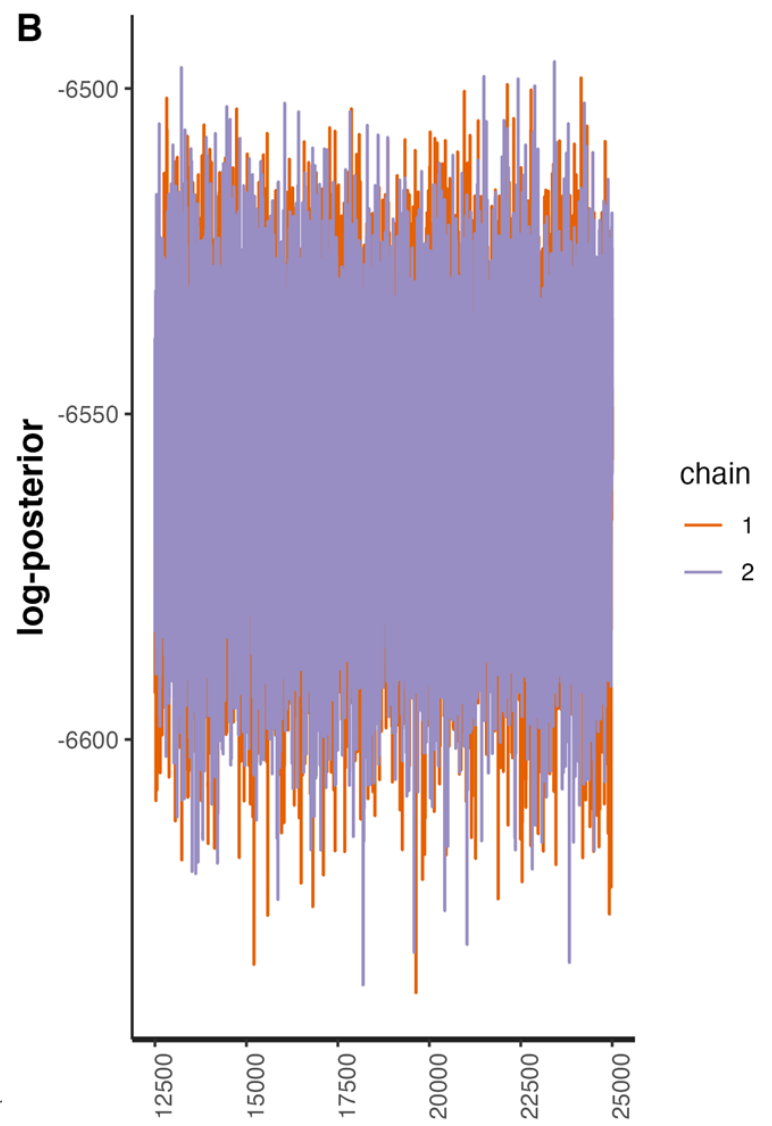

B

Figure S17 Plots validating the fit of the study-adjusted type-specific Poisson model to the full serotype data from child carriage and adult disease. (A) Histogram showing the distribution of Rhat values. (B) Post-warmup MCMC traces of the log posterior probability. 


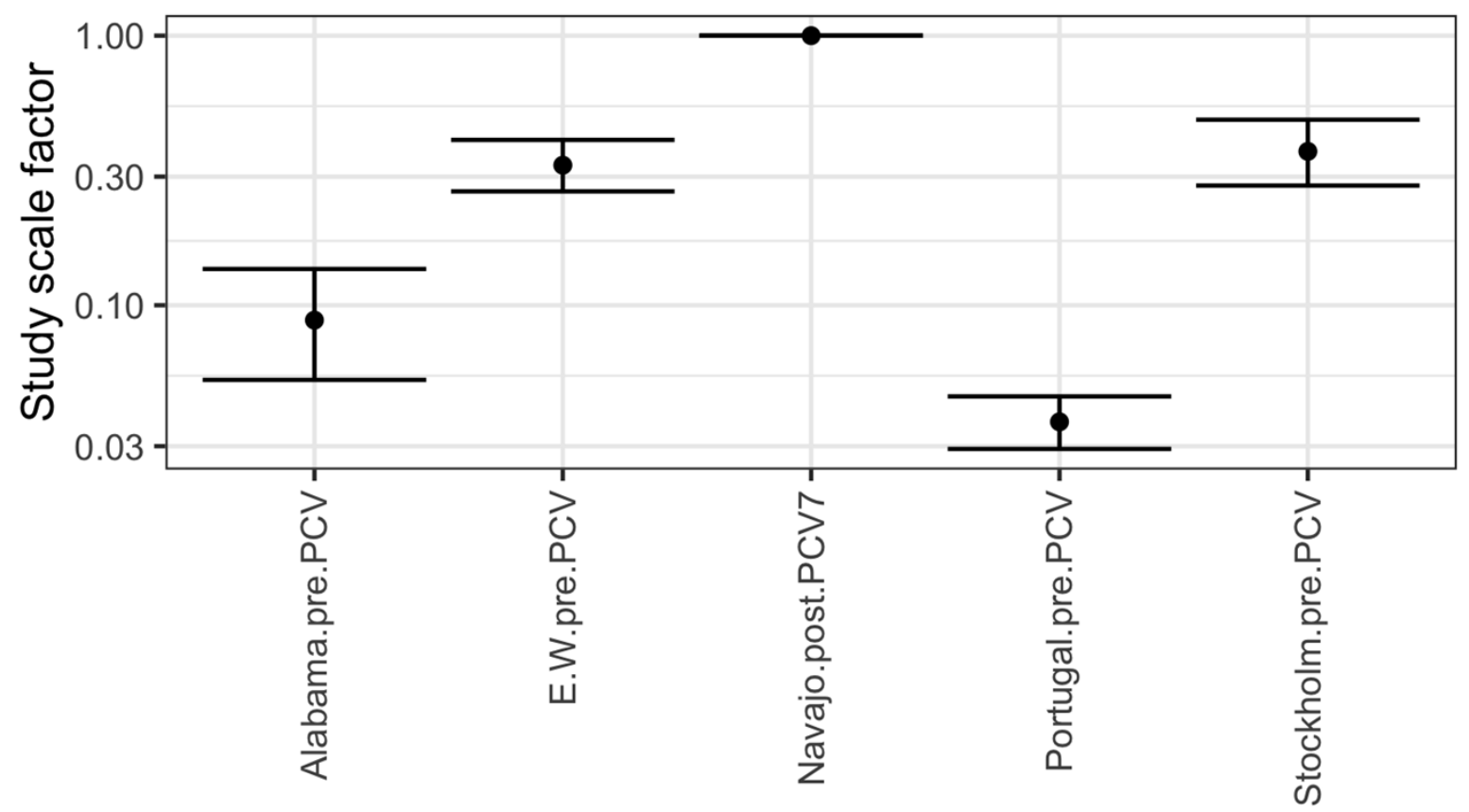

Study

3

Figure S18 Study-adjustment scale factors from the study-adjusted type-specific Poisson model fitted to the full serotype data from child carriage and adult disease. The reference study, for which the value was fixed at one, was the Navajo postPCV7 dataset, which had the greatest sample size in this meta-analysis (Fig. S11). 


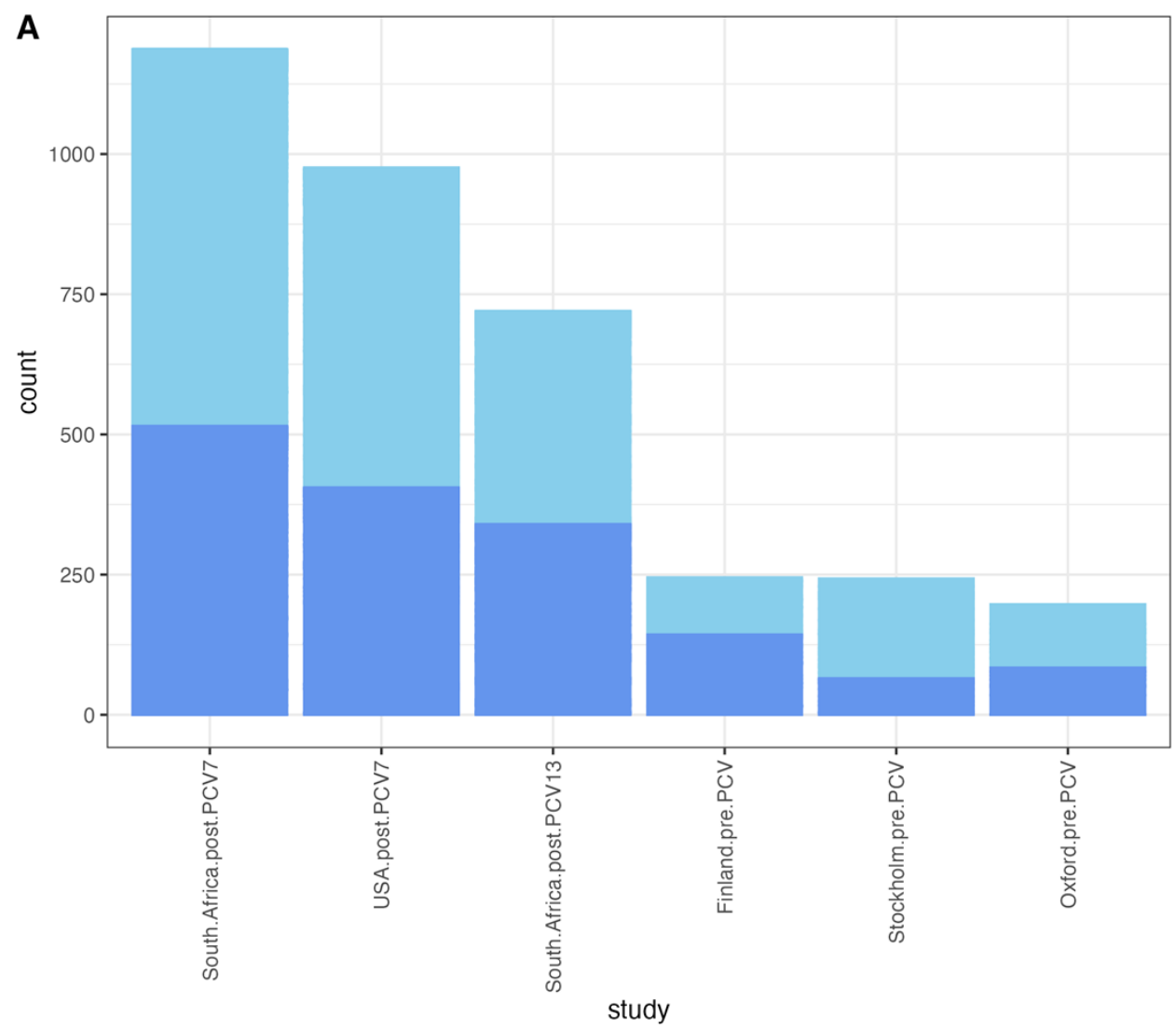

Sample type

carriage

disease

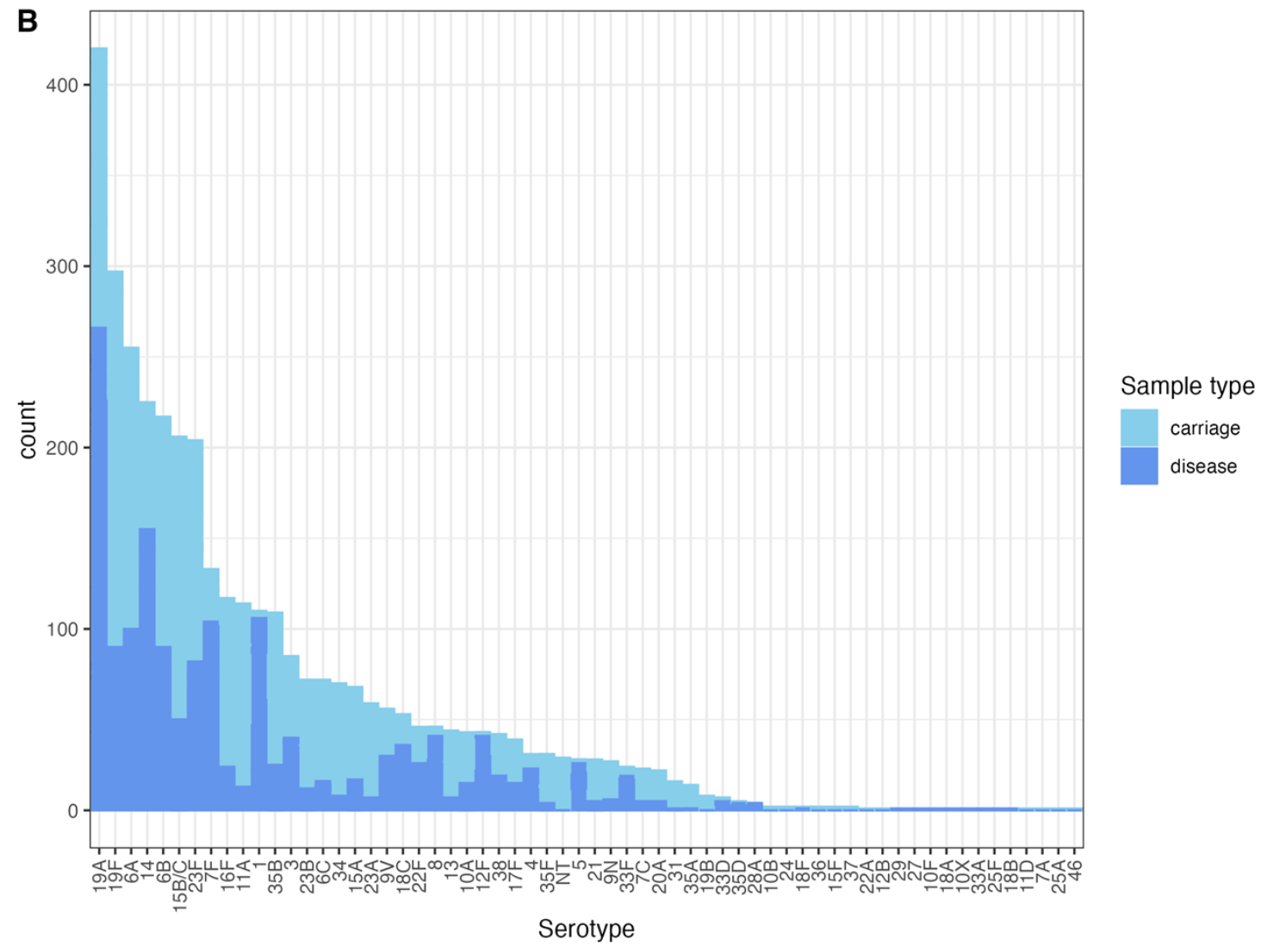

Figure S19 Properties of the child serotype and strain dataset. (A) Stacked bar plot showing the distribution of carriage and disease isolates between studies. (B)

4 Stacked bar plot showing the distribution of carriage and disease isolates between 5 serotypes. 

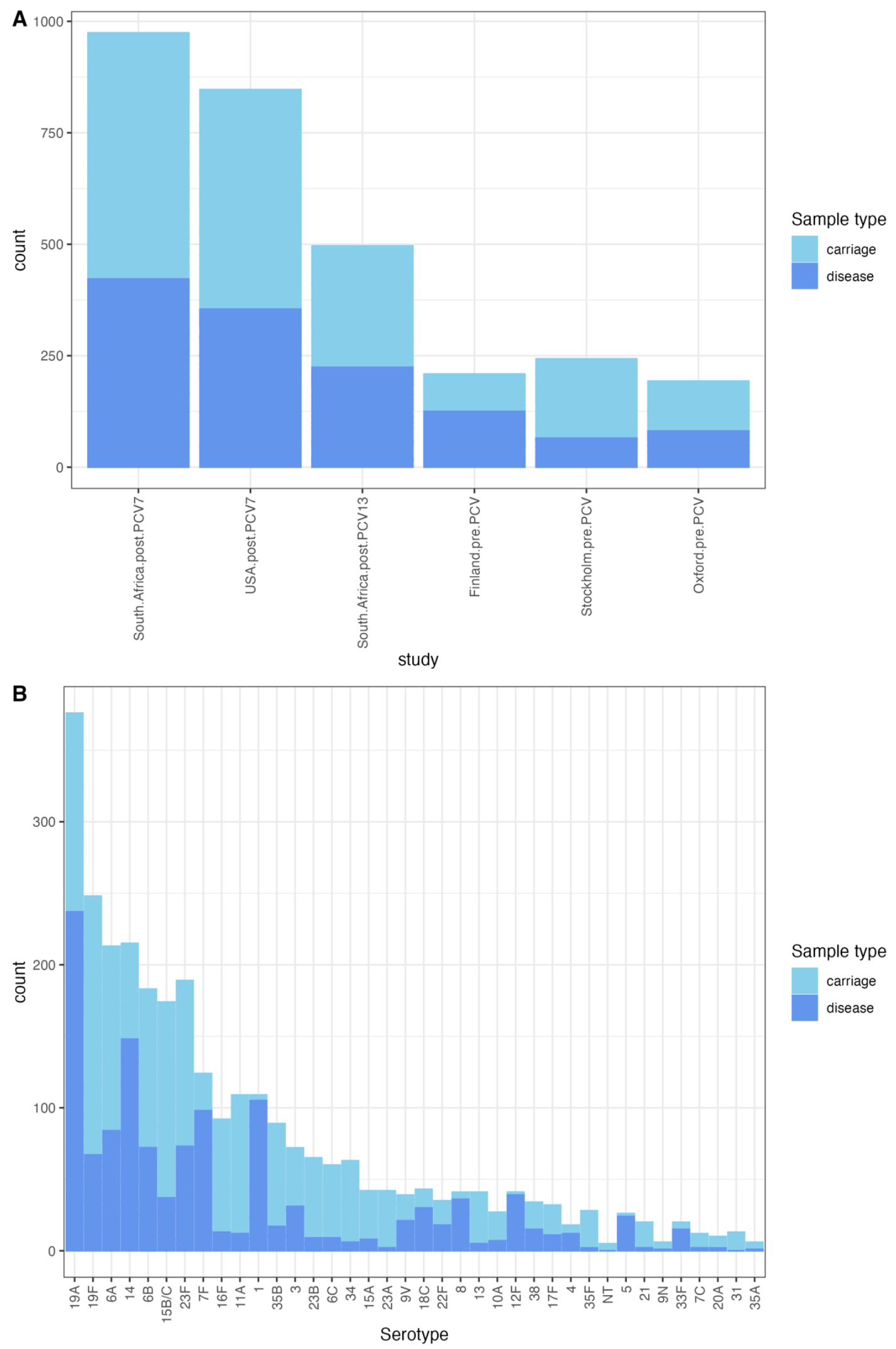

2 Figure $\mathbf{S 2 0}$ Properties of the child serotype and strain dataset after removing 3 datapoints in which fewer than five isolates of a serotype were recorded from both 4 carriage and disease in a given study. (A) Stacked bar plot showing the distribution 5 of carriage and disease isolates between studies. (B) Stacked bar plot showing the 6 distribution of carriage and disease isolates between serotypes. 

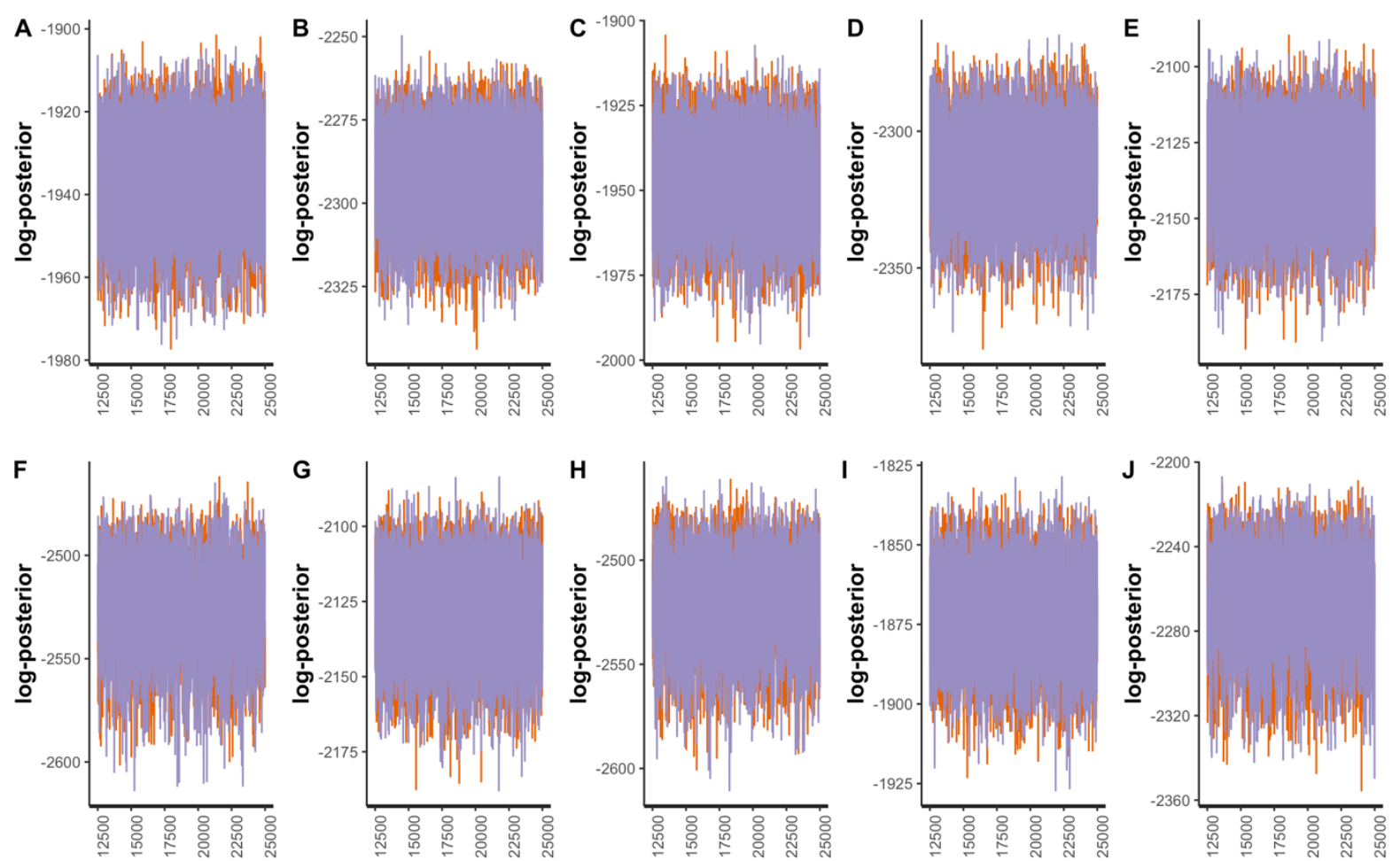

Figure S21 Line plots showing the post-warmup MCMC traces for the logarithmic posterior probabilities across two independent chains for models fitted to the filtered strain and serotype data from child carriage and disease. Each panel corresponds to a model with a different method of associating isolates with an invasiveness estimate: (A) serotype-determined, Poisson-distributed invasiveness; (B) serotypedetermined, negative binomially-distributed invasiveness; (C) strain-determined, Poisson-distributed invasiveness; (D) strain-determined, negative binomiallydistributed invasiveness; (E) serotype-determined, strain-modified Poissondistributed invasiveness; $(F)$ serotype-determined, strain-modified negative binomial model; (G) strain-determined, serotype-modified Poisson-distributed invasiveness; $(\mathrm{H})$ strain-determined, serotype-modified negative binomially-distributed invasiveness; (I) strain- and serotype-determined Poisson-distributed invasiveness; (J) strain- and serotype-determined negative binomially-distributed invasiveness. 

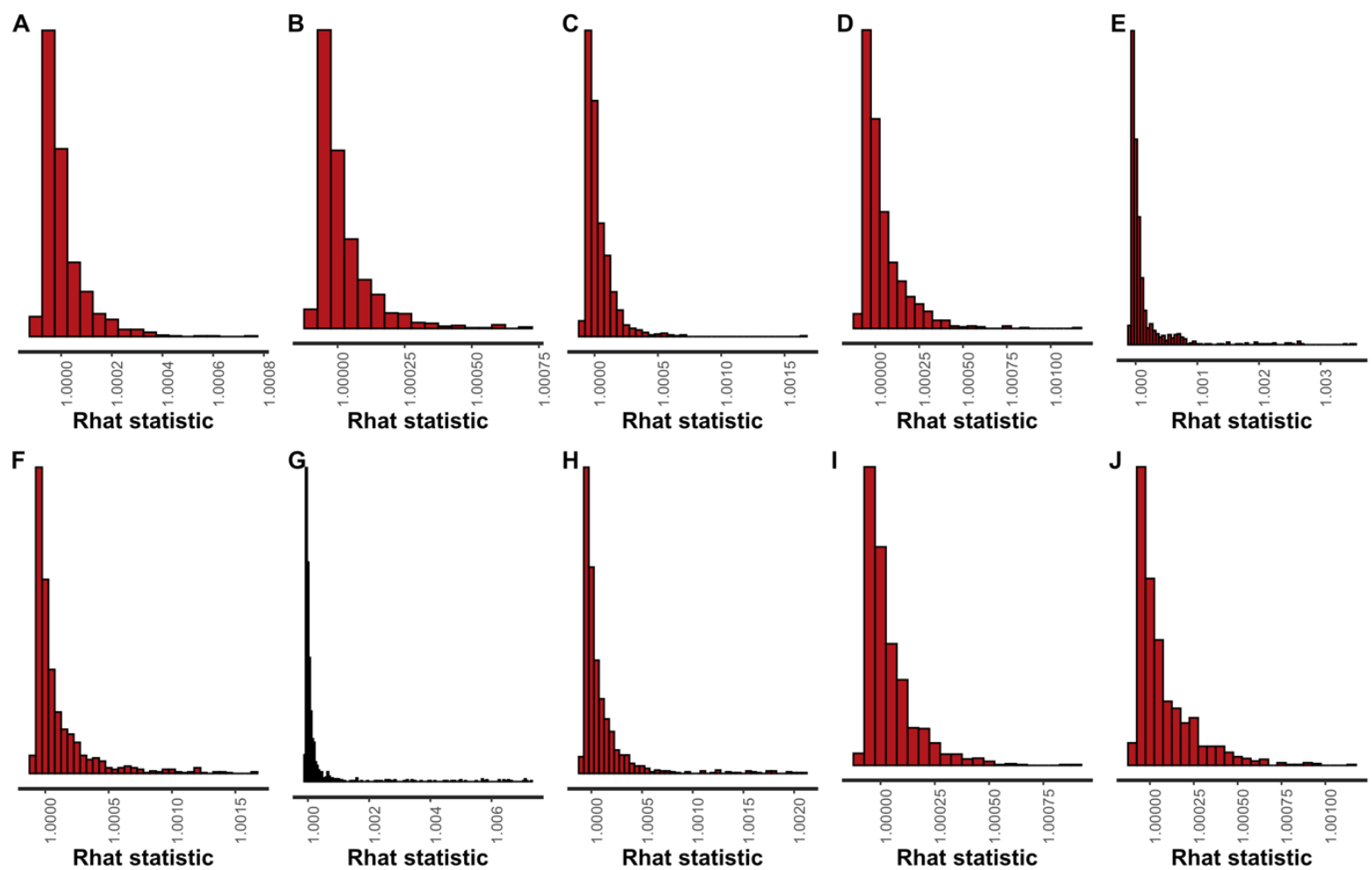

Figure S22 Histograms of Rhat values calculated from paired MCMCs for models fitted to the filtered strain and serotype data from child carriage and disease. Each panel corresponds to a different model: (A) serotype-determined, Poisson-distributed invasiveness; (B) serotype-determined, negative binomially-distributed invasiveness; (C) strain-determined, Poisson-distributed invasiveness; (D) strain-determined, negative binomially-distributed invasiveness; $(E)$ serotype-determined, strainmodified Poisson-distributed invasiveness; ( $F$ ) serotype-determined, strain-modified negative binomial model; (G) strain-determined, serotype-modified Poissondistributed invasiveness; $(\mathrm{H})$ strain-determined, serotype-modified negative binomially-distributed invasiveness; (I) strain- and serotype-determined Poissondistributed invasiveness; $(\mathrm{J})$ strain- and serotype-determined negative binomially13 distributed invasiveness. 
bioRxiv preprint doi: https://doi.org/10.1101/2021.09.01.458483; this version posted September 1, 2021. The copyright holder for this

preprint (which was not certified by peer review) is the author/funder, who has granted bioRxiv a license to display the preprint in perpetuity. It is made available under aCC-BY 4.0 International license.
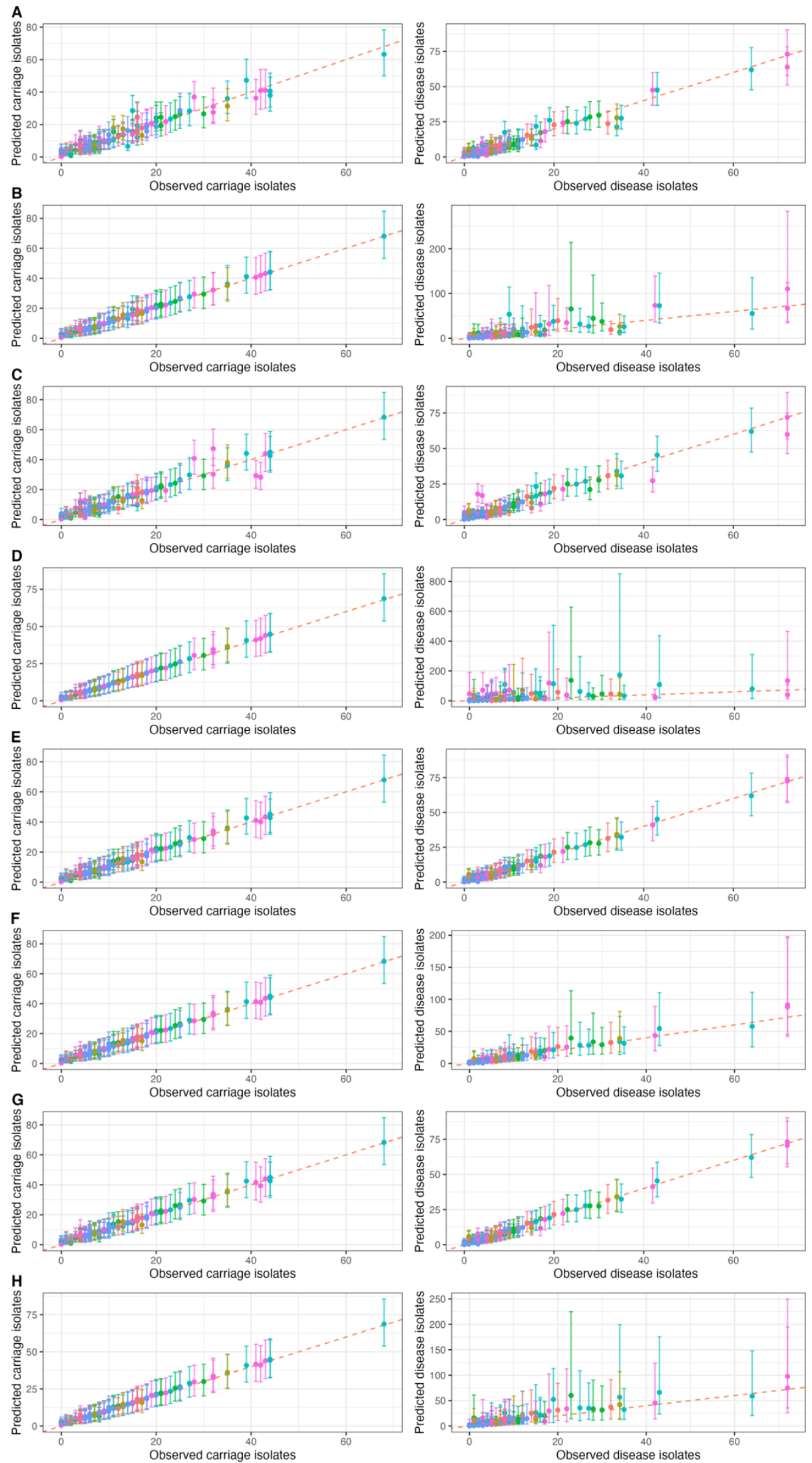

$\rightarrow$ Finland.pre.PCV $\rightarrow$ South.Africa.post.PCV13 $\rightarrow$ Stockholm.pre.PCV

study $\rightarrow$ Oxford.pre.PCV $\rightarrow$ South.Africa.post.PCV7 $\rightarrow$ USA.post.PCV7 
$1 \quad$ Figure $\mathbf{S 2 3}$ Comparison of observed and predicted counts of isolates, categorised

2 by both their serotype and strain background, within each study. The points are

3 coloured by the study to which they correspond, and represent the observed value

4 on the horizontal axis, and the mean predicted value on the vertical axis. The error

5 bars show the $95 \%$ credibility intervals. The red dashed line shows the line of

6 identity, corresponding to a perfect match between prediction and observation. The left column shows the correspondence for carriage data (values of $c_{i . j . k}$ ), and the right column shows the correspondence for disease isolates (values of $d_{i . j . k}$ ). Each row

9 corresponds to a different model: (A) serotype-determined, Poisson-distributed

10 invasiveness; (B) serotype-determined, negative binomially-distributed invasiveness;

11 (C) strain-determined, Poisson-distributed invasiveness; (D) strain-determined,

12 negative binomially-distributed invasiveness; $(E)$ serotype-determined, strain-

13 modified Poisson-distributed invasiveness; (F) serotype-determined, strain-modified

14 negative binomial model; $(G)$ strain-determined, serotype-modified Poissondistributed invasiveness; $(H)$ strain-determined, serotype-modified negative binomially-distributed invasiveness; (I) strain- and serotype-determined Poissondistributed invasiveness; $(\mathrm{J})$ strain- and serotype-determined negative binomially18 distributed invasiveness. 


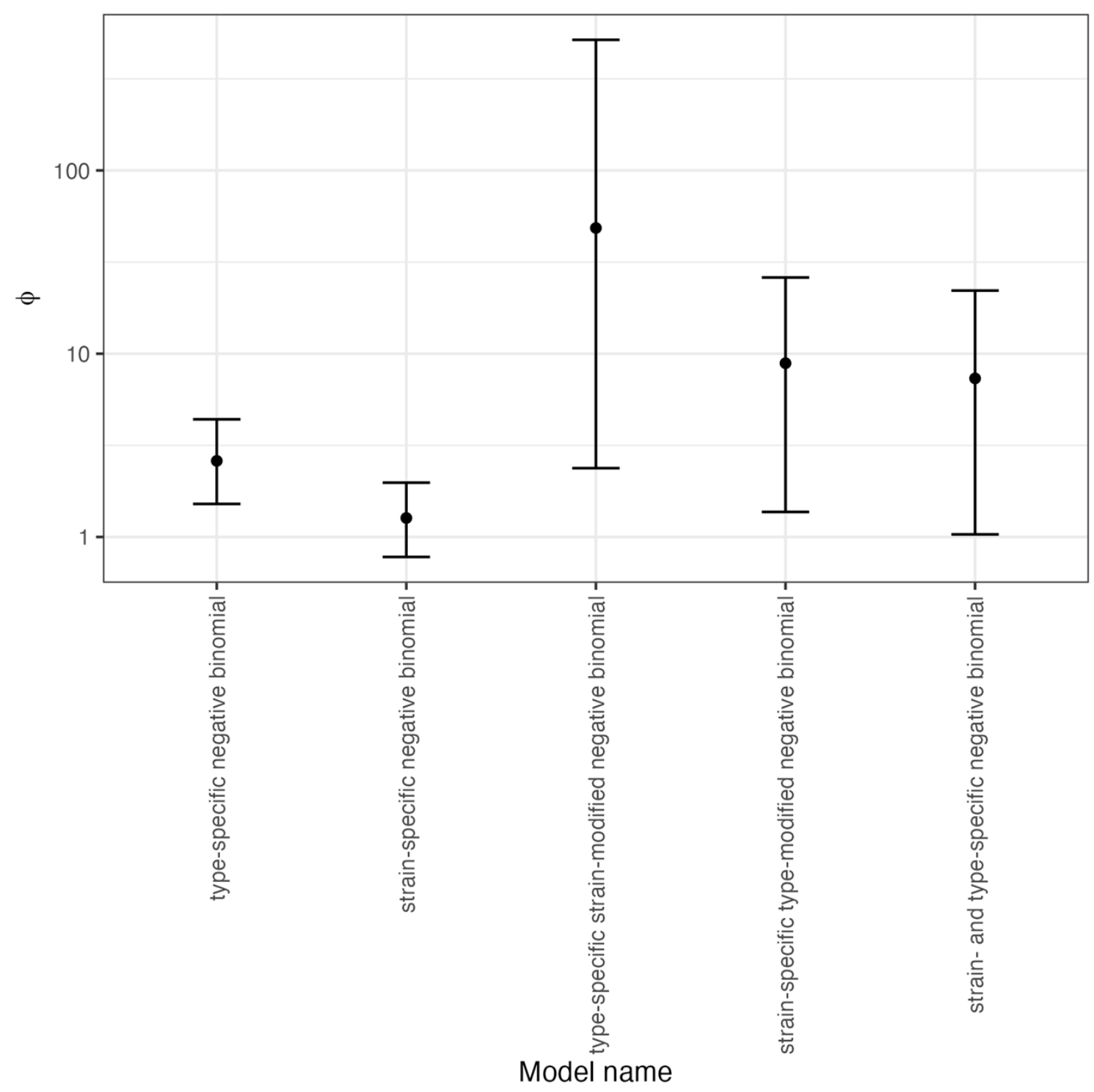

1

Figure S24 Graph showing the values of the negative binomial distribution's precision parameter, $\phi$, from model fits to the filtered strain and serotype data from child carriage and disease. The points represent the mean estimate from the MCMCs, and the error bars show the $95 \%$ credibility interval. 


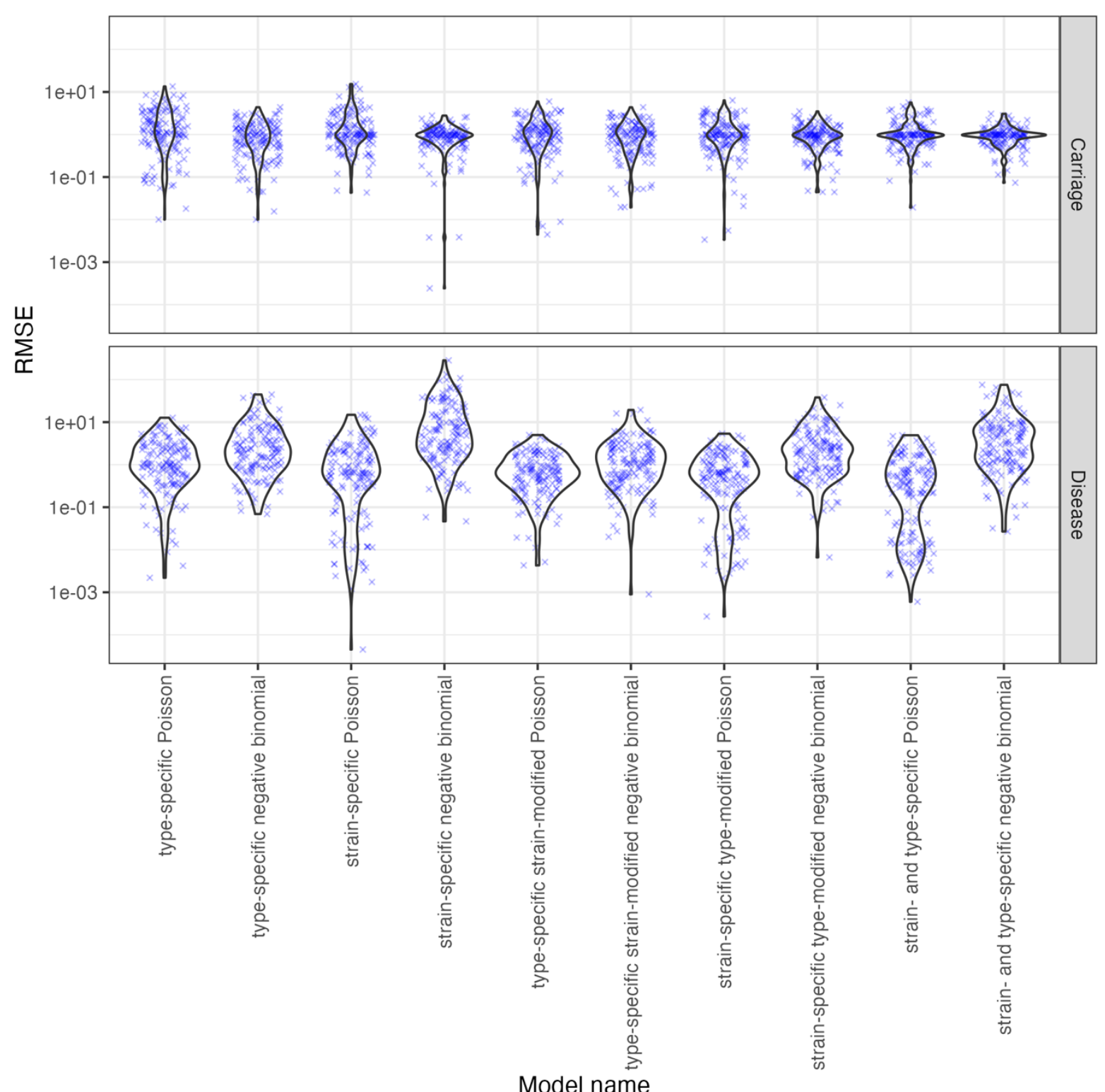

Figure S25 Violin plots showing the root mean square error between observed and predicted values across model fits to the filtered strain and serotype data from child carriage and disease. Blue crosses represent the individual observations. 


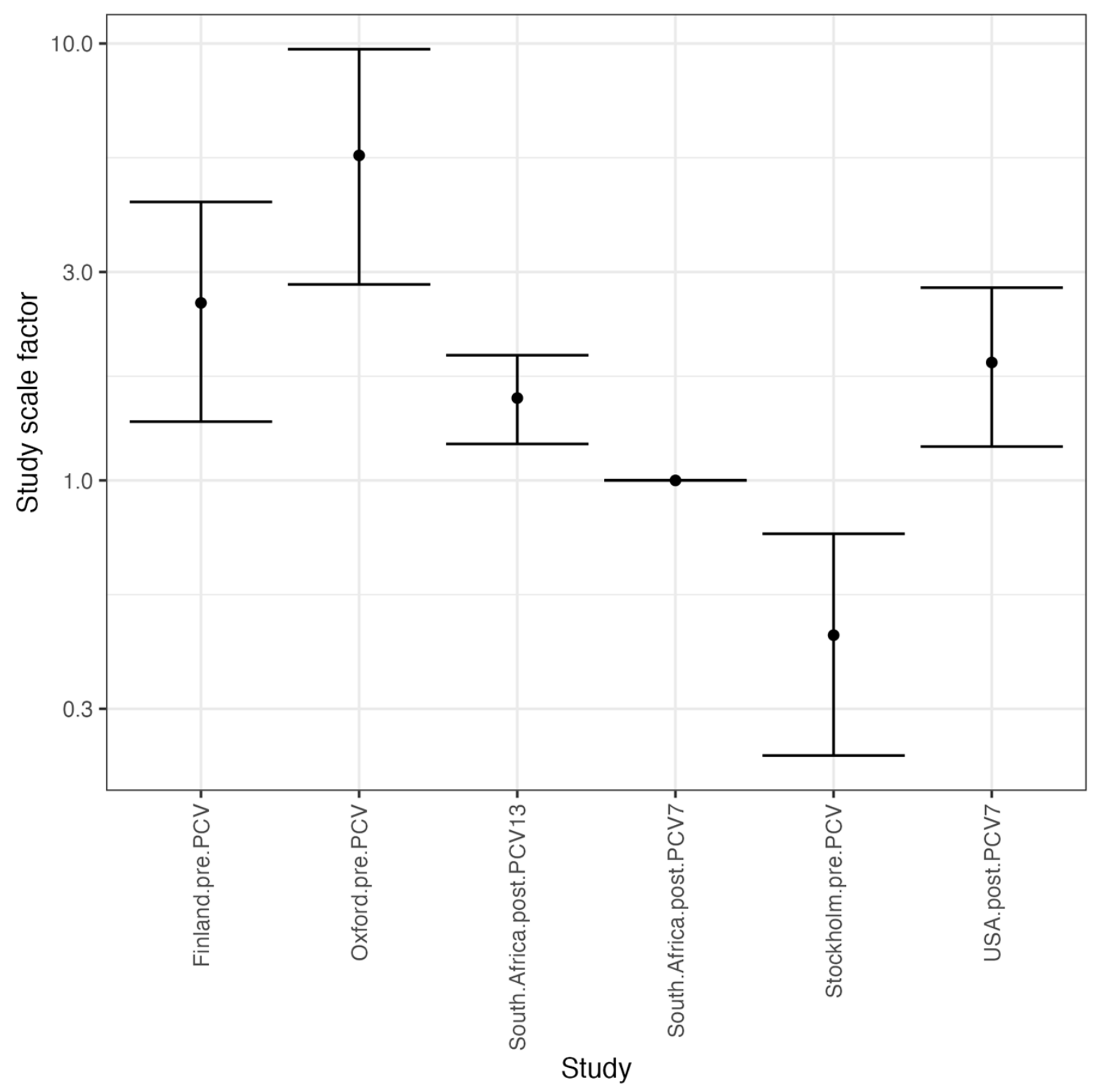

Figure S26 Study-adjustment scale factors from the study-adjusted type-specific Poisson model fitted to the full serotype and strain data from child carriage and disease, with the combination of both serotype and strain determining an isolate's invasiveness. The reference study, for which the value was fixed at one, was the 6 South Africa post-PCV7 dataset, which had the greatest sample size in this meta7 analysis, and was associated with a known carriage sample size (Text S1). 
A

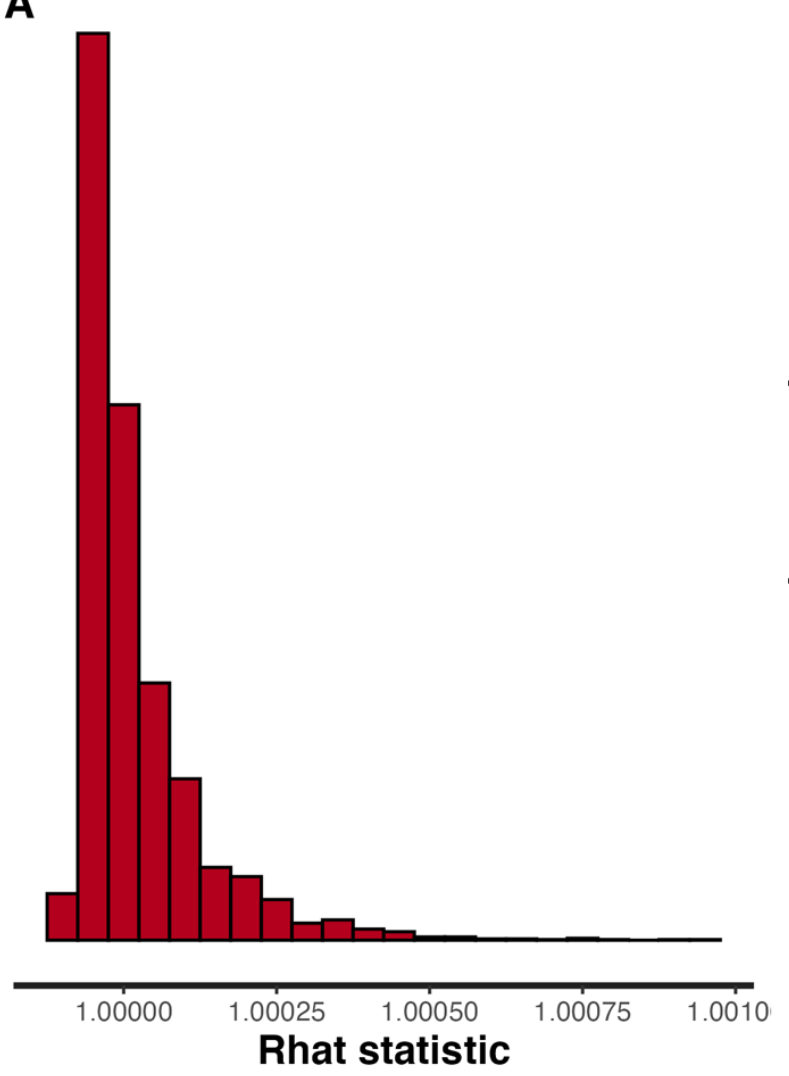

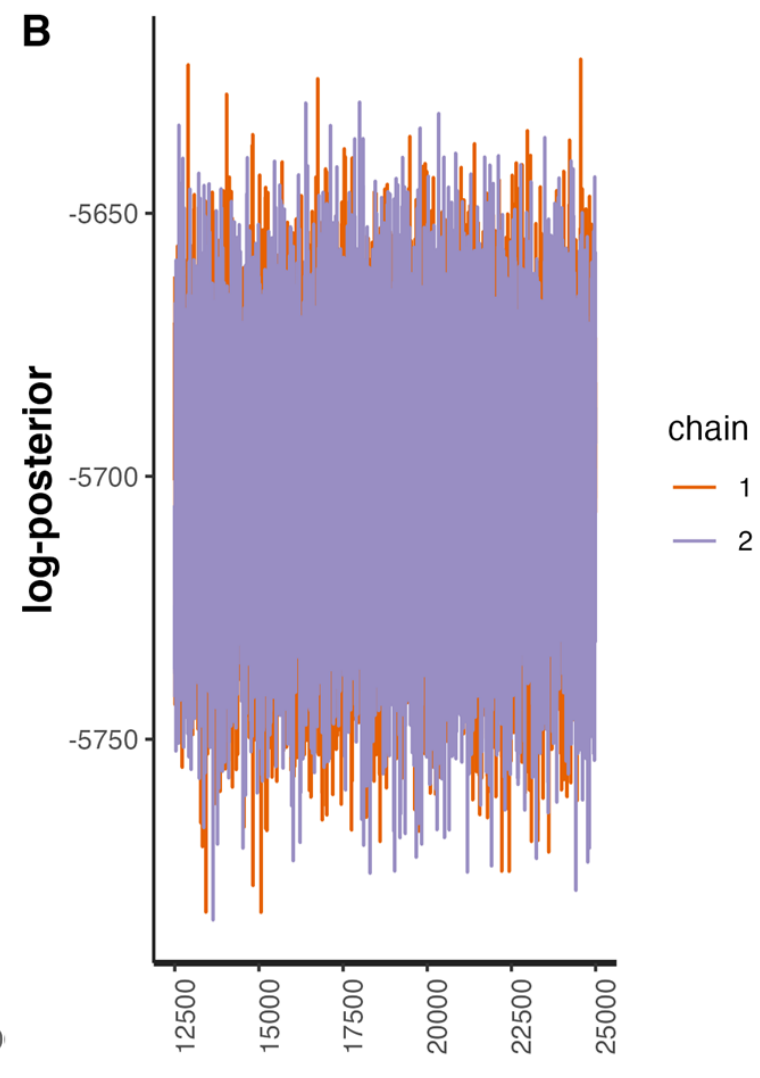

Figure S27 Plots validating the fit of the study-adjusted type-specific Poisson model to the full strain and serotype data from child carriage and disease, with the combination of both serotype and strain determining an isolate's invasiveness. (A) Histogram showing the distribution of Rhat values. (B) Post-warmup MCMC traces of the log posterior probability. 


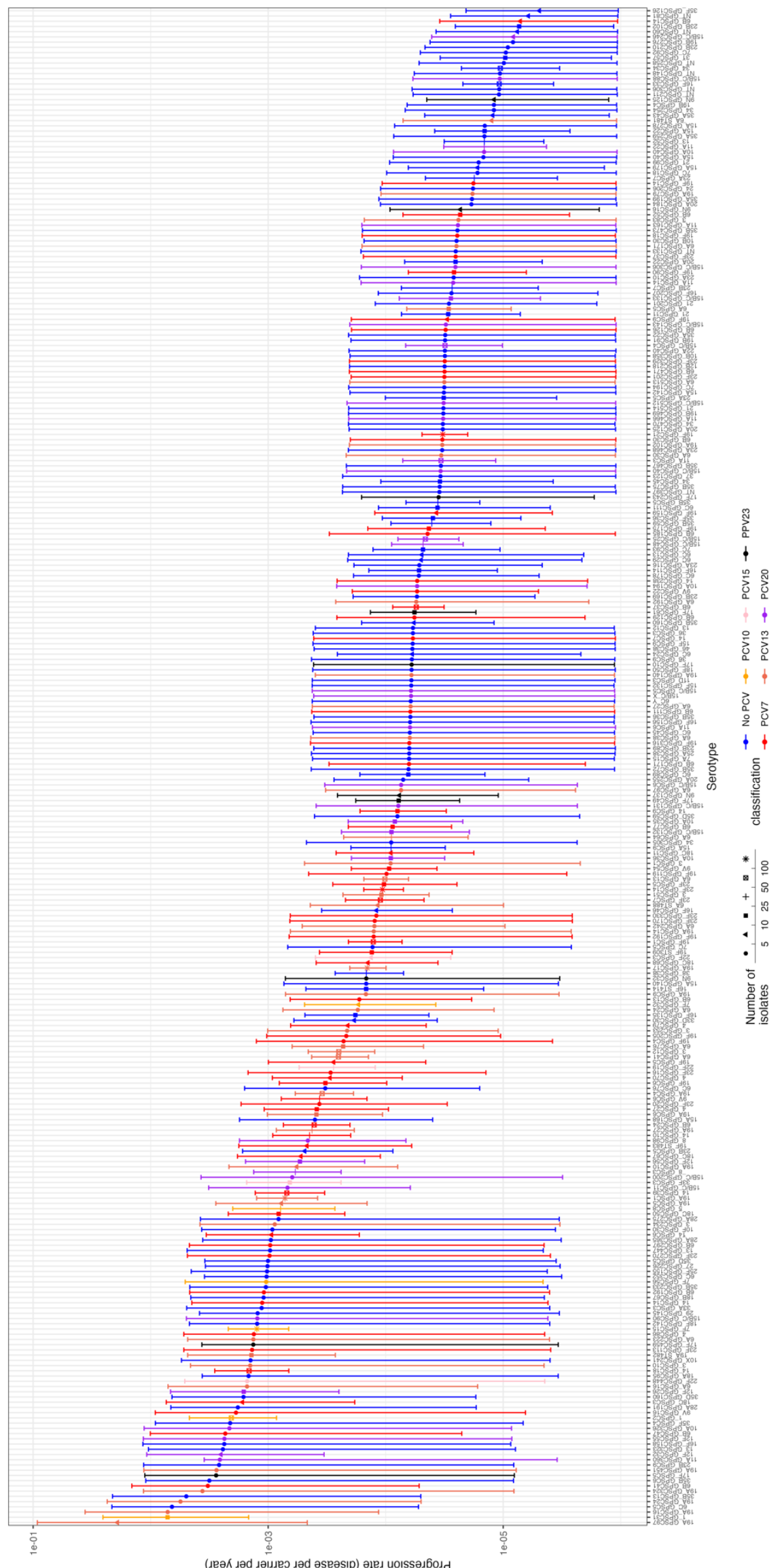

Figure S28 Invasiveness estimates for all strain and serotype combinations in the 3 full strain and serotype dataset from child carriage and disease. 


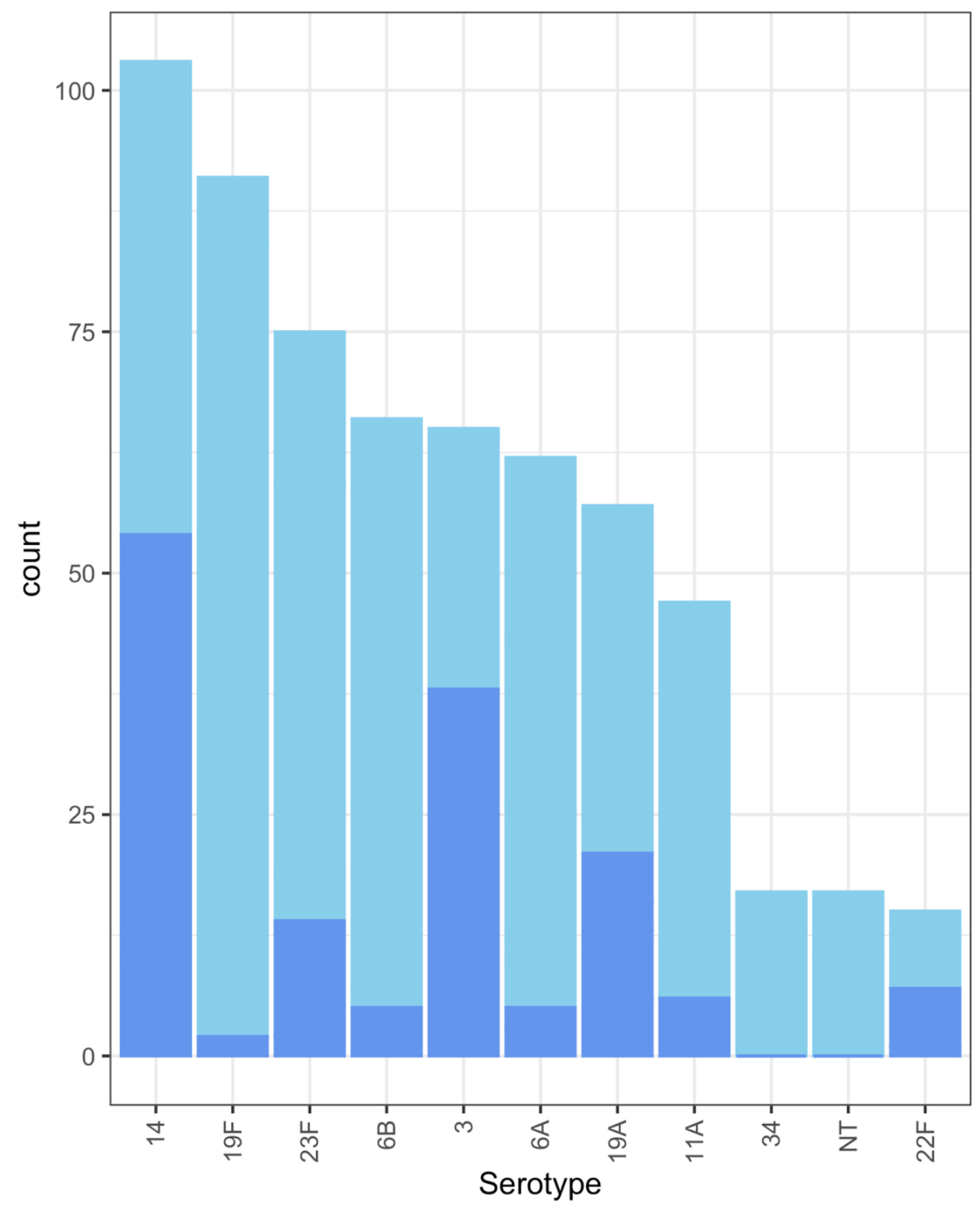

Sample type

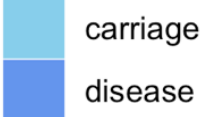

Figure S29 Bar plot showing the distribution of carriage and disease isolates between serotypes for the dataset from Portugal comparing child carriage with primarily adult disease. 
A

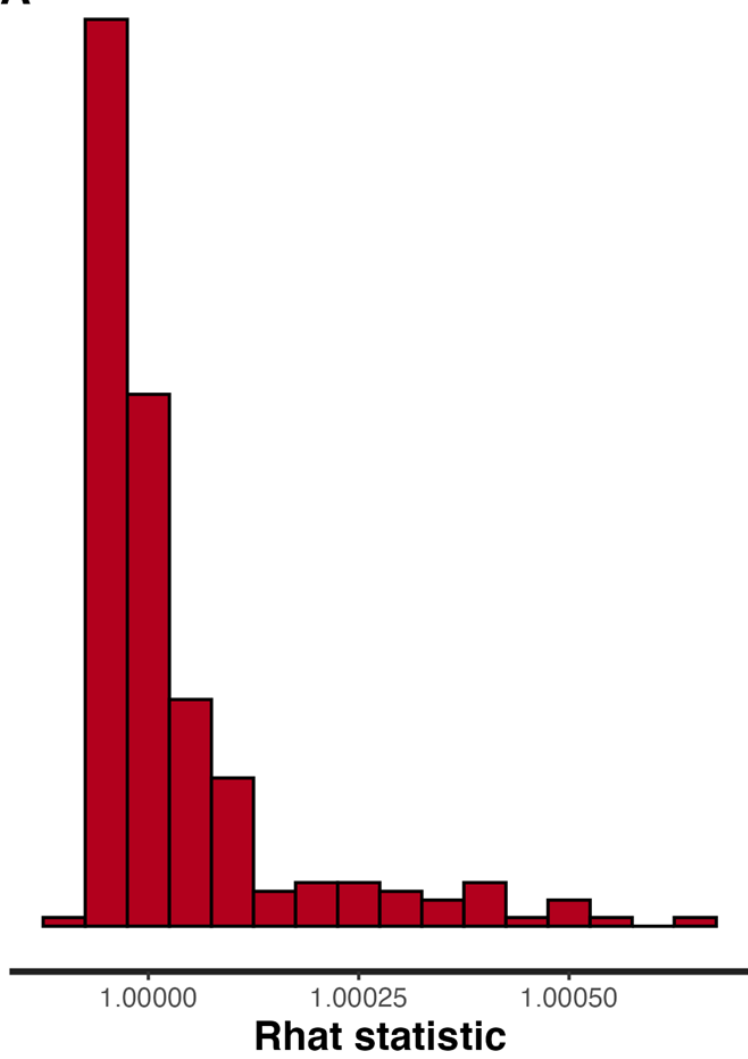

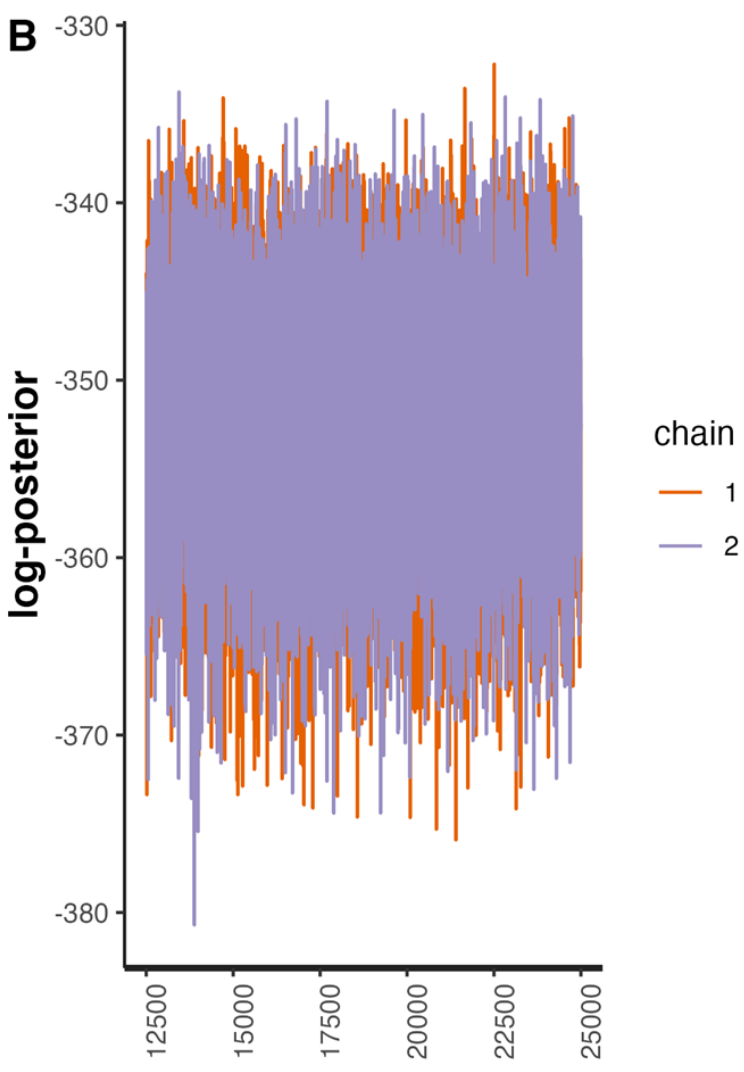

Figure S30 Plots validating the fit of the type-specific Poisson model to the strain and serotype data from child carriage and adult disease, with the combination of both serotype and strain determining an isolate's invasiveness. (A) Histogram showing the distribution of Rhat values. (B) Post-warmup MCMC traces of the log posterior probability. 

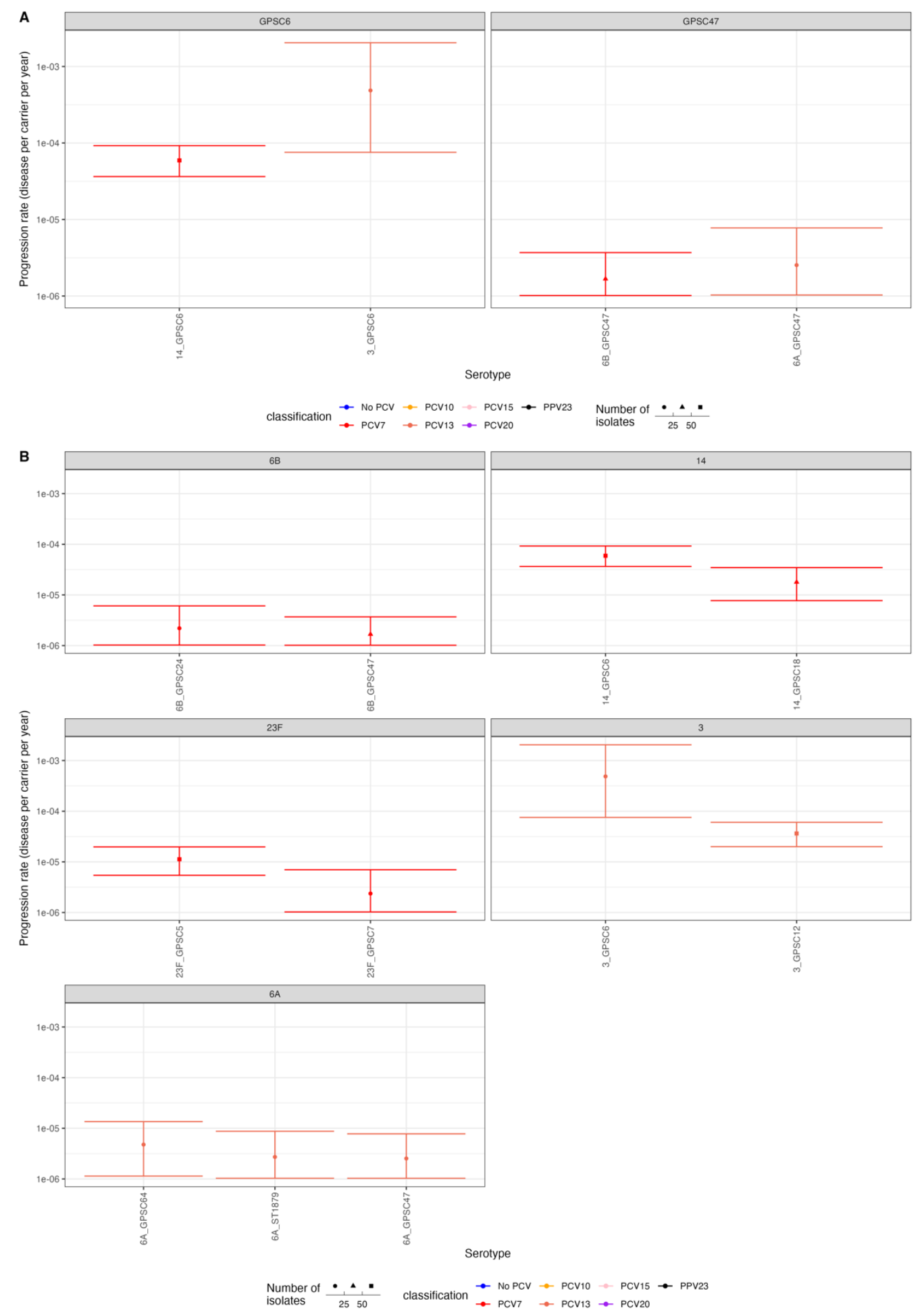

Figure S31 Invasiveness estimates for strain and serotype combinations represented by at least ten isolates in the study of child carriage and adult disease. Points represent the mean estimate, and are coloured by the vaccine formulations in which the corresponding serotype is present. The shape of the point represents the sample size on which the estimate is based. (A) Estimates are shown grouped by strain. Only strains for which estimates of multiple strain and serotype combinations were possible are displayed. (B) Estimates are shown grouped by serotype. Only serotypes for which estimates of multiple strain and serotype combinations were possible are displayed. 


\begin{tabular}{|c|c|c|c|c|c|c|c|c|c|c|}
\hline Population & $\begin{array}{l}\text { Vaccine } \\
\text { period }\end{array}$ & $\begin{array}{l}\text { Carriage } \\
\text { study time } \\
\text { interval }\end{array}$ & $\begin{array}{l}\text { Carriage } \\
\text { isolate source }\end{array}$ & $\begin{array}{l}\text { Disease isolate } \\
\text { source }\end{array}$ & $\begin{array}{l}\text { No. of } \\
\text { swabs }\end{array}$ & $\begin{array}{l}\text { Population } \\
\text { of children }\end{array}$ & $\begin{array}{l}\text { No. } \\
\text { disease } \\
\text { isolates } \\
\text { from } \\
\text { children }\end{array}$ & $\begin{array}{l}\text { Population } \\
\text { of adults }\end{array}$ & $\begin{array}{l}\text { No. } \\
\text { disease } \\
\text { isolates } \\
\text { from } \\
\text { adults } \\
\end{array}$ & References \\
\hline Alabama & $\begin{array}{l}\text { Pre- } \\
\text { PCV }\end{array}$ & $\begin{array}{l}\text { July } 1975 \text { - } \\
\text { December } \\
1978\end{array}$ & $\begin{array}{l}\text { Unvaccinated } \\
\text { sick and healthy } \\
\text { children }<18 \\
\text { years old from } \\
\text { Alabama }\end{array}$ & $\begin{array}{l}\text { Unvaccinated } \\
\text { children with } \\
\text { IPD <18 years } \\
\text { old from } \\
\text { Alabama and } \\
\text { unvaccinated } \\
\text { adults } \\
\text { hospitalised with } \\
\text { pneumonia or } \\
\text { IPD in Alabama }\end{array}$ & 827 & 19,316 & 114 & 232,373 & 86 & {$[114,115]$} \\
\hline Atlanta & $\begin{array}{l}\text { Pre- } \\
\text { PCV }\end{array}$ & $\begin{array}{l}\text { January - } \\
\text { December } \\
1995\end{array}$ & $\begin{array}{l}\text { Unvaccinated } \\
\text { children with } \\
\text { recent URI in } \\
\text { Atlanta }<5 \text { years } \\
\text { old }\end{array}$ & $\begin{array}{l}\text { Unvaccinated } \\
\text { children }<5 \\
\text { years old with } \\
\text { IPD in Atlanta }\end{array}$ & 231 & 204,680 & 202 & - & - & [116] \\
\hline Bogota & $\begin{array}{l}\text { Pre- } \\
\text { PCV }\end{array}$ & $\begin{array}{l}\text { May } 2005 \text { - } \\
\text { November } \\
2006\end{array}$ & $\begin{array}{l}\text { Healthy } \\
\text { unvaccinated } \\
\text { children }<18 \\
\text { months old in } \\
\text { Bogota }\end{array}$ & $\begin{array}{l}\text { IPD in children } \\
<2 \text { years old in } \\
\text { Bogota }\end{array}$ & 197 & 357,200 & 353 & - & - & [117] \\
\hline Caracas & $\begin{array}{l}\text { Pre- } \\
\text { PCV }\end{array}$ & $\begin{array}{l}\text { December } \\
2006 \text { - } \\
\text { January } \\
2008\end{array}$ & $\begin{array}{l}\text { Unvaccinated } \\
\text { healthy children } \\
<6 \text { years old in } \\
\text { Caracas }\end{array}$ & $\begin{array}{l}\text { Unvaccinated } \\
\text { children with } \\
\text { IPD }<6 \text { years old } \\
\text { in Caracas }\end{array}$ & 1,004 & 146,125 & 36 & - & - & {$[118,119]$} \\
\hline Czech & $\begin{array}{l}\text { Pre- } \\
\text { PCV }\end{array}$ & $\begin{array}{l}1996- \\
2005\end{array}$ & $\begin{array}{l}\text { Unvaccinated } \\
\text { healthy children } \\
3-5 \text { years old } \\
\text { across the } \\
\text { Czech Republic }\end{array}$ & $\begin{array}{l}\text { Unvaccinated } \\
\text { children }<6 \\
\text { years old with } \\
\text { IPD across the } \\
\text { Czech Republic }\end{array}$ & 425 & 478,177 & 138 & - & - & {$[120,121]$} \\
\hline $\begin{array}{l}\text { England \& } \\
\text { Wales }\end{array}$ & $\begin{array}{l}\text { Pre- } \\
\text { PCV }\end{array}$ & $\begin{array}{l}\text { July } 1996- \\
\text { June } 2006\end{array}$ & $\begin{array}{l}\text { Unvaccinated } \\
\text { healthy children }\end{array}$ & $\begin{array}{l}\text { Unvaccinated } \\
\text { children }<5\end{array}$ & 3,752 & $3,091,000$ & 461 & $48,702,414$ & 1,876 & [122] \\
\hline
\end{tabular}




\begin{tabular}{|c|c|c|c|c|c|c|c|c|c|c|}
\hline & & & $\begin{array}{l}<5 \text { years old in } \\
\text { Hertfordshire }\end{array}$ & $\begin{array}{l}\text { years old across } \\
\text { and } \\
\text { predominantly } \\
\text { unvaccinated } \\
\text { individuals }>4 \\
\text { years old across } \\
\text { England \& } \\
\text { Wales }\end{array}$ & & & & & & \\
\hline Goroka & $\begin{array}{l}\text { Pre- } \\
\text { PCV }\end{array}$ & $\begin{array}{l}1981- \\
1987\end{array}$ & $\begin{array}{l}\text { Unvaccinated } \\
\text { children } \\
\text { attending clinics } \\
\text { near Goroka } \\
\text { Town }\end{array}$ & $\begin{array}{l}\text { Unvaccinated } \\
\text { children with } \\
\text { IPD in Goroka } \\
\text { hospital }\end{array}$ & 2,844 & 96,207 & 56 & - & - & {$[28,123]$} \\
\hline Morocco & $\begin{array}{l}\text { Pre- } \\
\text { PCV }\end{array}$ & $\begin{array}{l}\text { November } \\
2010- \\
\text { December } \\
2011\end{array}$ & $\begin{array}{l}\text { Unvaccinated } \\
\text { healthy children } \\
\text { in Rabat }\end{array}$ & $\begin{array}{l}\text { Children } \\
\text { hospitalised with } \\
\text { severe } \\
\text { pneumonia in } \\
\text { Rabat }<5 \text { years } \\
\text { old }\end{array}$ & 200 & 212,566 & 118 & - & - & {$[124,125]$} \\
\hline Netherlands & $\begin{array}{l}\text { Pre- } \\
\text { PCV }\end{array}$ & $\begin{array}{l}\text { June } 2004 \\
\text { - May } 2006\end{array}$ & $\begin{array}{l}\text { Unvaccinated } \\
\text { healthy children } \\
<2 \text { years old in } \\
\text { Noord-Holland, } \\
\text { Zuid-Holland } \\
\text { and Utrecht }\end{array}$ & $\begin{array}{l}\text { Children }<5 \\
\text { years with IPD } \\
\text { across } \\
\text { Netherlands }\end{array}$ & 321 & 250,924 & 100 & - & - & {$[126,127]$} \\
\hline Ontario & $\begin{array}{l}\text { Pre- } \\
\text { PCV }\end{array}$ & 1995 & $\begin{array}{l}\text { Unvaccinated } \\
\text { healthy children } \\
\text { primarily }<4 \\
\text { years old in } \\
\text { Toronto }\end{array}$ & $\begin{array}{l}\text { Unvaccinated } \\
\text { children }<18 \\
\text { years old with } \\
\text { IPD in Toronto } \\
\text { and surrounding } \\
\text { area }\end{array}$ & 1,139 & 580,507 & 89 & - & - & [128] \\
\hline Portugal & $\begin{array}{l}\text { Pre- } \\
\text { PCV }\end{array}$ & $\begin{array}{l}\text { January } \\
2001- \\
\text { December } \\
2003\end{array}$ & $\begin{array}{l}\text { Unvaccinated } \\
\text { healthy children } \\
<7 \text { years old in } \\
\text { Lisbon and } \\
\text { Oeiras }\end{array}$ & $\begin{array}{l}\text { Unvaccinated } \\
\text { children }(<18 \\
\text { years) and } \\
\text { adults ( }>18 \\
\text { years) across } \\
\text { Portugal }\end{array}$ & 1,170 & $2,071,223$ & 90 & $8,284,894$ & 378 & {$[52,129]$} \\
\hline
\end{tabular}




\begin{tabular}{|c|c|c|c|c|c|c|c|c|c|c|}
\hline Stockholm & $\begin{array}{l}\text { Pre- } \\
\text { PCV }\end{array}$ & 1997 & $\begin{array}{l}\text { Unvaccinated } \\
\text { healthy children } \\
<7 \text { years old in } \\
\text { Stockholm }\end{array}$ & $\begin{array}{l}\text { Unvaccinated } \\
\text { adults (and a } \\
\text { small number of } \\
\text { children) } \\
\text { hospitalised with } \\
\text { IPD in } \\
\text { Stockholm }\end{array}$ & 611 & - & - & $2,004,152$ & 273 & {$[130,131]$} \\
\hline Atlanta & $\begin{array}{l}\text { Post- } \\
\text { PCV7 }\end{array}$ & $\begin{array}{l}\text { June } 2008 \\
\text { - May } 2009\end{array}$ & $\begin{array}{l}\text { PCV7- } \\
\text { vaccinated sick } \\
\text { Georgia- } \\
\text { resident children } \\
<5 \text { years old }\end{array}$ & $\begin{array}{l}\text { PCV7- } \\
\text { vaccinated } \\
\text { children }<5 \\
\text { years old with } \\
\text { IPD in Atlanta }\end{array}$ & 451 & 298,831 & 47 & - & - & [116] \\
\hline Barcelona & $\begin{array}{l}\text { Post- } \\
\text { PCV7 }\end{array}$ & $\begin{array}{l}2007- \\
2011\end{array}$ & $\begin{array}{l}\text { PCV7- } \\
\text { vaccinated } \\
\text { healthy children } \\
<7 \text { years old in } \\
\text { Barcelona }\end{array}$ & $\begin{array}{l}\text { PCV7- } \\
\text { vaccinated } \\
\text { children }<7 \\
\text { years old with } \\
\text { IPD in } \\
\text { Barcelona }\end{array}$ & 209 & 228,000 & 159 & - & - & [132] \\
\hline Bogota & $\begin{array}{l}\text { Post- } \\
\text { PCV7 }\end{array}$ & $\begin{array}{l}\text { June - } \\
\text { November } \\
2011\end{array}$ & $\begin{array}{l}\text { PCV7- } \\
\text { vaccinated } \\
\text { healthy children } \\
<18 \text { months old } \\
\text { in Bogota }\end{array}$ & $\begin{array}{l}\text { IPD in children } \\
<2 \text { years old in } \\
\text { Bogota }\end{array}$ & 246 & 357,200 & 91 & - & - & [117] \\
\hline France & $\begin{array}{l}\text { Post- } \\
\text { PCV7 }\end{array}$ & $\begin{array}{l}\text { January } \\
2008- \\
\text { December } \\
2009\end{array}$ & $\begin{array}{l}\text { PCV7- } \\
\text { vaccinated } \\
\text { healthy children } \\
<2 \text { years old } \\
\text { across France }\end{array}$ & $\begin{array}{l}\text { PCV7- } \\
\text { vaccinated } \\
\text { children with } \\
\text { IPD <2 years old } \\
\text { across France }\end{array}$ & 1,212 & 838,866 & 388 & - & - & {$[133,134]$} \\
\hline Massachusetts & $\begin{array}{l}\text { Post- } \\
\text { PCV7 }\end{array}$ & $\begin{array}{l}2001- \\
\text { April } 2009\end{array}$ & $\begin{array}{l}\text { PCV7- } \\
\text { vaccinated } \\
\text { children visiting } \\
\text { physicians }<7 \\
\text { years old across } \\
\text { Massachusetts } \\
\end{array}$ & $\begin{array}{l}\text { PCV7- } \\
\text { vaccinated } \\
\text { children }<7 \\
\text { years with IPD } \\
\text { old across } \\
\text { Massachusetts }\end{array}$ & 2,969 & 820,000 & 206 & - & & [135] \\
\hline Navajo & $\begin{array}{l}\text { Post- } \\
\text { PCV7 }\end{array}$ & $\begin{array}{l}\text { March } 2006 \\
\text { - March } \\
2008\end{array}$ & $\begin{array}{l}\text { PCV7- } \\
\text { vaccinated } \\
\text { Navajo or White } \\
\text { Mountain }\end{array}$ & $\begin{array}{l}\text { Active IPD } \\
\text { surveillance of } \\
\text { PCV7- } \\
\text { vaccinated }\end{array}$ & 6,541 & 65,048 & 132 & 201,553 & 514 & {$[37,39,136]$} \\
\hline
\end{tabular}




\begin{tabular}{|c|c|c|c|c|c|c|c|c|c|c|}
\hline & & & $\begin{array}{l}\text { Apache native } \\
\text { American } \\
\text { children }<9 \\
\text { years old }\end{array}$ & $\begin{array}{l}\text { Navajo or White } \\
\text { Mountain } \\
\text { Apache native } \\
\text { American } \\
\text { children }<7 \\
\text { years old and } \\
\text { people at least } \\
18 \text { years old }\end{array}$ & & & & & & \\
\hline Netherlands & $\begin{array}{l}\text { Post- } \\
\text { PCV7 }\end{array}$ & $\begin{array}{l}\text { June } 2008 \\
\text { - May } 2012\end{array}$ & $\begin{array}{l}\text { Vaccinated } \\
\text { healthy children } \\
<2 \text { years old in } \\
\text { Noord-Holland, } \\
\text { Zuid-Holland } \\
\text { and Utrecht }\end{array}$ & $\begin{array}{l}\text { IPD in children } \\
\text { (<5 years) } \\
\text { across } \\
\text { Netherlands }\end{array}$ & 660 & 232,251 & 73 & - & - & {$[126,127]$} \\
\hline France & $\begin{array}{l}\text { Post- } \\
\text { PCV13 }\end{array}$ & $\begin{array}{l}\text { January } \\
2012- \\
\text { December } \\
2013\end{array}$ & $\begin{array}{l}\text { PCV13- } \\
\text { vaccinated } \\
\text { healthy children } \\
<2 \text { years old } \\
\text { across France }\end{array}$ & $\begin{array}{l}\text { PCV13- } \\
\text { vaccinated } \\
\text { children with } \\
\text { IPD <2 years old } \\
\text { across France }\end{array}$ & 1,212 & 842,076 & 181 & - & - & {$[133,134]$} \\
\hline Netherlands & $\begin{array}{l}\text { Post- } \\
\text { PCV10 }\end{array}$ & $\begin{array}{l}\text { June } 2012 \\
\text { - May } 2016\end{array}$ & $\begin{array}{l}\text { Vaccinated } \\
\text { healthy children } \\
<2 \text { years old in } \\
\text { Noord-Holland, } \\
\text { Zuid-Holland } \\
\text { and Utrecht }\end{array}$ & $\begin{array}{l}\text { IPD in children } \\
\text { (<5 years) } \\
\text { across } \\
\text { Netherlands }\end{array}$ & 659 & 222,671 & 47 & - & - & {$[126,127]$} \\
\hline
\end{tabular}

2 Table S1: Study populations used for the joint analysis of strain and serotype invasiveness. 


\begin{tabular}{|l|r|r|}
\hline & ELPD & $\begin{array}{l}\text { ELPD } \\
\text { difference } \\
\text { standard } \\
\text { Model }\end{array}$ \\
\hline $\begin{array}{l}\text { study-adjusted type-specific } \\
\text { Poisson }\end{array}$ & 0 & 0 \\
\hline $\begin{array}{l}\text { study-adjusted type-specific } \\
\text { negative binomial }\end{array}$ & -11.61731 & 13.49535 \\
\hline type-specific negative binomial & -179.09155 & 23.2183 \\
\hline study-adjusted negative binomial & -239.06206 & 25.67848 \\
\hline null negative binomial & -283.58518 & 25.5161 \\
\hline type-specific Poisson & -825.94846 & 138.34479 \\
\hline study-adjusted null Poisson & -920.16588 & 112.08258 \\
\hline null Poisson & -1774.3198 & 213.90718 \\
\hline
\end{tabular}

Table S2 Model fit comparison with leave-one-out (LOO) cross-validation using the child serotype data on carriage and disease. These values were generated using the logarithm of the likelihoods calculated within the models. Models are ranked by their expected log pointwise predictive density (ELPD), calculated from the individual pointwise log predictive densities across all observed data points. The ELPD difference column shows the difference between the ELPD of a model and that of the most likely model (this value is zero for the first row, corresponding to the most likely model given the data). The ELPD difference standard error is calculated from the distribution of individual pointwise log predictive densities from the same comparison. 


\begin{tabular}{|l|r|r|}
\hline & ELPD & $\begin{array}{l}\text { ELPD } \\
\text { difference } \\
\text { standard } \\
\text { error }\end{array}$ \\
\hline $\begin{array}{l}\text { study-adjusted type-specific } \\
\text { negative binomial }\end{array}$ & 0 & 0 \\
\hline $\begin{array}{l}\text { study-adjusted type-specific } \\
\text { Poisson }\end{array}$ & -16.68564 & 10.50462 \\
\hline type-specific negative binomial & -148.19801 & 13.72573 \\
\hline study-adjusted negative binomial & -203.23604 & 16.36764 \\
\hline null negative binomial & -249.59283 & 17.21276 \\
\hline type-specific Poisson & -729.33726 & 112.9739 \\
\hline study-adjusted null Poisson & -821.7134 & 96.65528 \\
\hline null Poisson & -1638.1251 & 190.51644 \\
\hline
\end{tabular}

3 Table S3 Model fit comparison with LOO cross-validation using the child serotype data on carriage and disease. These values 4 were generated using the logarithm of the likelihoods calculated for the observations of isolates from disease only, as these were 5 more constrained than the modelling of isolate counts from carriage. The table is displayed as described for Table S2. 


\begin{tabular}{|l|l|}
\hline Model & $\begin{array}{l}\text { Log(Bayes factor) relative to } \\
\text { most likely model }\end{array}$ \\
\hline $\begin{array}{l}\text { study-adjusted type-specific } \\
\text { Poisson }\end{array}$ & 0.0000 \\
\hline type-specific Poisson & -406.5216 \\
\hline type-specific negative binomial & -459.7201 \\
\hline null negative binomial & -600.7347 \\
\hline $\begin{array}{l}\text { study-adjusted type-specific } \\
\text { negative binomial }\end{array}$ & -666.8982 \\
\hline study-adjusted null Poisson & -848.4240 \\
\hline $\begin{array}{l}\text { study-adjusted negative } \\
\text { binomial }\end{array}$ & -876.0923 \\
\hline null Poisson & -1445.7665 \\
\hline
\end{tabular}

3 Table S4 Comparison of model fits to child carriage and disease serotype data using Bayes factors calculated with bridge 4 sampling. Models are ranked by their logarithmic marginal likelihoods. The logarithmic Bayes factors are calculated for each model 5 relative to the most likely given the data; hence the value is zero for the first row. 


\begin{tabular}{|l|l|}
\hline Model & $\begin{array}{l}\text { Log(Bayes factor) relative to } \\
\text { most likely model }\end{array}$ \\
\hline $\begin{array}{l}\text { study-adjusted type-specific } \\
\text { Poisson }\end{array}$ & 0.0000 \\
\hline type-specific negative binomial & -131.7431 \\
\hline $\begin{array}{l}\text { study-adjusted type-specific } \\
\text { negative binomial }\end{array}$ & -185.9657 \\
\hline null negative binomial & -205.1582 \\
\hline $\begin{array}{l}\text { study-adjusted negative } \\
\text { binomial }\end{array}$ & -286.0869 \\
\hline type-specific Poisson & -362.1535 \\
\hline study-adjusted null Poisson & -1010.5423 \\
\hline null Poisson & -1787.1696 \\
\hline
\end{tabular}

2 Table S5 Comparison of model fits to child carriage and adult disease serotype data using Bayes factors calculated with bridge 3 sampling. The table is displayed as described for Table S4. 


\begin{tabular}{|c|c|c|c|c|c|c|c|c|c|c|}
\hline Population & $\begin{array}{l}\text { Vaccine } \\
\text { period }\end{array}$ & $\begin{array}{l}\text { Carriage } \\
\text { study time } \\
\text { interval }\end{array}$ & $\begin{array}{l}\text { Carriage } \\
\text { isolate source }\end{array}$ & $\begin{array}{l}\text { Disease isolate } \\
\text { source }\end{array}$ & $\begin{array}{l}\text { No. of } \\
\text { swabs }\end{array}$ & $\begin{array}{l}\text { Population } \\
\text { of children }\end{array}$ & $\begin{array}{l}\text { No. } \\
\text { disease } \\
\text { isolates } \\
\text { from } \\
\text { children }\end{array}$ & $\begin{array}{l}\text { Population } \\
\text { of adults }\end{array}$ & $\begin{array}{l}\text { No. } \\
\text { disease } \\
\text { isolates } \\
\text { from } \\
\text { adults }\end{array}$ & References \\
\hline Finland & $\begin{array}{l}\text { Pre- } \\
\text { PCV }\end{array}$ & $\begin{array}{l}1994- \\
1996\end{array}$ & $\begin{array}{l}\text { Unvaccinated } \\
\text { children }<2 \\
\text { years old in } \\
\text { Tampere }\end{array}$ & $\begin{array}{l}\text { Unvaccinated } \\
\text { children }<2 \\
\text { years across } \\
\text { Finland }\end{array}$ & 329 & 120,238 & 143 & - & - & {$[71,137]$} \\
\hline Oxford & $\begin{array}{l}\text { Pre- } \\
\text { PCV }\end{array}$ & $\begin{array}{l}1994- \\
2001\end{array}$ & $\begin{array}{l}\text { Unvaccinated } \\
\text { healthy } \\
\text { children }<5 \\
\text { years old } \\
\text { in Oxford }\end{array}$ & $\begin{array}{l}\text { Unvaccinated } \\
\text { children }<5 \\
\text { years old with } \\
\text { IPD in Oxford }\end{array}$ & 639 & 37,467 & 84 & - & - & {$[29,138]$} \\
\hline Portugal & $\begin{array}{l}\text { Pre- } \\
\text { PCV }\end{array}$ & $\begin{array}{l}\text { January } \\
2001 \text { - } \\
\text { December } \\
2003\end{array}$ & $\begin{array}{l}\text { Unvaccinated } \\
\text { healthy } \\
\text { children }<7 \\
\text { years old } \\
\text { in Lisbon and } \\
\text { Oeiras }\end{array}$ & $\begin{array}{l}\text { Unvaccinated } \\
\text { children }(<18 \\
\text { years) and } \\
\text { adults ( }>18 \\
\text { years) across } \\
\text { Portugal }\end{array}$ & 1,170 & $2,071,223$ & - & $8,284,894$ & 152 & {$[52,129]$} \\
\hline Stockholm & $\begin{array}{l}\text { Pre- } \\
\text { PCV }\end{array}$ & $\begin{array}{l}1997- \\
2004\end{array}$ & $\begin{array}{l}\text { Unvaccinated } \\
\text { children }<7 \\
\text { years old } \\
\text { attending day } \\
\text { care centres in } \\
\text { Stockholm } \\
\text { County }\end{array}$ & $\begin{array}{l}\text { Unvaccinated } \\
\text { children }<18 \\
\text { years old from } \\
\text { the Stockholm } \\
\text { area }\end{array}$ & 1,330 & 397,289 & 65 & - & - & $\begin{array}{l}{[75,111,112,} \\
130]\end{array}$ \\
\hline South Africa & $\begin{array}{l}\text { Post- } \\
\text { PCV7 }\end{array}$ & $\begin{array}{l}2009- \\
2010\end{array}$ & $\begin{array}{l}\text { HIV negative } \\
\text { children }<13 \\
\text { years old in } \\
\text { Soweto and } \\
\text { Agincourt }\end{array}$ & $\begin{array}{l}\text { HIV negative } \\
\text { children }<7 \\
\text { years old in } \\
\text { South Africa }\end{array}$ & 2,674 & $7,187,314$ & 515 & - & - & $\begin{array}{l}{[35,102,104,} \\
105]\end{array}$ \\
\hline USA & $\begin{array}{l}\text { Post- } \\
\text { PCV7 }\end{array}$ & $\begin{array}{l}2006- \\
2009\end{array}$ & $\begin{array}{l}\text { Children }<7 \\
\text { years of age in } \\
\text { Massachusetts }\end{array}$ & $\begin{array}{l}\text { Children }<7 \\
\text { years old in the } \\
\text { USA ABCS } \\
\text { regions }\end{array}$ & 1,983 & $1,931,331$ & 405 & - & - & $\begin{array}{l}{[35,91,107,1} \\
39,140]\end{array}$ \\
\hline
\end{tabular}




\begin{tabular}{|c|c|c|c|c|c|c|c|c|c|c|}
\hline South Africa & $\begin{array}{l}\text { Post- } \\
\text { PCV13 }\end{array}$ & $\begin{array}{l}2011- \\
2013\end{array}$ & $\begin{array}{l}\text { HIV negative } \\
\text { children }<13 \\
\text { years old in } \\
\text { Soweto and } \\
\text { Agincourt }\end{array}$ & $\begin{array}{l}\text { HIV negative } \\
\text { children }<7 \\
\text { years old in } \\
\text { South Africa }\end{array}$ & 2,023 & $7,329,006$ & 340 & - & - & $\begin{array}{l}{[35,102,104,} \\
105]\end{array}$ \\
\hline
\end{tabular}

2 Table S6: Study populations used for the joint analysis of strain and serotype invasiveness. The disease isolates from Portugal 3 came from a mixture of infants and adults, but are tabulated based on them primarily arising from the latter age category. 


\begin{tabular}{|l|r|r|}
\hline & ELPD & \multicolumn{1}{l|}{$\begin{array}{l}\text { ELPD } \\
\text { difference } \\
\text { standard } \\
\text { error }\end{array}$} \\
\hline strain- and serotype-specific Poisson & 0 & 0 \\
\hline strain-specific serotype-modified Poisson & -3.7248 & 5.477322 \\
\hline type-specific strain-modified Poisson & -6.287393 & 5.468617 \\
\hline serotype-specific Poisson & -37.42351 & 18.306771 \\
\hline serotype-specific negative binomial & -46.514338 & 12.630727 \\
\hline strain-specific serotype-modified negative binomial & -56.069404 & 7.98463 \\
\hline type-specific strain-modified negative binomial & -57.304676 & 7.837755 \\
\hline strain- and serotype-specific negative binomial & -67.860004 & 7.923821 \\
\hline strain-specific Poisson & -90.523468 & 29.006827 \\
\hline strain-specific negative binomial & -98.704763 & 13.503281 \\
\hline
\end{tabular}

3 Table S7 Model fit comparison with LOO cross-validation using the child strain and serotype data on carriage and disease. These 4 values were generated using the logarithm of the likelihoods calculated for the observations of isolates from carriage and disease. 5 The table is displayed as described for Table S2. 


\begin{tabular}{|l|r|r|}
\hline & ELPD & \multicolumn{1}{l|}{$\begin{array}{l}\text { ELPD } \\
\text { difference } \\
\text { standard } \\
\text { error }\end{array}$} \\
\hline strain- and serotype-specific Poisson & 0 & 0 \\
\hline strain-specific serotype-modified Poisson & -6.069704 & 4.036103 \\
\hline type-specific strain-modified Poisson & -6.667989 & 4.181882 \\
\hline serotype-specific negative binomial & -33.721585 & 10.603748 \\
\hline serotype-specific Poisson & -43.800528 & 15.81467 \\
\hline type-specific strain-modified negative binomial & -48.519279 & 6.091823 \\
\hline strain-specific serotype-modified negative binomial & -50.379496 & 6.308592 \\
\hline strain- and serotype-specific negative binomial & -58.830455 & 6.314365 \\
\hline strain-specific Poisson & -78.341963 & 24.643501 \\
\hline strain-specific negative binomial & -83.515938 & 11.810553 \\
\hline
\end{tabular}

Table S8 Model fit comparison with LOO cross-validation using the child strain and serotype data on carriage and disease. These 4 values were generated using the logarithm of the likelihoods calculated for the observations of isolates from disease only. The table 5 is displayed as described for Table S2. 


\begin{tabular}{|l|r|}
\hline Model & \multicolumn{2}{|l|}{$\begin{array}{l}\text { Log(Bayes factor) } \\
\text { best-fitting model }\end{array}$} \\
\hline strain- and serotype-specific Poisson & 0 \\
\hline serotype-specific Poisson & -77.5832 \\
\hline strain-specific Poisson & -86.35369 \\
\hline strain-specific serotype-modified Poisson & -258.18324 \\
\hline type-specific strain-modified Poisson & -260.87589 \\
\hline strain- and serotype-specific negative binomial & -334.62845 \\
\hline strain-specific negative binomial & -371.46834 \\
\hline serotype-specific negative binomial & -388.66057 \\
\hline type-specific strain-modified negative binomial & -575.30246 \\
\hline $\begin{array}{l}\text { strain-specific serotype-modified negative } \\
\text { binomial }\end{array}$ & -575.70213 \\
\hline
\end{tabular}

3 Table S9 Comparison of model fits to child carriage and disease strain and serotype data using Bayes factors calculated with 4 bridge sampling. The table is displayed as described for Table S4. 


\begin{tabular}{|l|r|}
\hline Model & \multicolumn{2}{|l|}{$\begin{array}{l}\text { Log(Bayes factor) relative to } \\
\text { best-fitting model }\end{array}$} \\
\hline strain- and serotype-specific Poisson & 0.00000 \\
\hline serotype-specific Poisson & -77.67605 \\
\hline strain-specific Poisson & -86.35044 \\
\hline type-specific strain-modified Poisson & -257.60470 \\
\hline strain-specific serotype-modified Poisson & -267.16176 \\
\hline strain- and serotype-specific negative binomial & -334.11318 \\
\hline strain-specific negative binomial & -371.16642 \\
\hline serotype-specific negative binomial & -388.88025 \\
\hline type-specific strain-modified negative binomial & -574.35959 \\
\hline $\begin{array}{l}\text { strain-specific serotype-modified negative } \\
\text { binomial }\end{array}$ & -577.58130 \\
\hline
\end{tabular}

3 Table S10 Comparison of model fits to child carriage and disease strain and serotype data using Bayes factors calculated with 4 bridge sampling. In this analysis, the carriage sample size for three studies (Finland pre-PCV, Oxford pre-PCV and Stockholm pre5 PCV) was increased 100-fold, to test for the sensitivity of the model comparisons to the uncertainty in this parameter (Text S1). The 6 table is displayed as described for Table S4. 


\begin{tabular}{|c|c|c|c|c|c|c|}
\hline $\begin{array}{l}\text { Previous } \\
\text { publication }\end{array}$ & Serotype & $\begin{array}{l}\text { Low } \\
\text { invasiveness } \\
\text { genotype }\end{array}$ & $\begin{array}{l}\text { Low } \\
\text { invasiveness } \\
\text { strain }\end{array}$ & $\begin{array}{l}\text { High } \\
\text { invasiveness } \\
\text { genotype }\end{array}$ & $\begin{array}{l}\text { High } \\
\text { invasiveness } \\
\text { strain }\end{array}$ & Results from this study \\
\hline $\begin{array}{l}\text { Gladstone et } \\
\text { al } 2019\end{array}$ & $6 \mathrm{~A}$ & CC172 & GPSC5 & CC1094 & GPSC41 & $\begin{array}{l}\text { GPSC41-6A invasiveness significantly higher than } \\
\text { GPSC5-6A }\end{array}$ \\
\hline $\begin{array}{l}\text { Gladstone et } \\
\text { al } 2019\end{array}$ & 14 & CC63 & GPSC9 & CC15 & GPSC18 & $\begin{array}{l}\text { GPSC18-14 invasiveness significantly higher than } \\
\text { GPSC9-14 }\end{array}$ \\
\hline $\begin{array}{l}\text { Gladstone et } \\
\text { al } 2019\end{array}$ & $16 \mathrm{~F}$ & CC4088 & GPSC33 & CC30 & GPSC46 & Not tested \\
\hline $\begin{array}{l}\text { Gladstone et } \\
\text { al } 2019\end{array}$ & $19 \mathrm{~F}$ & CC347 & GPSC21 & CC320 & GPSC1 & $\begin{array}{l}\text { GPSC1-19F invasiveness significantly higher than } \\
\text { GPSC21-19F }\end{array}$ \\
\hline $\begin{array}{l}\text { Gladstone et } \\
\text { al } 2019\end{array}$ & 23B & CC439 & GPSC7 & CC172 & GPSC5 & Not tested \\
\hline $\begin{array}{l}\text { Sá-Leão et al } \\
2011\end{array}$ & 3 & ST180 & GPSC12 & ST156 & GPSC6 & $\begin{array}{l}\text { GPSC6 found to have significantly higher } \\
\text { invasiveness }\end{array}$ \\
\hline $\begin{array}{l}\text { Sá-Leão et al } \\
2011\end{array}$ & $6 \mathrm{~A}$ & $\begin{array}{l}\text { ST460, } \\
\text { ST315, } \\
\text { ST1879 }\end{array}$ & $\begin{array}{l}\text { GPSC47, } \\
\text { GPSC64, } \\
\text { ST1879 }\end{array}$ & - & - & $\begin{array}{l}\text { GPSC64 does not exhibit significantly divergent } \\
\text { invasiveness; others not tested }\end{array}$ \\
\hline $\begin{array}{l}\text { Sá-Leão et al } \\
2011\end{array}$ & $6 B$ & ST176, ST315 & $\begin{array}{l}\text { GPSC24, } \\
\text { GPSC47 }\end{array}$ & - & - & Other GPSCs of this serotype not tested \\
\hline $\begin{array}{l}\text { Sá-Leão et al } \\
2011\end{array}$ & $11 \mathrm{~A}$ & ST62 & GPSC3 & - & - & Not tested \\
\hline $\begin{array}{l}\text { Sá-Leão et al } \\
2011\end{array}$ & 14 & - & - & ST156 & GPSC6 & More invasive than GPSC9-14 \\
\hline $\begin{array}{l}\text { Sá-Leão et al } \\
2011\end{array}$ & $19 \mathrm{~A}$ & ST81 & GPSC16 & ST193, ST230 & $\begin{array}{l}\text { GPSC11, } \\
\text { GPSC10 }\end{array}$ & Not tested \\
\hline $\begin{array}{l}\text { Sá-Leão et al } \\
2011\end{array}$ & $19 \mathrm{~F}$ & ST177 & GPSC44 & - & - & Not tested \\
\hline $\begin{array}{l}\text { Sá-Leão et al } \\
2011\end{array}$ & $22 \mathrm{~F}$ & - & - & ST443 & ST443 & Not tested \\
\hline $\begin{array}{l}\text { Sá-Leão et al } \\
2011\end{array}$ & $23 \mathrm{~F}$ & ST176, ST439 & $\begin{array}{l}\text { GPSC24, } \\
\text { GPSC7 }\end{array}$ & - & - & $\begin{array}{l}\text { GPSC7-23F has lower invasiveness than GPSC5- } \\
\text { 23F }\end{array}$ \\
\hline $\begin{array}{l}\text { Sá-Leão et al } \\
2011\end{array}$ & 34 & ST1439 & GPSC45 & - & - & Not tested \\
\hline $\begin{array}{l}\text { Brueggemann } \\
\text { et al } 2003\end{array}$ & 14 & - & - & ST9 & GPSC18 & More invasive than GPSC9-14 \\
\hline
\end{tabular}




\begin{tabular}{|l|l|l|l|l|l|l|}
\hline $\begin{array}{l}\text { Brueggemann } \\
\text { et al 2003 }\end{array}$ & 14 & - & - & ST124 & GPSC39 & More invasive than GPSC9 \\
\hline $\begin{array}{l}\text { Brueggemann } \\
\text { et al } 2003\end{array}$ & $18 \mathrm{C}$ & - & - & ST113 & GPSC50 & $\begin{array}{l}\text { Higher invasiveness than GPSC68-18C, but with } \\
\text { overlapping credibility intervals }\end{array}$ \\
\hline $\begin{array}{l}\text { Hanage et al } \\
2005\end{array}$ & 14 & - & - & ST156 & GPSC6 & More invasive than GPSC9-14 \\
\hline $\begin{array}{l}\text { Hanage et al } \\
2005\end{array}$ & $19 \mathrm{~A}$ & - & - & ST482 & ST482 & Higher invasiveness than GPSC17-19A \\
\hline $\begin{array}{l}\text { Hanage et al } \\
2005\end{array}$ & $7 \mathrm{~F}$ & - & - & ST191 & GPSC15 & Not tested \\
\hline $\begin{array}{l}\text { Hanage et al } \\
2005\end{array}$ & 14 & - & - & ST124 & GPSC39 & More invasive than GPSC9-14 \\
\hline $\begin{array}{l}\text { Hanage et al } \\
2005\end{array}$ & $6 \mathrm{~B}$ & - & - & ST138 & GPSC24 & More invasive than other 6B GPSCs \\
\hline $\begin{array}{l}\text { Hanage et al } \\
2005\end{array}$ & $19 \mathrm{~F}$ & ST485 & GPSC175 & - & - & $\begin{array}{l}\text { Low invasiveness, with overlapping credibility } \\
\text { intervals with other GPSCs }\end{array}$ \\
\hline $\begin{array}{l}\text { Hanage et al } \\
2005\end{array}$ & $11 \mathrm{~A}$ & ST62 & GPSC3 & - & - & Similar to GPSC22 \\
\hline
\end{tabular}

2 Table S11 Comparison of previously-identified within-serotype differences in strain invasiveness with those supported by this 3 analysis. The exclusion of strain and serotype combinations represented by fewer than ten isolates, summed across carriage and 4 disease, meant that some within-serotype tests between strains were not undertaken in this analysis. 


\section{Supplementary Datasets}

2

3 Dataset S1 Invasiveness estimates for serotypes in children. The mean estimates, 4 and lower and upper bounds of the $95 \%$ credibility interval, are listed for each 5 serotype.

6

Dataset S2 Invasiveness estimates for serotypes in adults. The mean estimates, and lower and upper bounds of the $95 \%$ credibility interval, are listed for each

9 serotype.

11 Dataset S3 Invasiveness estimates for serotype-strain combinations in children. The mean estimates, and lower and upper bounds of the $95 \%$ credibility interval, are 13 listed for each serotype-strain combination. 